
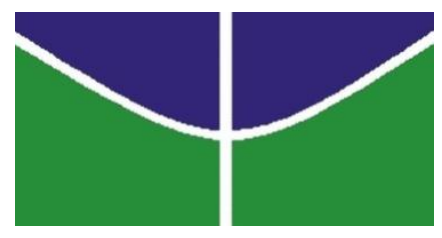

UNIVERSIDADE DE BRASÍLIA - UNB

INSTITUTO DE GEOCIÊNCIAS - IG

ANÁLISE MULTITEMPORAL DA RECUPERAÇÃO DAS ÁREAS IMPACTADAS PELO PROCESSO DE EXPLORAÇÃO E PRODUÇÃO DE PETRÓLEO E GÁS NATURAL NA FLORESTA AMAZÔNICA.

DISSERTAÇÃO DE MESTRADO No 104

EMMANUEL CARLOS GUIMARÃES MOREIRA

BRASÍLIA - DF

SETEMBRO 2016 


$$
\text { Instituto de Geociências - IG }
$$

Programa de Pós-Graduação Stricto Sensu em Geociências Aplicadas

\title{
ANÁLISE MULTITEMPORAL DA RECUPERAÇÃO DAS ÁREAS IMPACTADAS PELO PROCESSO DE EXPLORAÇÃO E PRODUÇÃO DE PETRÓLEO E GÁS NATURAL NA FLORESTA AMAZÔNICA.
}

\section{Emmanuel Carlos Guimarães Moreira}

Orientador: Prof. Dr. Edilson de Souza Bias

\begin{abstract}
Dissertação de Mestrado apresentada à banca examinadora do Instituto de Geociências Aplicadas (Geoprocessamento e Análise Ambiental) da Universidade de Brasília, como exigência para a obtenção do título de mestre em Geociências.
\end{abstract}

Brasília - DF

Setembro 2016 
UNIVERSIDADE DE BRASÍLIA

Instituto de Geociências

\section{ANÁLISE MULTITEMPORAL DA RECUPERAÇÃO DAS ÁREAS IMPACTADAS PELO PROCESSO DE EXPLORAÇÃO E PRODUÇÃO DE PETRÓLEO E GÁS NATURAL NA FLORESTA AMAZÔNICA.}

Emmanuel Carlos Guimarães Moreira

BANCA EXAMINADORA

Prof. Dr. Edilson de Souza Bias

Orientador

Prof. Dr. Gustavo Macedo de M. Baptista

Avaliador Interno

Prof. Dr. Edson Eyji Sano

Avaliador Externo (suplente)

Brasília, 09 de Setembro de 2016. 
Dedico este trabalho aos meus filhos

Davi Isaac e Mateus Felipe:

tenham a sede do conhecimento,

conheçam a ciência e

aproximem-se de Deus. 


\section{AGRADECIMENTOS}

Aos meus dois filhos, Davi Isaac e Mateus Felipe, as fontes de alegria e renovação.

À minha esposa, Mara Núbia, a reserva de paciência e amor.

À minha mãe, Maria Aparecida Guimarães, a rocha da segurança e fé.

Ao meu pai, Antonio Carlos Moreira, o símbolo da determinação e força.

Aos professores do Instituto de Geociências da UnB, especialmente ao meu orientador Prof. Dr. Edilson S. Bias e aos professores Gustavo M. Baptista; Paulo R. Meneses; Tati de Almeida; Henrique L. Roig; Rejanne E. Cicerelli e Ricardo S. Brites.

Aos amigos do Laboratório de Sensoriamento Remoto e Análise Ambiental - LSRAE, IG/UnB, pelas discussões, apontamentos e sugestões tão importantes para a consolidação deste trabalho, especialmente ao Diogo Olivetti; Henrique Bernini; Fernando Hiago; Marceli Terra; Ilana S. Rego e, Kássia B. de Castro.

Ao técnico de informática Fabrício, que resolveu todos os problemas de informática que surgiram.

Às funcionárias da copa, Socorro e Fátima, que sempre mantiveram as salas, laboratórios, banheiros e copa limpinhos e passaram aquele importante café quentinho.

E, finalmente e mais importante, agradeço a Jesus Cristo, nosso Salvador, que colocou todas essas pessoas tão maravilhosas em meu caminho e me possibilitou alcançar este tão almejado objetivo. Sinceramente, muito obrigado!!! 
"Quando você muda o modo de observar as coisas, as coisas que você observa mudam."

(anônimo) 


\section{RESUMO}

A produção de petróleo e gás natural tem uma demanda crescente na região amazônica e conta com importantes infraestruturas de escoamento (oleoduto e gasoduto) interligados na Base de Operações da Petrobras no Amazonas. O crescimento da exploração de petróleo e gás natural no Estado do Amazonas aumenta o desmatamento da floresta sob agravantes circunstâncias, pois os Programas de Recuperação das Áreas Degradadas (PRAD) perdem sua eficácia, devido à falta de gestão, à remoção do horizonte superficial do solo, aos aterramentos e a alta compactação aplicada para suportar maquinários de extremo peso, vinculados, ainda, às condições climáticas, geomorfológicas e ao difícil acesso às clareiras remotas. Este estudo utilizou o Modelo Linear de Mistura Espectral - MLME, para a identificação das áreas de exploração mineral da Petrobras/BR e análise do desenvolvimento de recuperação das clareiras. Assim, foi realizado o processamento digital da imagem com a remoção dos ruídos (MNF), a identificação dos endmembers (PPI), a visualização das classes por meio do $n$ $d$ visualizer e a classificação da imagem com os algoritmos SAM e SFF. Logo após foi realizada a identificação das classes, divididas em: vegetação, solo exposto, asfalto e água. Os resultados foram exportados para o software ArcGis 10.2, no qual houve a espacialização das áreas desmatadas para a verificação do aumento do número de clareiras e análise da eficácia dos PRADs. A qualidade dos dados foi verificada com a aplicação de uma Matriz de Confusão e do Índice Kappa. Os resultados do algoritmo SFF foram insatisfatórios, o que motivou a redução das categorias visando diminuir a mistura espectral para melhorar os resultados. O algoritmo SAM foi efetuado com um número inicial de 06 classes (vegetação, corte raso, solo exposto, asfalto, rio Urucu e rio Tefé), o qual foi reduzido para um total de 04 classes (vegetação, solo exposto, asfalto, corpos d'água). E, assim, demonstrou um resultado satisfatório no delineamento das feições, apontando o aumento do número de clareiras decorrentes de novas frentes de exploração (de 65 para 123) e, também, o resultado diminuto da revegetação alcançada pelos PRADs. Portanto, concluiu-se com este estudo que nos últimos 15 anos houve um aumento expressivo no número de clareiras; as condições físicas e as alterações provocadas pelo desmatamento impedem a recuperação das áreas degradas e a classificação das clareiras a partir do Spectral Angle Mapper (SAM) alcançou um bom delineamento das áreas de solo exposto, quantificando uma área degradada total de 224,55ha.

\section{Palavras-chaves: Análise linear de Mistura Espectral; Programas de Recuperação de Áreas Degradadas e Spectral Angle Mapper.}




\begin{abstract}
The oil and natural gas have a growing demand in the Amazon region and has significant infrastructure flow (Pipeline and Gas Pipeline) interconnected in Petrobras Operations Base - Geologist Pedro de Moura (BOGPM). The growth of oil and natural gas exploration in Amazonas state increase forest clearing under aggravating circumstances. The Degraded Areas Recovery Program (DARP) lose their effectiveness due to lack of management and also because of the high compaction process applied in the soil to support machinery extremely heavy, added to this the climate and geomorphological conditions, as well the difficult access to remote clearings. This study used the Linear Spectral Mixture Model - LSMM, to identify the areas of mineral exploration of Petrobras/BR and analysis of the clearings recovery development. It was carried out the digital processing of the image by removing noise (MNF), the identification of endmembers (PPI), the display of classes by $n$-d visualizer and a image classification with algorithms SAM and SFF. Soon after it was carried out the identification of classes, divided into: vegetation, bare soil, asphalt and water. The results were exported to ArcGis 10.2 software, in which there was a spatial distribution of deforested areas to check the increase number of clearings and the efficacy of analysis of DARP. The quality of data was verified with the application of a confusion matrix and Kappa Index. The results of SFF algorithm were unsatisfactory, which led to the reduction of categories in order to decrease the spectral mixture to improve results. The SAM algorithm was performed with an initial number of 06 classes (vegetation, clear-cut, exposed soil, asphalt, river Urucu and river Tefé, which was reduced to a total of 04 classes (vegetation, exposed soil, asphalt and bodies of water). Thus it was demonstrated a satisfactory result in the delineation of the features, pointing to the increased number of clearings from new exploration fronts (65 to 123) and also the tiny result of revegetation achieved by DARP. Therefore, this study concluded that over the past 15 years there has been a significant increase in the number of clearings; physical conditions and the alterations caused by deforestation hinder the recovery of degraded areas, and the classification of clearings from the Spectral Angle Mapper (SAM) achieved a good design of exposed soil areas, quantifying a degraded area total of 224,55ha.
\end{abstract}

Keywords: Linear Analysis of Spectral Mixture; Degraded Areas Recovery Program and Spectral Angle Mapper. 


\section{LISTA DE FIGURAS}

Figura 1 - Mapa dos Blocos de Concessão da ANP à Petrobras no Amazonas.................4

Figura 2 - Mapa Pedológico do Amazonas........................................................................5

Figura 3 - Mapa Geológico do Amazonas.....................................................................6

Figura 4 - Mapa de Formações Florestais do Amazonas....................................................8

Figura 5 - Mapa de Potencialidade das Bacias Sedimentares do Amazonas................... 10

Figura 6 - Importância Petrolífera das Áreas com Atividades Exploratórias..................11

Figura 7 - Importância Petrolífera das Áreas de Prospectividade...................................12

Figura 8 - Importância Petrolífera das Áreas de Infraestruturas de Abastecimento.........13

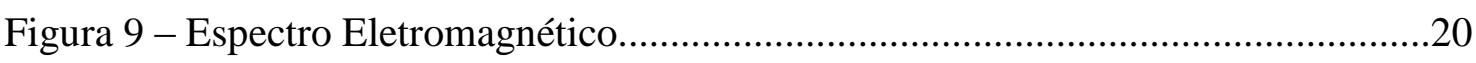

Figura 10 - Gráfico dos espectros de referência (r) e espectro do pixel (t)....................28

Figura 11 - Mapa dos Blocos de Concessão da Bacia do Solimões...............................35

Figura 12 - Mapa dos Blocos de Concessão da Bacia do Amazonas..............................35

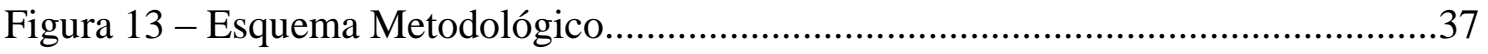

Figura 14 - Resultado PPI com Valor limiar de 9.6 com 10.000 iterações......................42

Figura 15 - Resultado PPI com Valor limiar de 9.8 com 10.000 iterações......................42

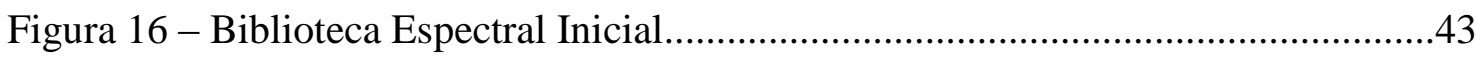

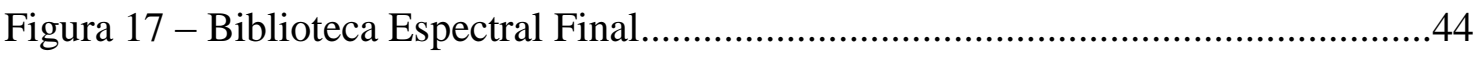

Figura 18 - Panorama do Resultado da Classificação SFF - vegetação..........................45

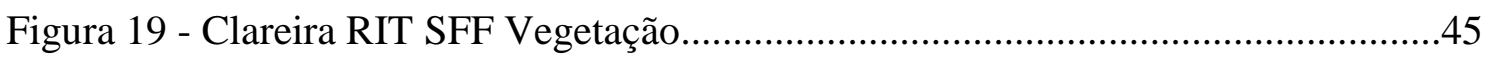

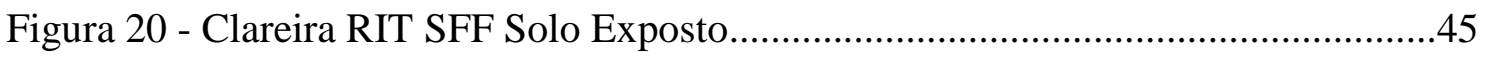

Figura 21 - Panorama do Resultado da Classificação SAM - vegetação.........................47

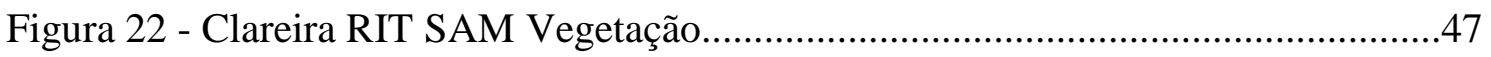

Figura 23 - Clareira RIT SAM Solo exposto............................................................ 47

Figura 24 - Panorama do Resultado da Classificação SAM - Bloco Solimões..............48

Figura 25 - Resultado Multitemporal da Classificação SAM nas clareiras......................50

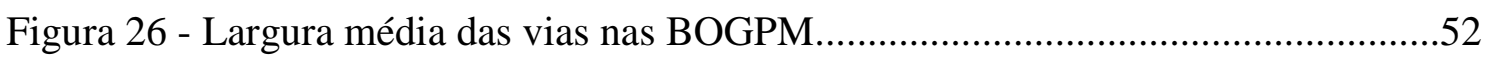

Figura 27 - Resultado multitemporal agrupado por clareira.........................................52

Figuras 28 a 40 - Clareiras dos Blocos Devolvidos...............................................56-57

Figura 41 - Áreas das Clareiras Desativadas nos Blocos de E\&P................................60

Figuras 42 a 96 - Áreas das Clareiras Não-Ativas dos Blocos de E\&P...................62-69 


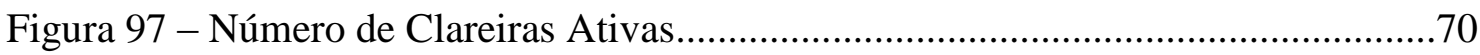

Figura 98 - Aproximação das clareiras do Bloco do Amazonas.....................................71

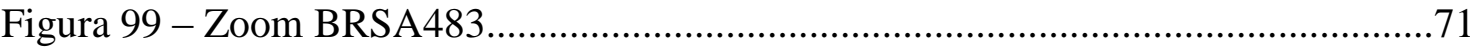

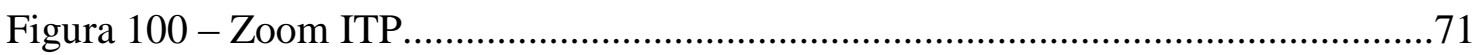

Figura 101 - Blocos da área de estudo da Bacia do Amazonas.....................................72

Figuras 102 a 104 - Área das Clareiras Antigas nos Blocos do Solimões.......................73 


\section{LISTA DE TABELAS}

Tabela 1 - Qualidade do mapa temático - índice Kappa .............................................. 33

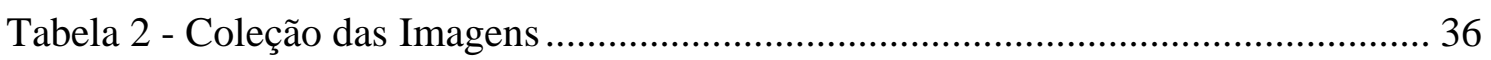

Tabela 3 - Treinamentos realizados com o PPI ....................................................... 41

Tabela 4 - Resultado Multitemporal das Áreas das Clareiras dos Blocos Devolvidos .. 53

Tabela 5 - Área Total das Clareiras dos Blocos Devolvidos ......................................... 55

Tabela 6 - Resultado Multitemporal das Áreas de Clareiras Não-Ativas dos Blocos de

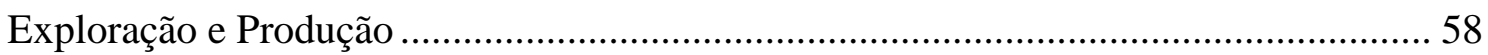

Tabela 7 - Desenvolvimento multitemporal do número de clareiras ativas ....................69

Tabela 8 - Total de Clareiras na Bacia Sedimentar do Amazonas ................................ 72

Tabela 9 - Matriz de Confusão - Bloco do Solimões 2015 ............................................ 75

Tabela 10 - Exatidão do Produtor/ Exatidão do Usuário - Solimões 2015 .................... 76

Tabela 11 - Matriz de Confusão - Bloco do Amazonas 2015 ....................................... 76

Tabela 12 - Exatidão do Produtor/ Exatidão do Usuário - Amazonas 2015 ................... 77

Tabela 13 - Matriz de Confusão - Bloco do Solimões 2001 _......................................... 89

Tabela 14 - Matriz de Confusão - Bloco do Solimões 2006 …...................................... 89

Tabela 15 - Matriz de Confusão - Bloco do Solimões 2010 .......................................... 89

Tabela 16 - Matriz de Confusão - Bloco do Solimões 2015 ........................................ 90

Tabela 17 - Matriz de Confusão - Bloco do Amazonas 1999 ……................................. 90

Tabela 18 - Matriz de Confusão - Bloco do Amazonas 2006 ........................................ 90

Tabela 19 - Matriz de Confusão - Bloco do Amazonas 2011 ........................................ 91

Tabela 20 - Matriz de Confusão - Bloco do Amazonas 2015 ......................................... 91

Tabela 21 - Exatidão do Produtor/ Exatidão do Usuário - Solimões 2001 ..................... 92

Tabela 22 - Exatidão do Produtor/ Exatidão do Usuário - Solimões 2006.................... 92

Tabela 23 - Exatidão do Produtor/ Exatidão do Usuário - Solimões 2010 .................... 92

Tabela 24 - Exatidão do Produtor/ Exatidão do Usuário - Solimões 2015 ..................... 92

Tabela 25 - Exatidão do Produtor/ Exatidão do Usuário - Amazonas 1999 ................... 93

Tabela 26 - Exatidão do Produtor/ Exatidão do Usuário - Amazonas 2006 ................... 93

Tabela 27 - Exatidão do Produtor/ Exatidão do Usuário - Amazonas 2011 .................. 93

Tabela 28 - Exatidão do Produtor/ Exatidão do Usuário - Amazonas 2015 .................. 93 


\section{LISTA DE SIGLAS E ABREVIATURAS}

ANP

BA

$\mathrm{BD}$

BDEP

BEP

BOGPM

BPD

BS

CPRM

$\mathrm{E} \& \mathrm{P}$

$\mathrm{E}_{\mathrm{A}}$

$\mathrm{E}_{\mathrm{I}}$

EPD

EPE

$E_{R}$

$\mathrm{E}_{\mathrm{T}}$

IBGE

INPE

IPA

IVM

IVP

LUC

MCTI

MMA

MME

MNF

PDI

PPI

PRAD

PRODES

ROI

RUC

SAM

SCN

SFF

SGB

SGMB

SRTM

USGS

VIS
Agência Nacional do Petróleo

Bacia do Amazonas

Blocos Devolvidos

Banco de Dados de Exploração e Produção de Petróleo

Blocos de Exploração e Produção

Base de Operações Geólogo Pedro de Moura

Blocos de Produção e Desenvolvimento

Bacia do Solimões

Serviço Geológico Brasileiro

Exploração \& Produção

Energia Absorvida;

Energia Incidente

Exploração, Produção e Devolvidos

Empresa de Pesquisa Energética

Energia Refletida

Energia Transmitida;

Instituto Brasileiro de Geografia e Estatística

Instituto Nacional de Pesquisas Espaciais

Importância Petrolífera da Área

Infravermelho Médio

Infravermelho Próximo

Leste de Urucu

Ministério da Ciências e Tecnologia

Ministério do Meio Ambiente

Ministério de Minas e Energia

Minimum Noise Fraction

Processamento Digital de Imagens

Pure Pixel Index

Programas de Recuperação de Áreas Degradadas

Projeto de Desmatamento da Amazônia

Regiões de Interesse

Rio Urucu

Spectral Angle Mapper

Sistema Cartográfico Nacional

Spectral Feature Fitting

Sistema Geodésico Brasileiro

Serviço Geológico e Mineralógico do Brasil

Shuttle Radar Topography Mission

United States Geologic Service

Visível 


\section{SUMÁRIO}

1. INTRODUÇÃ

1.1 HISTÓRICO DO PETRÓLEO NA AMAZÔNIA ................................................. 2

1.2 ÁREA DE ESTUDO - ASPECTOS FÍSICOS E AMBIENTAIS ........................... 3

1.2.1 Geologia das bacias Amazônicas .............................................................. 6

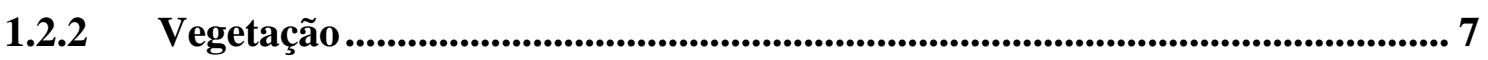

1.2.3 Áreas de Exploração de Petróleo e Gás Natural no Estado do Amazonas.9

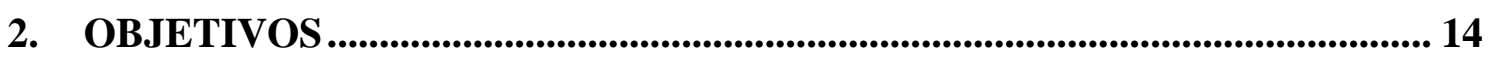

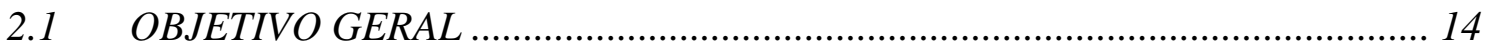

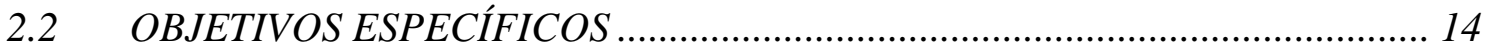

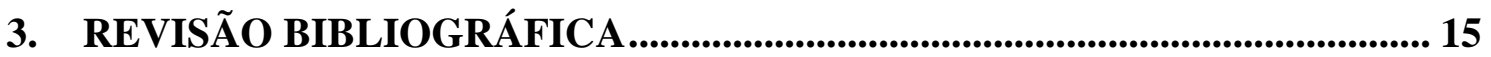

3.1 ASPECTOS AMBIENTAIS DO DESMATAMENTO ….................................... 15

3.1.1 Programas de Recuperação de Áreas Degradadas - PRAD...................... 17

3.2 SENSORIAMENTO REMOTO MULTIESPECTRAL .................................. 19

3.2.1 Características Espectrais da Vegetação e do Solo .................................... 22

3.3 PROCESSAMENTO DIGITAL DE IMAGENS ............................................... 24

3.3.1 Pré-processamento Digital de Imagens.............................................................. 24

3.4 ANÁLISE LINEAR DE MISTURA ESPECTRAL - ALME ........................... 25

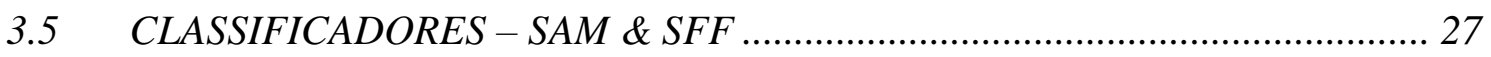

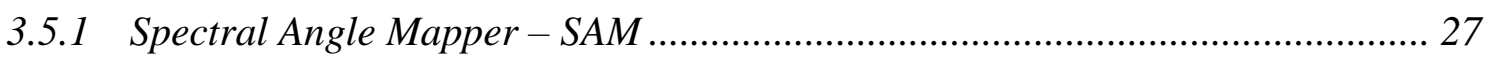

3.5.2 Spectral Feature Fitting - SFF ............................................................................ 29

3.6 QUALIDADE DE DADOS: MATRIZ DE CONFUSÃO E ÍNDICE KAPPA...... 30

4. MATERIAL E MÉTODOS............................................................................... 34 


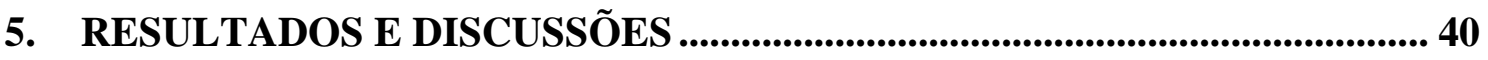

5.1 ÍNDICE DE PIXEL PURO - PPI \& VISUALIZADOR N-DIMENSIONAL ....... 40

5.2 CLASSIFICAÇÃO SPECTRAL FEATURE FITTING - SFF .......................... 44

5.3 CLASSIFICAÇÃO SPECTRAL ANGLE MAPPER - SAM .............................. 46

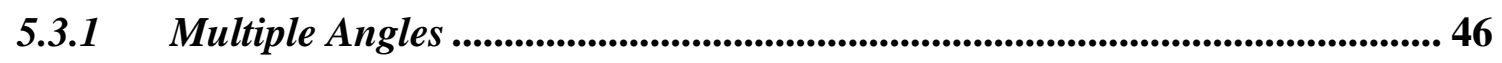

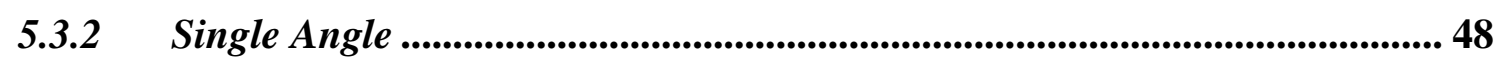

5.3.3 Qualidade de Dados ....................................................................................... 75

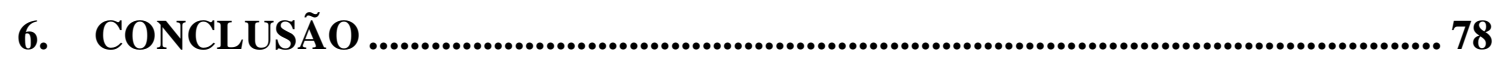

7. REFERÊNCIAS BIBLIOGRÁFICAS ........................................................... 80

ANEXO 1 - MATRIZES DE ERROS .............................................................. 89

ANEXO 2 - EXATIDÃO DO PRODUTOR E EXATIDÃO DO USUÁRIO........... 92 


\section{INTRODUÇÃO}

A necessidade de se descobrir novas fontes de energia para abastecer a população e manter o crescimento econômico da nação impulsiona a intensa exploração das reservas de petróleo e gás natural. Isso provoca o aumento das frentes de exploração e produção no Estado do Amazonas e, consequentemente, amplia a taxa de área degradada da Floresta Amazônica. Conforme evidenciado nas taxas anuais de desmatamento apresentadas pelo projeto PRODES, que faz o monitoramento da floresta amazônica brasileira por satélite, o qual apontou um aumento de $405 \mathrm{~km}^{2}$ no ano de 2009, subindo para $769 \mathrm{~km}^{2}$ no ano de 2015 (INPE, 2014).

Tendo em vista o modelo energético atual que aponta para o uso cada vez maior do petróleo, faz-se necessário diagnosticar a situação das áreas já alteradas na floresta para tomar o conhecimento das circunstâncias atuais e, assim, analisar os impactos ambientais associados visando garantir o desenvolvimento sustentável na região.

A Região Amazônica é dotada de muitas riquezas naturais, com uma exuberante flora, alta disponibilidade hídrica e uma grande diversidade de minerais. Portanto, este bioma requer ações sustentáveis para o aproveitamento de seus recursos naturais, afinal, suas características ambientais são sensivelmente equilibradas devido à complexidade das interações e interdependências existentes entre os recursos hídricos, a geomorfologia, a flora e a fauna.

A descoberta de reservas de petróleo e gás natural nessa região atraiu grandes empresas de energia, que iniciaram um processo de exploração que vem gerando alterações ambientais preocupantes. As atividades envolvidas na produção de petróleo e gás natural estão causando o desmatamento progressivo da floresta em virtude da crescente demanda de explorações.

A realização das etapas necessárias à perfuração de um novo poço de exploração acarreta impactos ambientais prolongados, porque o acesso à mata é muito difícil e com várias áreas alagadas. Por isso, além do desmatamento, também é necessário muito aterramento e compactação do solo, para permitir a entrada de veículos e equipamentos, extremamente pesados, como tratores, contêineres de hospedagem e sonda de perfuração. Ademais a construção de pistas de pouso, heliportos e portos fluviais.

O conjunto desses fatores dificulta a reabilitação das áreas desmatadas para perfuração dos poços e compromete o resultado dos Planos de Recuperação de Áreas Degradadas (PRAD). O que justifica a necessidade de um levantamento real sobre as 
condições destas locações para demonstrar a eficácia dos PRADs, bem como, o estágio de sucessão ecológica alcançado.

Haja vista a riqueza natural do bioma amazônico e a necessidade de se acompanhar os impactos ambientais decorrentes da exploração mineral, mediante as limitações ocasionadas pelo difícil acesso ao interior da floresta, o sensoriamento remoto entra como uma ferramenta fundamental para a identificação, classificação e monitoramento das alterações geradas no dossel. Nesse quesito o Ministério da Ciência, Tecnologia e Inovação (MCTI), juntamente com o Ministério do Meio Ambiente (MMA) criaram, em 1988, o Projeto PRODES, responsável pelo monitoramento da floresta amazônica brasileira por satélite (INPE, 2014). E também diversos autores têm utilizado o sensoriamento remoto para analisar e monitorar a vegetação (SHIMABUKURO, 1998; MOREIRA, 2000; NASCIMENTO, 2009; PRADO, 2008).

\subsection{HISTÓRICO DO PETRÓLEO NA AMAZÔNIA}

O interesse pela Bacia Sedimentar do Amazonas data do início do século XX (1917), com mapeamentos geológicos realizados pelo Serviço Geológico e Mineralógico do Brasil (SGMB), com foco, principalmente, nas jazidas de carvão. Em 1925, surgiram os primeiros indícios de petróleo e gás natural, Bom Jardim e Itaituba (ANP, 2009). A busca por petróleo e seus derivados foi uma afirmação da nacionalidade brasileira que culminou na assinatura da Lei 2.004/53, que garantia o monopólio da União na pesquisa, lavra, refinaria e transporte de petróleo e também criava a Petrobras, fato esse que deu um grande impulso à exploração de petróleo no Brasil (ALMEIDA, 2008).

As primeiras descobertas de petróleo na Amazônia ocorreram em 1953, quando a Petrobras encontrou quantidades, não comerciais, nas cidades de Nova Olinda, Autaz Mirim e Maués, na Bacia Sedimentar do Amazonas. Em 1976 foi feito o primeiro levantamento de sísmica de reflexão na bacia do Solimões e em 1978 houve a descoberta significativa de petróleo na região, na Província de Juruá, município de Carauari/AM (PETROBRAS, 2014).

Mas somente oito anos depois, em 1986, o sonho de prospecção petrolífera na Amazônia tornou-se realidade com a descoberta da Província Petrolífera de Urucu, município de Coari/ AM, na Bacia Sedimentar do Solimões, a distância de $600 \mathrm{~km}$ de Manaus. Dois anos depois o petróleo já estava sendo escoado por balsas, através do rio Solimões, até a Refinaria Isaac Sabbá (UN-Reman), na capital do Estado. Em 1998, 
teve início a operação do poliduto, com $285 \mathrm{Km}$ de extensão, entre Urucu e Coari, cidade mais próxima da base petrolífera (PETROBRAS, 2014).

O desenvolver da história teve profundas alterações com a regulamentação da Lei 9.478/97, conhecida como a Lei do Petróleo, que criou a Agência Nacional do Petróleo (ANP) e pôs um fim à hegemonia nacional, quebrando o monopólio da Petrobras e abrindo a exploração petrolífera para outras empresas estrangeiras (ALMEIDA, 2008). O último marco histórico foi o gasoduto Urucu-Coari-Manaus, que iniciou sua operacionalização em 2009, com uma extensão de 663,2km e uma geração de 760MW de energia elétrica .

Mas, conforme Almeida (2008) é importante salientar que o desenvolvimento desse setor em meio à floresta foi acompanhado de diversas medidas para a diminuição dos impactos ambientais como: não abertura de estradas ao longo do oleoduto para evitar a aproximação de madeireiras, implantação de unidades de reflorestamento e criação de programas de pesquisa de gestão ambiental com instituições locais.

\section{2 ÁREA DE ESTUDO - ASPECTOS FÍSICOS E AMBIENTAIS}

O Estado do Amazonas abriga duas bacias sedimentares com grande potencial para a produção de petróleo e gás natural; a Bacia do Amazonas (BA) e a Bacia do Solimões (BS). Entre elas a Bacia do Amazonas teve um papel histórico precursor que abriu importantes caminhos para o desenvolvimento da bacia do Solimões.

As bacias sedimentares do Solimões e do Amazonas são classificadas como intra cratônicas ou paleozóicas e são muito antigas. Suas idades são variadas, estendendo-se desde o período Ordoviciano, que integra a era Paleozóica, com 490 milhões de anos. Essas bacias possuem rochas muito duras, o que aumenta o tempo e o custo de perfuração de poços (PETROBRAS, 2014).

Atualmente, a Bacia Sedimentar do Amazonas é composta por 08 blocos de concessão da ANP, divididos entre: blocos de produção (2), exploração (1) e devolvidos (5), que estão localizados na porção leste do estado do Amazonas, entre os municípios de Manaus/ AM e Barreirinhas/AM.

Enquanto, a Bacia Sedimentar do Solimões é composta por 32 blocos de concessão da ANP divididos entre: blocos de produção (11), exploração (2) e devolvidos (19), que estão localizados na porção meio-oeste do estado do Amazonas, entre os municípios de Carauari/AM e Coari/AM. 
As duas áreas de estudos tiveram o foco principal nos blocos concedidos para Exploração e Produção, porém as partes de alguns blocos devolvidos foram vinculados ao escopo do estudo, visando complementar as análises e interpretações decorrentes de seu estado de desativação. A figura 01 mostra um mapa com os blocos de concessão da ANP nas bacias sedimentares do Amazonas e do Solimões no estado do Amazonas.

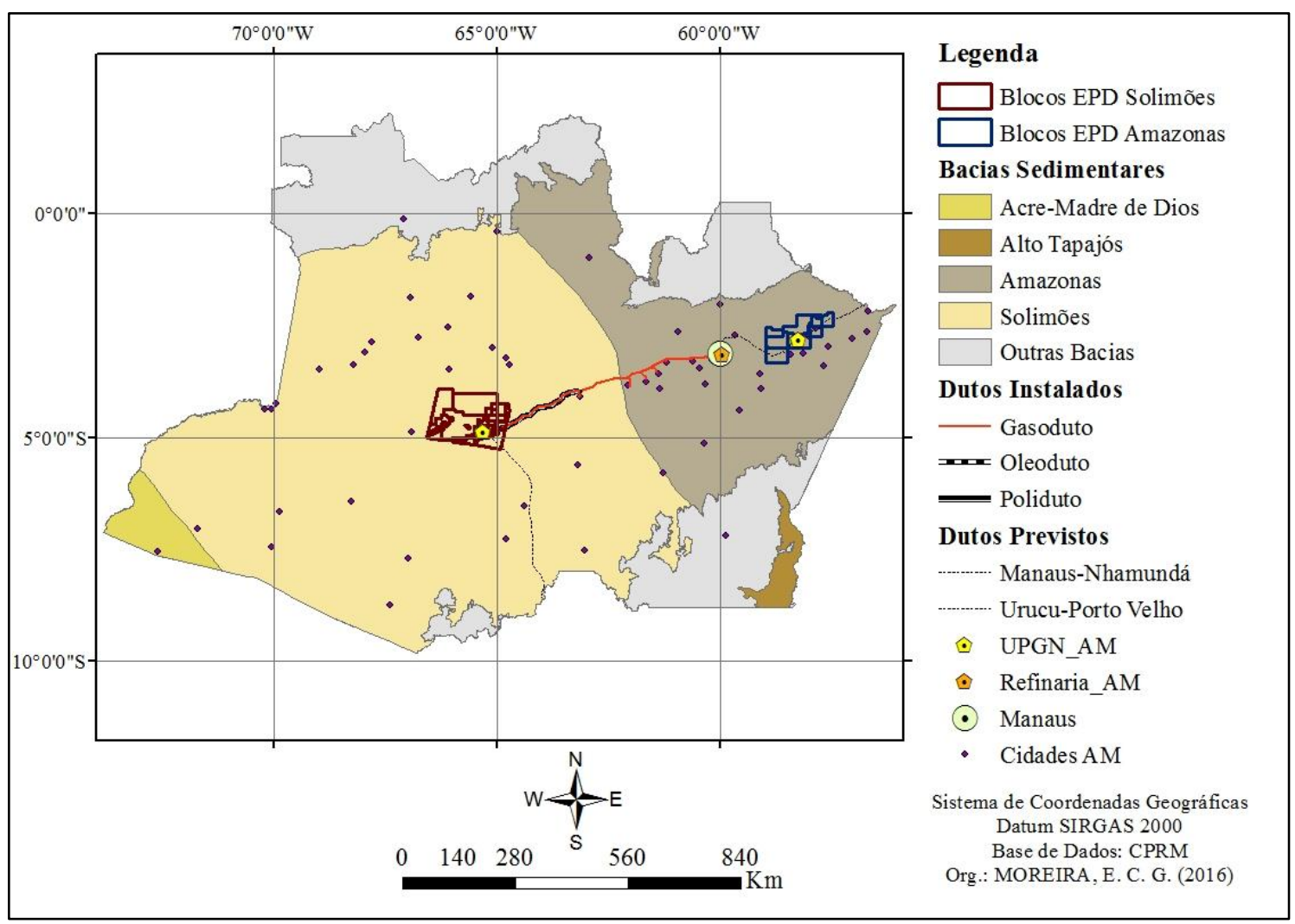

Figura 01 - Mapa dos Blocos de Concessão da ANP à Petrobras no Amazonas

Segundo dados fornecidos pela Base de Dados de Exploração e Produção (BDEP) da Agência Nacional do Petróleo (ANP), atualmente, existe um total de 344 poços na Bacia do Solimões e 216 na Bacia do Amazonas. Após a delimitação da área de estudo, em torno dos Blocos de Produção e Exploração, permaneceram 279 poços na Bacia do Solimões e 13 na Bacia do Amazonas. Os Blocos Devolvidos não foram contemplados em sua íntegra, pois houve o seu recorte na medida da cena.

O clima do Estado do Amazonas é equatorial úmido. A temperatura média oscila entre $22^{\circ} \mathrm{C}$ e $28^{\circ} \mathrm{C}$, e a precipitação média anual varia entre $1500 \mathrm{~mm}$ e $3000 \mathrm{~mm}$. A geomorfologia do estado é dominada por depressões, como a Depressão Norte Amazônica e a Depressão da Amazônia Ocidental. A Planície do Rio Amazonas estende-se ao longo de seu curso e dos seus principais afluentes (PESSOA, 2004). A figura 02 apresenta o mapa geomorfológico do estado do Amazonas. 


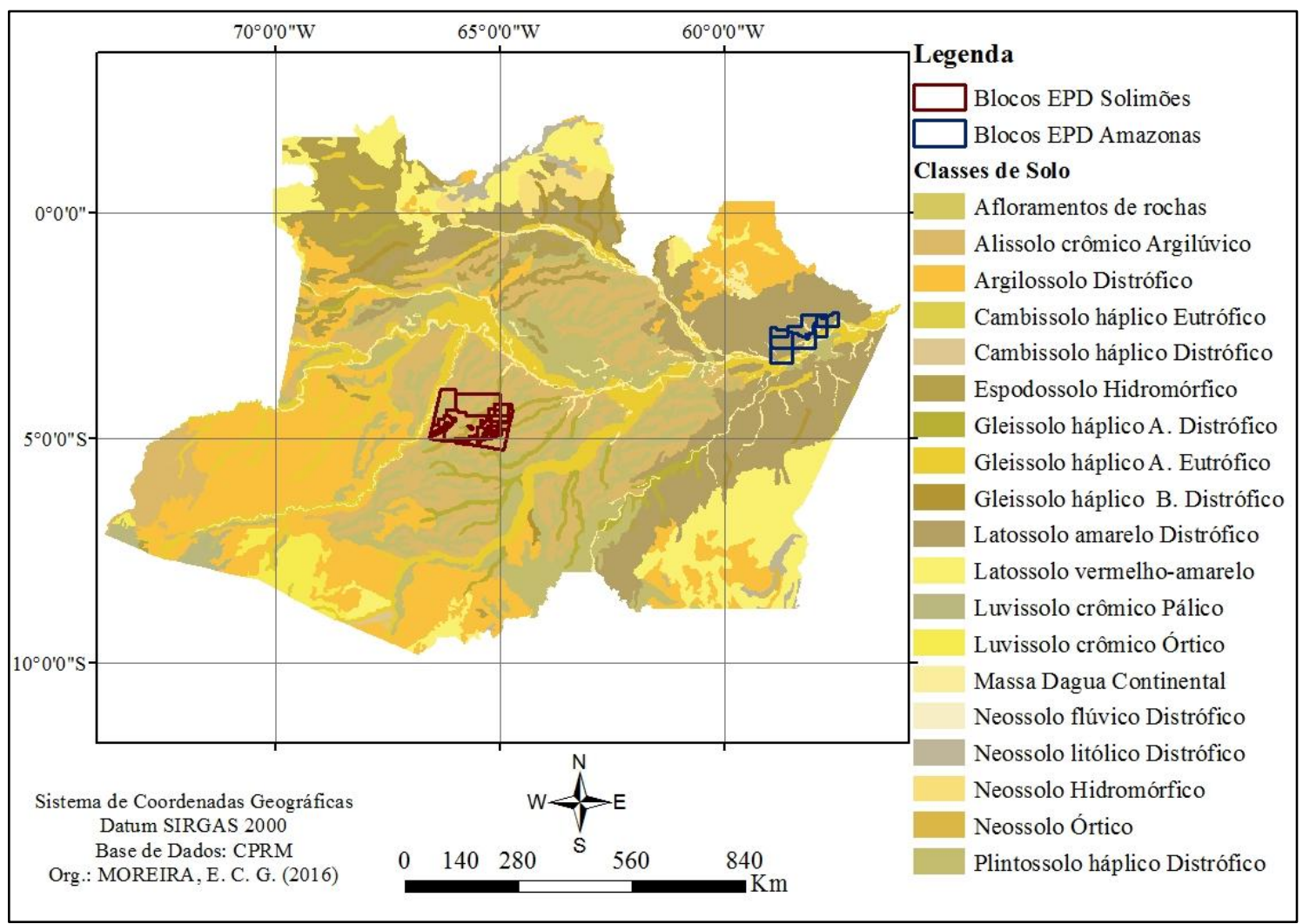

Figura 02 - Mapa Pedológico do Amazonas

Segundo Maia \& Marmos (2010) o levantamento realizado pelo Serviço Geológico Brasileiro (CPRM) destacou dentre as classes de solo dominantes no estado do Amazonas, os Argissolos abrangendo 45\% da área do estado. Os Latossolos estão presentes em $26 \%$ da área, sendo predominantemente Latossolos Amarelos, que se concentram basicamente na região central do estado nas áreas de terra firme. Gleissolos háplicos e Neossolos Flúvicos prevalecem nas planícies de inundações e totalizam 9\% dos solos do estado do Amazonas. Os Espodossolos preenchem mais de 7\% da área do estado e sobressaem na área norte do Amazonas. Os Plintossolos ocupam 3,5\% em sua maioria presentes no sul do estado. E as demais classes aparecem em menor proporção em relação as outras classes, contudo, são as classes dominantes em algumas regiões, como os Cambissolos na região do Alto Solimões e na bacia do rio Urucu, na Província Petrolífera de Urucu. 


\subsubsection{Geologia das bacias Amazônicas}

A Bacia Amazônica é caracterizada como fossa de afundamento entre os escudos das Guianas, Brasil Central e a Cordilheira dos Andes. Foi depositada sobre rochas ígneas e metamórficas formadas há 2,6 bilhões. Duas distintas bacias sedimentares: Amazonas e Solimões, cortadas pela calha do rio Amazonas, encontramse alojadas entre cinco arcos estruturais que, de oeste para leste, são identificados como: Iquitos, Carauari, Purus, Monte Alegre e Gurupá. Este último relacionado à separação dos continentes, que deu origem ao oceano Atlântico (BARATA \& CAPUTO, 2007).

A Bacia do Solimões, de idade paleozóica, limita-se ao norte pelo escudo das Guianas, ao sul pelo escudo do Brasil Central, a oeste pelo arco de Iquitos e a leste pelo arco do Purus. $\mathrm{O}$ arco do Purus limitou a sedimentação entre as bacias do Amazonas e Solimões durante grande parte do paleozóico (500-220 milhões de anos). O arco de Carauari divide a bacia sedimentar do Solimões nas sub-bacias do Jandiatuba, a oeste, e Juruá, a leste (BARATA \& CAPUTO, 2007). A figura 03 apresenta o mapa geológico das áreas de estudo no Estado do Amazonas.

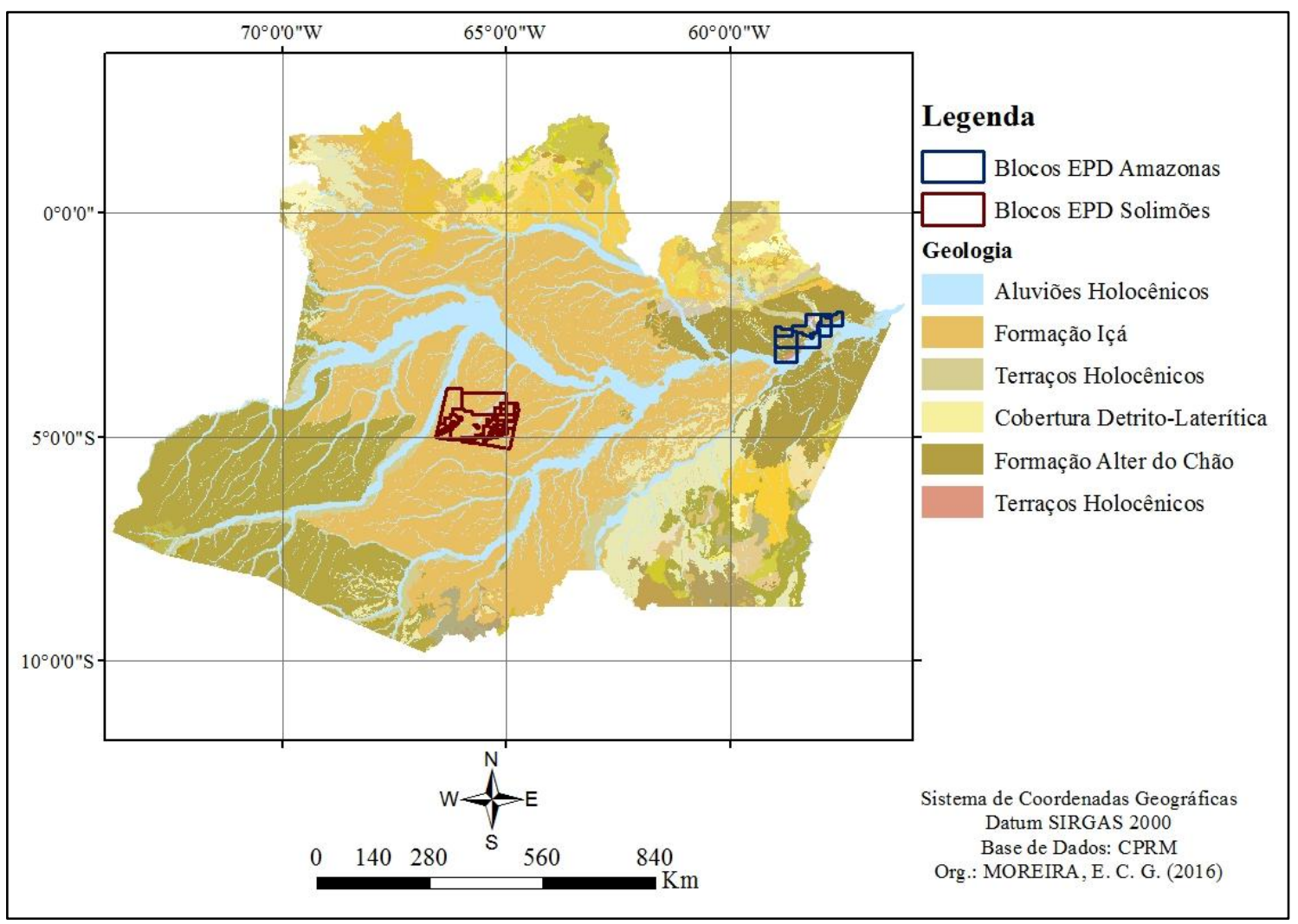

Figura 03 - Mapa Geológico do Amazonas 
Na Amazônia brasileira a bacia do Solimões é a primeira a produzir petróleo e gás natural comercialmente. No ano de 2009 já haviam sido identificados quinze campos de gás natural e três campos de petróleo e gás natural. Este potencial e sua exploração aumentaram com a chegada do gás natural a Manaus, pelo gasoduto CoariManaus, que incrementou a demanda sobre o produto (NASCIMENTO, 2009).

O estudo geofísico é prejudicado pela alta velocidade das ondas nessas rochas antigas e pela presença de rochas vulcânicas intercaladas nelas, o que reduz a qualidade sísmica e cria falsas estruturas geológicas. Sob o ponto de vista geofísico, o mapeamento das rochas-reservatório nas seções sísmicas é difícil devido à má qualidade da resposta sísmica e a complexidade geológica da área. Em conseqüência do soterramento de material orgânico as bacias sedimentares são associadas à presença de combustíveis fósseis, principalmente petróleo e gás natural (PETROBRAS, 2014).

\subsubsection{Vegetação}

A região florística amazônica é composta das seguintes classes fitoecológicas: Floresta Ombrófila Densa Aluvial (Da); Floresta Ombrófila Densa das Terras Baixas (Db); Floresta Ombrófila Aberta Aluvial (Aa) e Floresta Ombrófila Aberta das Terras Baixas (Ab), Floresta Estacional Sempre-Verde, Savana e Campinarana. A vegetação predominante na Amazônia é a Floresta Ombrófila Densa, que corresponde a 41,67\% do bioma. Cerca de $12,47 \%$, deste, foram alterados por ação humana, sendo que $2,97 \%$ encontram-se em recuperação (vegetação secundária) e 9,50\% encontram-se com uso agrícola ou pecuária (MMA, 2014).

A palavra Pluvial (origem latina) foi substituída pelo termo Ombrófila (origem grega), mas os dois carregam o mesmo significado "amigo das chuvas". Os termos Densa e Aberta funcionam como uma divisão das florestas no espaço intertropical. Essas designações foram propostas por Ellenberg e Mueller-Dombis em 1967 (IBGE, 2012). A figura 04 traz o mapa de formações florestais do Instituto Brasileiro de Geografia e Estatística - IBGE para o Estado do Amazonas. 


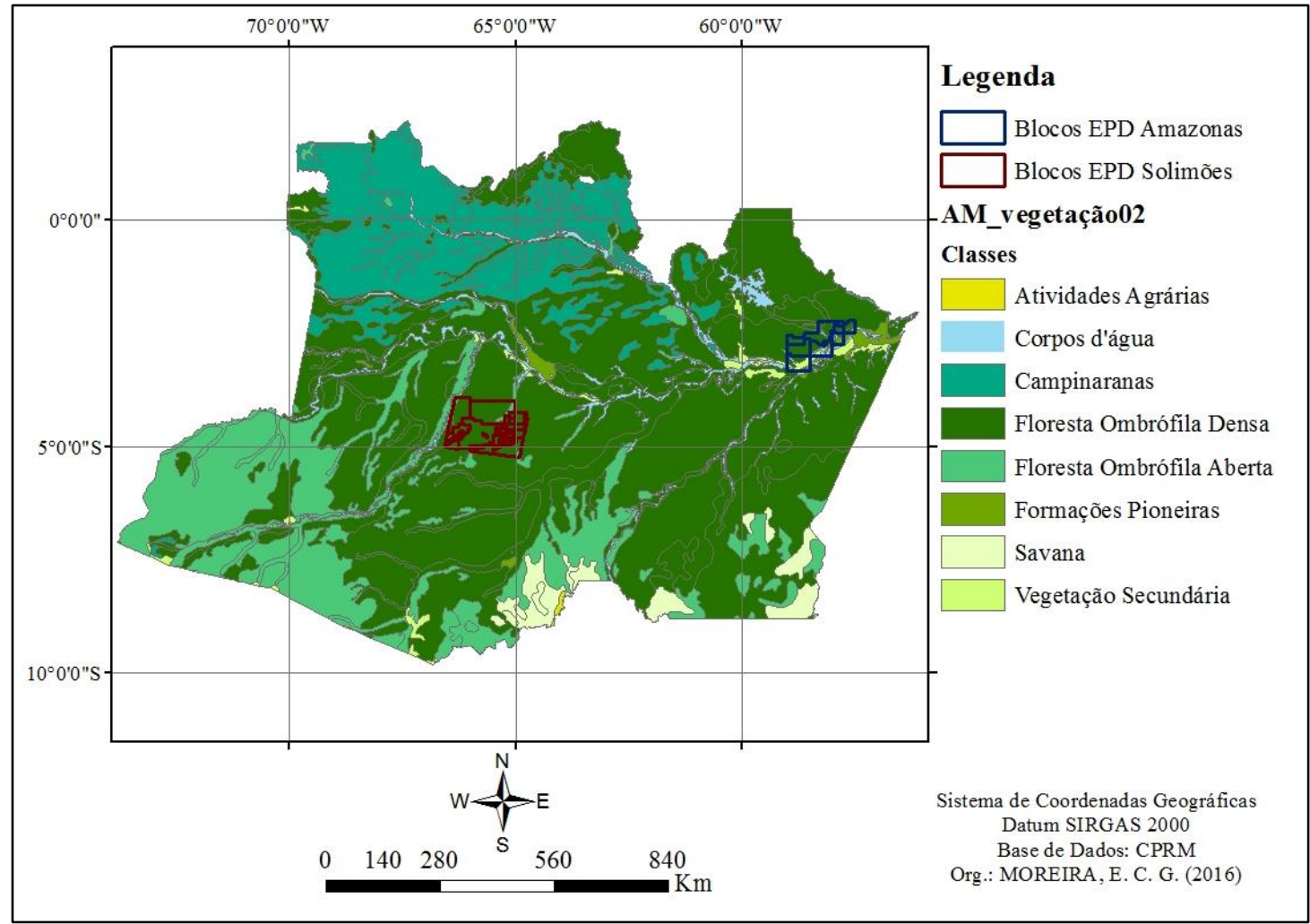

Figura 04 - Mapa de Formações Florestais do Amazonas

$\rightarrow$ Floresta Ombrófila Densa das Terras Baixas $(\mathrm{Db})$ : estende-se por vasta área da Amazônia recobrindo praticamente a totalidade da superfície caracterizada como Depressão da Amazônia Central. Apresenta variações edáficas e altitudinais que alteram sua composição e estrutura. Nas planícies acompanham o rio Amazonas e seus grandes afluentes e incluem as duas fisionomias florestais conhecidas como matas de várzeas (periodicamente inundada) e matas igapó (permanentemente inundadas) (IBGE, 2010).

$\rightarrow$ Floresta Ombrófila Densa Aluvial (Da): tem a característica de "floresta ciliar", como uma formação ribeirinha que segue ao longo dos corpos d'água, ocupando terraços antigos e planícies quaternárias. Costuma ter um dossel emergente uniforme, com muitas palmeiras no estrato dominado e na submata. Sua formação apresenta muitas lianas lenhosas e herbáceas, muitas epífitas e poucos parasitas (IBGE, 2010).

$\rightarrow$ Floresta Ombrófila Aberta Aluvial (Aa): caracteriza-se por retratar uma floresta com indivíduos arbóreos bem espaçados, em dossel se destacam principalmente palmeiras e por vezes bambus, sororocas e/ou cipós lenhosos. Em geral ocupa espaços intermediários entre o domínio da Floresta Ombrófila Densa e a Floresta Estacional Semidecidual. Porém, também, pode ocorrer em formato de mosaicos em áreas reduzidas no meio da Floresta Densa (IBGE, 2010). 
$\rightarrow$ Floresta Ombrófila Aberta das Terras Baixas (Ab): situada em altitudes variando de 05 até 100 metros, normalmente capeada por tabuleiros pliopleistocênicos do Grupo Barreiras, apresenta-se com florística bastante típica, caracterizadas por ecótipos dos gêneros Ficus, Alchornea e Handroanthu (IBGE, 2010).

$\rightarrow$ Campinarana - Caatinga da Amazônia (L): trata-se de uma vegetação com formas de vida e florística bem definidas e adaptadas às áreas deprimidas, em correspondência aos solos podzóis hidromórficos e areias quartzosas hidromórficas, quase sempre encharcados. Vegetação típica da Amazônia concentrada na região do alto-médio rio Negro, onde o clima é extremamente ombrófilo (IBGE, 2010).

$\rightarrow$ Savana - Cerrado $(\mathrm{S})$ : trata-se de uma vegetação xeromorfa, preferencialmente de clima estacional com mais ou menos cinco meses secos. Reveste solos geralmente lixiviados e aluminizados. No Estado do Amazonas aparece como disjunção ecológica nos terrenos mesozóicos de cobertura arenítica e onde o caráter edáfico predomina sobre o climático. Sua ocorrência no estado é mais disseminada na forma de encraves, em meio à floresta (IBGE, 2010).

$\rightarrow$ Floresta Estacional Sempre-Verde $(\mathrm{Ha} / \mathrm{Hb})$ - essa classe apresenta alto verdor mesmo em períodos de estiagem, é constituída por espécies de baixa decidualidade. Seus indivíduos pode atingir de 30 a 40 metros, em regiões com altitudes em torno de 200 metros (IBGE, 2010).

$\rightarrow$ Vegetação Secundária (Vs) - essa classificação refere-se as áreas que tiveram intervenção humana para o uso da terra, independente da finalidade, mineradora, agrícola ou pecuária, mas que descaracterizou a vegetação original (IBGE, 2010).

$\rightarrow$ Áreas das Formações Pioneiras (Pah) - sistema edáfico de primeira ocupação, que ocorre em planícies fluviais, ocupando terrenos rejuvenescidos pelas seguidas deposições de areias e aluviões. Reconhecidas pelas comunidades de restingas, manguezais e comunidades aluviais (IBGE, 2010).

\subsection{3 Áreas de Exploração de Petróleo e Gás Natural no Estado do Amazonas}

O modelo de desenvolvimento energético do Brasil ainda recorre muito ao uso das energias não renováveis, por isso há o intenso crescimento da exploração de novas fontes de petróleo para abastecer o mercado nacional. Além da zona costeira, uma das regiões que vem sendo muito pesquisadas é o interior do Estado do Amazonas.

A Empresa Brasileira de Pesquisa Energética (EPE) em parceria com o Ministério de Minas e Energia (MME) possuem um estudo contínuo sobre o 
planejamento energético nacional, que destaca a importância relativa das diversas áreas do país para o desenvolvimento do setor de petróleo e gás natural (EPE, 2014). Um dos produtos desse planejamento são os mapas da Importância Petrolífera da Área (IPA) feitos com dados fornecidos pela EPE (2014).

A figura 05 demonstra a Importância Petrolífera da Área do Amazonas, fazendo uma síntese da combinação dos argumentos de atividade exploratória, prospectividade e infraestrutura, entre outros. Igualmente para servir de balizador para o planejamento e ordenamento territorial, expressando diversos interesses do setor de exploração e produção de petróleo e gás natural (EPE, 2014). Neste mapa são abordados elementos geológicos, com a proximidade de áreas contratadas para as atividades de exploração e as instalações de infraestrutura de abastecimento de petróleo e gás natural. Com estas informações torna-se possível a determinação de áreas prioritárias para o desenvolvimento das atividades desse setor industrial, além de definir os locais prioritários para os estudos e investigações geológicas a serem realizados no território nacional (EPE, 2014).

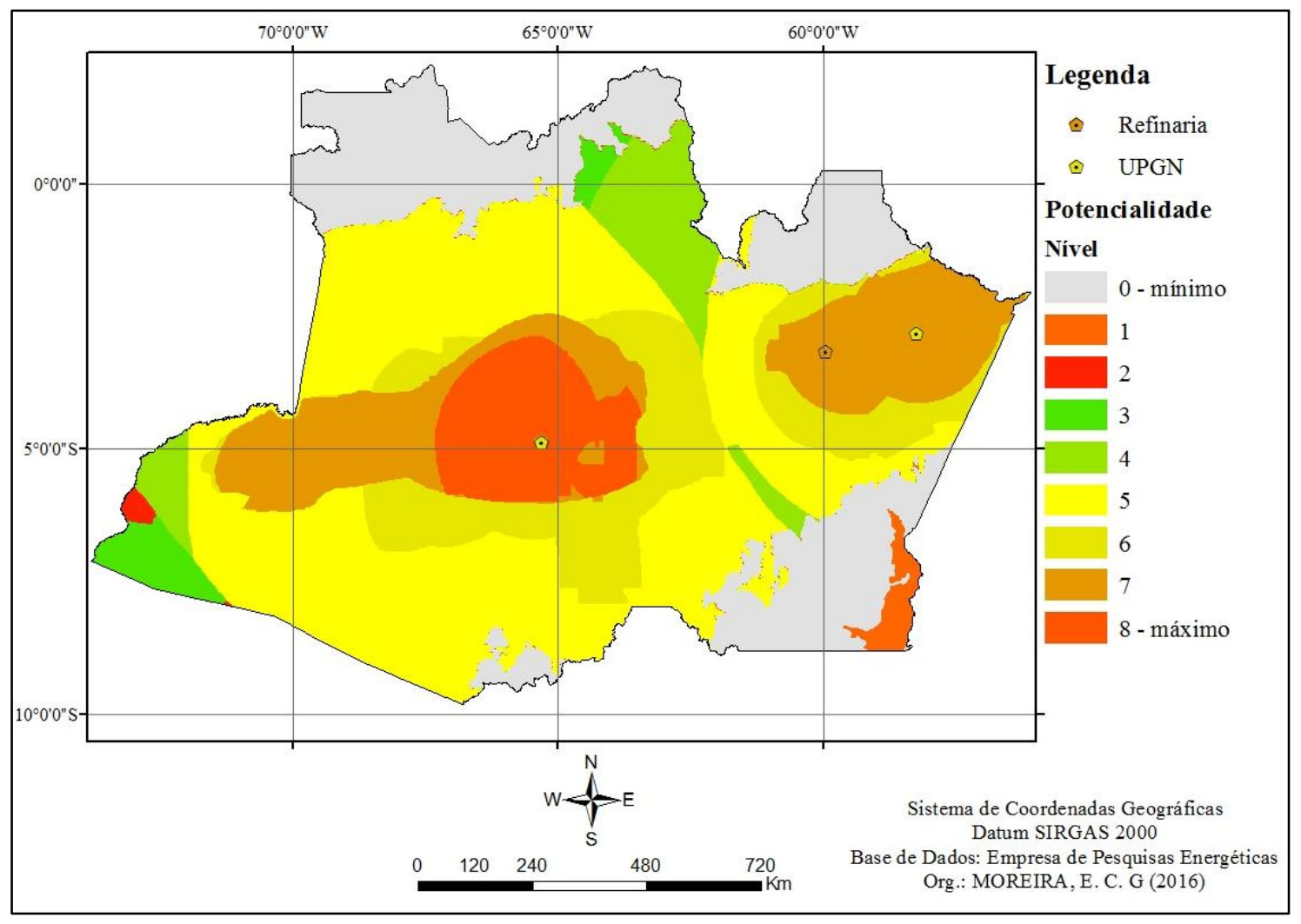

Figura 05 - Mapa de Potencialidade das Bacias Sedimentares do Amazonas 
A partir da combinação de alguns fatores como os elementos geológicos, proximidade de áreas sob contrato com empresas de Exploração e Produção (E\&P) e com instalações de infraestruturas de abastecimento de petróleo e gás natural foi elaborado um mapa síntese sobre a Importância Petrolífera da Área (IPA), referente à atividade exploratória nos contratos da União (EPE, 2014). Figura 06.

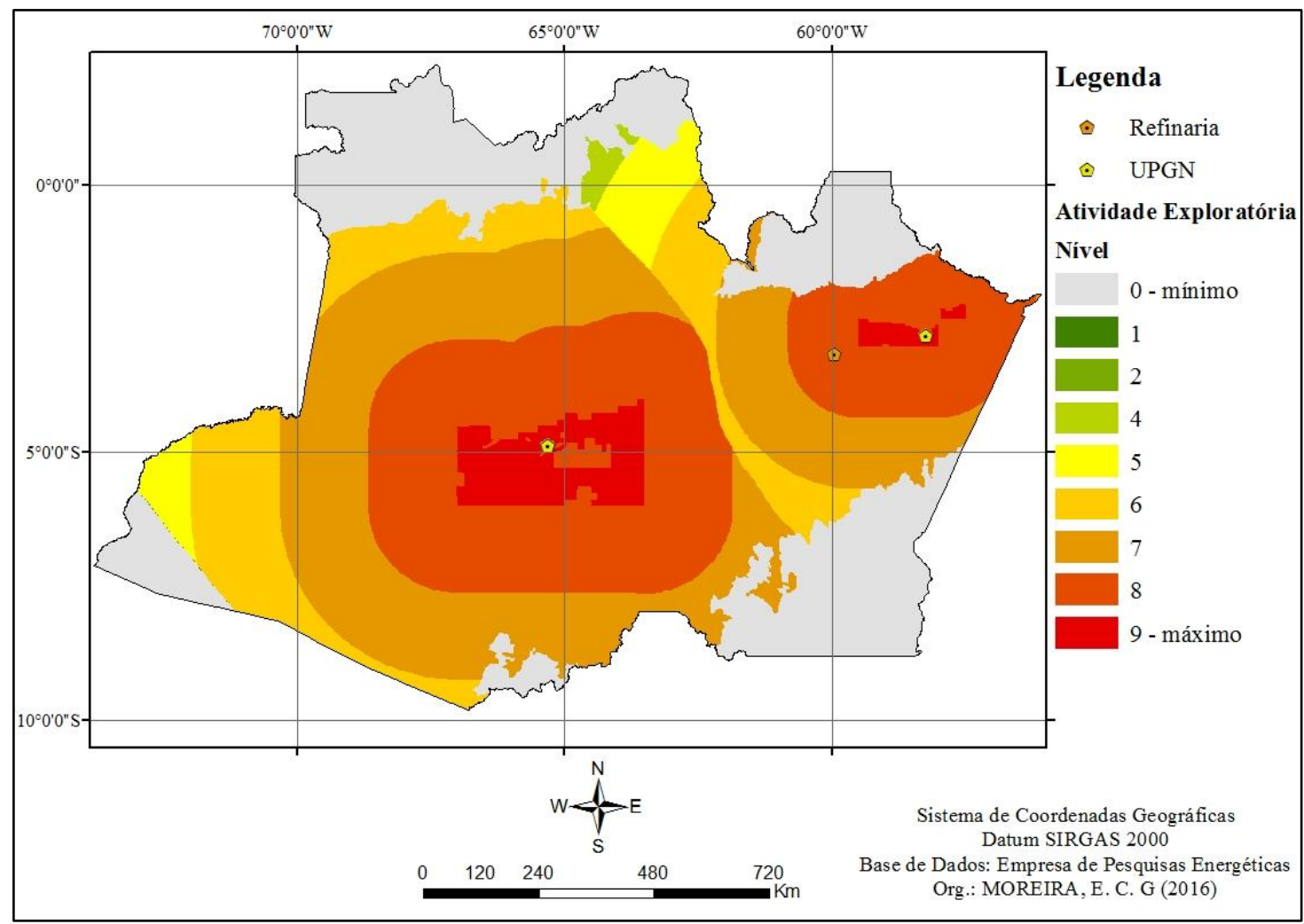

Figura 06 - Importância Petrolífera das Áreas com Atividades Exploratórias

A atividade Exploratória é o argumento sobre a importância das áreas contratadas pela União para atividades de E\&P que ainda na fase exploratória. Sendo representada pela distância de blocos exploratórios a todo e qualquer ponto de uma bacia. As áreas mais próximas de blocos exploratórios foram consideradas mais atrativas do que áreas mais distantes, tanto do ponto de vista operacional (movimentação de pessoas, materiais, equipamentos e instalações), quanto geológico (EPE, 2014). 
Ainda para a composição da Importância Petrolífera da Área (IPA) a figura 07 ilustra as bacias com maior potencialidade para a descoberta de novas acumulações de hidrocarbonetos.

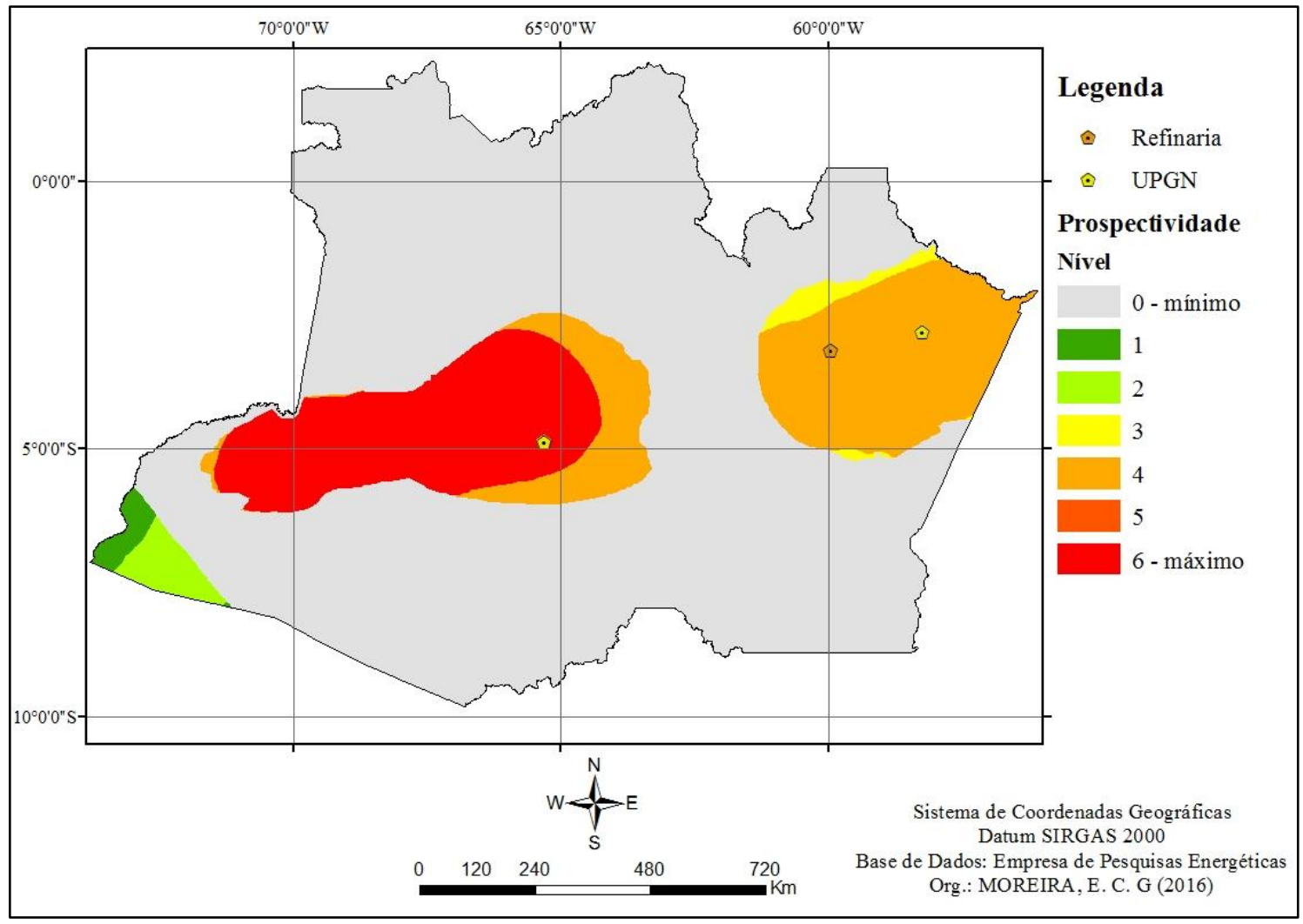

Figura 07 - Importância Petrolífera das Áreas de Prospectividade

$\mathrm{O}$ argumento de Prospectividade refere-se ao potencial petrolífero das áreas de uma bacia sedimentar e é representado pelo componente de risco exploratório na perfuração de poços pioneiros. Assim, quanto maior o risco, menor a importância da área, ou dito de modo complementar, quanto maior a chance de sucesso exploratório de uma área, maior sua importância (EPE, 2014). Outro fator destacado dentre os componentes do IPA é a Infraestrutura de Abastecimento, que conforme podemos ver na figura 08 já possui importantes instalações concluídas. 


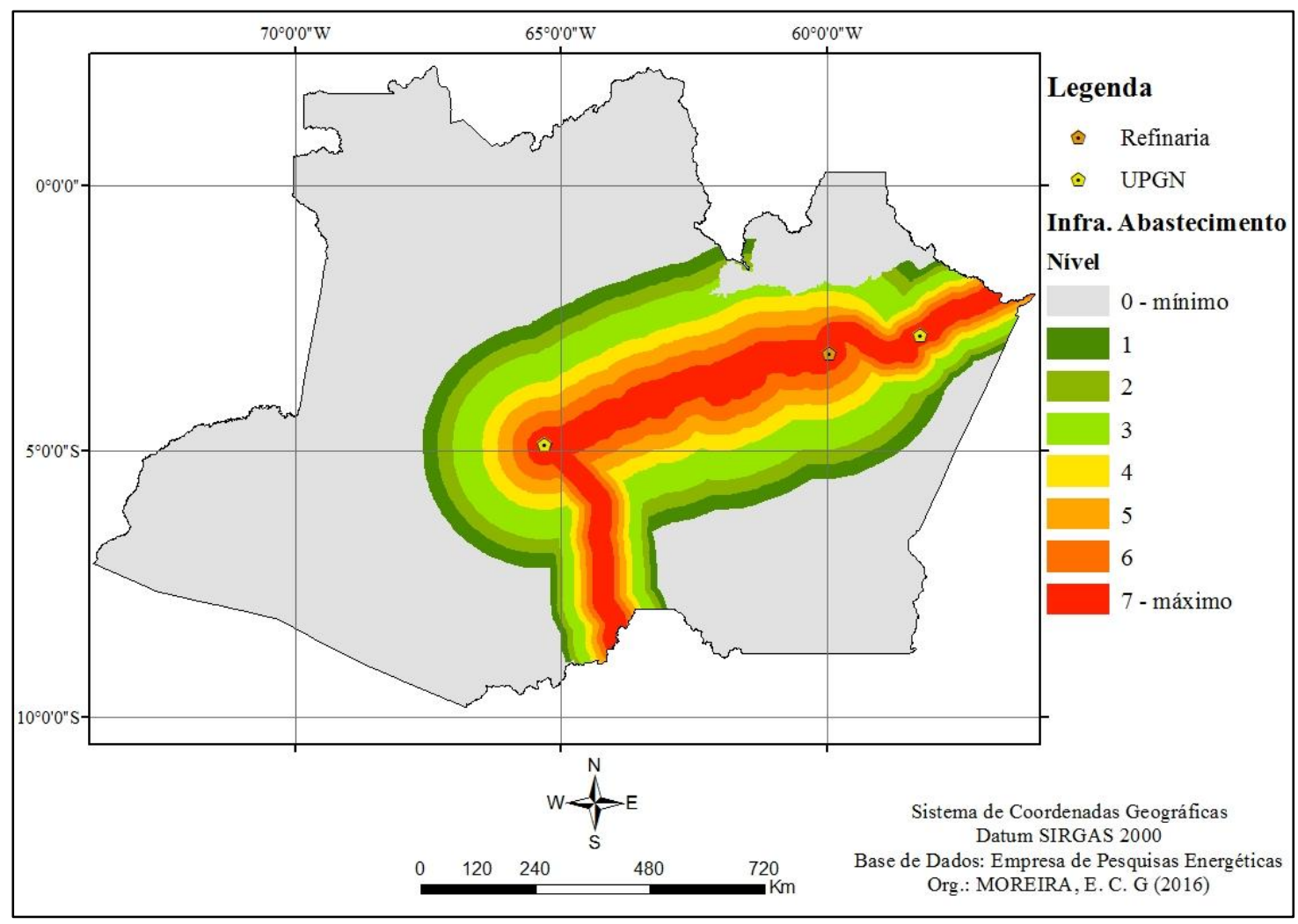

Figura 08 - Importância Petrolífera das Áreas de Infraestrutura de Abastecimento

$\mathrm{O}$ argumento da Infraestrutura de Abastecimento representa a importância operacional e econômica atribuída às áreas mais próximas de dutos ou instalações do segmento, em comparação com aquelas mais longínquas, considerando-se inclusive aqueles planejados e em construção. Do ponto de vista econômico, esse argumento de importância está atrelado ao custo/ benefício de um campo de petróleo ou gás natural, descoberto ou não, que esteja mais próximo de infraestrutura do que aquele mais distante. 


\section{OBJETIVOS}

\subsection{OBJETIVO GERAL}

Analisar o processo de recuperação das áreas de exploração e produção de petróleo e gás natural, na Bacia Sedimentar do Solimões e do Amazonas, no período de 2000 a 2015.

\subsection{OBJETIVOS ESPECÍFICOS}

a) Comparar o desempenho dos classificadores Spectral Angle Mapper(SAM) e Spectral Feature Fitting (SFF).

b) Quantificar as áreas desmatadas nas clareiras de perfuração de petróleo e gás natural.

c) Identificar o aumento do número de clareiras decorrentes da exploração petrolífera.

d) Discutir a eficiência da aplicação dos PRADs nas áreas estudadas, comparando os alcances obtidos. 


\section{REVISÃO BIBLIOGRÁFICA}

A seguir são abordados alguns conceitos sobre a recuperação de áreas degradadas e o processamento digital de imagens para classificação do desmatamento.

\subsection{ASPECTOS AMBIENTAIS DO DESMATAMENTO}

A região amazônica é o centro da biodiversidade mundial e também muito utilizada para a exploração de hidrocarbonetos. Inclusive, decorrente desta atividade, incide uma variedade de impactos ambientais e sua expansão agrega um sério risco aos componentes da vida selvagem, às espécies vegetais, populações tradicionais e a paisagem como um todo (FINER et al., 2008).

As atividades da indústria petrolífera precisam abrir espaço na floresta para a exploração e perfuração de poços. O desmatamento é um aspecto ambiental negativo que vem atrelado a uma série de impactos ao meio ambiente. Em geral essas áreas estão localizadas em topos de morros e planícies, mas também ocorrem nas margens dos rios. As intervenções acontecem por meio de maquinário de terraplanagem, para realizar o corte, compactação e aterramento do solo (NASCIMENTO, 2009).

As áreas degradadas para exploração de petróleo comumente tem um processo de regeneração mais lento quando comparadas com áreas desmatadas. A remoção do solo e a exposição das camadas subsuperficiais induzem mudanças físicas, químicas e biológicas nas características do solo e distúrbios no ecossistema (SANTOS JR., 2006).

As interferências de exploração e produção podem ter finalidades distintas, a transformação do uso do solo alterna entre um simples desmatamento até o decapeamento de $15 \mathrm{~m}$ de profundidade, ou a instalação de um porto, poço ou planta industrial. Essas singularidades são importantes estarem claras na hora da elaboração do Programa de Recuperação de Áreas Degradadas (PRAD), para orientar a determinação das medidas necessárias a cada caso (NASCIMENTO, 2009).

O sistema florestal quando sofre um corte no dossel perde o equilíbrio dinâmico devido a distúrbios em três dimensões: temporal, espacial e na magnitude. A freqüência e a data de ocorrência são fatores da dimensão temporal. A extensão (escala) e a localização do distúrbio fazem parte da dimensão espacial. E a magnitude diz respeito à severidade indicada por seus efeitos no ecossistema, refletindo na capacidade de regeneração da área afetada. A questão é que variações ocorridas nessas dimensões podem afetar a resiliência dos ecossistemas locais (JENTSCH, 2007). 
A retirada da cobertura vegetal está associada à perda do banco de sementes, que é o agrupamento derivado das sementes que chegam ao solo pelos mecanismos de dispersão (chuvas de sementes) e por aquelas presentes na serrapilheira. Entendido como reservatório de sementes viáveis presentes em determinada parcela do solo, o banco de sementes constitui um elemento fundamental na sucessão ecológica da floresta (BAKER, 1989; GARWOOD, 1989).

A alteração seqüencial na densidade e freqüência de espécies animais e vegetais de uma comunidade biótica é um conceito conhecido como sucessão ecológica. Quando o processo diz respeito apenas à comunidade de plantas recebe a denominação de sucessão vegetal. Quando esta ocorre em ambiente estéril, desprovido de legado biológico é chamada sucessão primária. A sucessão evoluída em locais previamente habitados, com participação de sementes ou plântulas da vegetação é denominada como sucessão secundária (GLENN-LEWIN et al., 1993).

No processo de regeneração da floresta o estabelecimento de novos indivíduos se dá por propágulos oriundos da dispersão pelo banco de sementes, plântulas ou da reprodução vegetativa. $\mathrm{O}$ balanço entre estes modos de regeneração influencia o sucesso ou a dominância de cada espécie na comunidade. Na regeneração de clareiras naturais ou artificiais a dispersão de propágulos é um elemento chave (NASCIMENTO, 2009).

A retirada dos horizontes do solo é outro distúrbio submetido às áreas abertas para atender a exploração petrolífera e que resulta em solos superficiais $(0$ a $10 \mathrm{~cm}) \mathrm{com}$ densidade de até $1,76 \mathrm{~g} / \mathrm{cm} 3$ e porosidade de $32,43 \%$. Reduzindo drasticamente a circulação vertical da água no perfil do solo. Ocorre um incremento de até $217 \%$ na densidade do solo e uma redução de ate $49 \%$ na porosidade, ao se comparar com solos superficiais da floresta primária (ARRUDA, 2005; TEIXEIRA et al., 2006).

As alterações supracitadas para a exploração e produção de petróleo e gás natural na Amazônia são aspectos ambientais decorrentes do desmatamento, mas desde o ano de 2000 o Instituto Nacional de Pesquisas Espaciais - INPE - vem monitorando a floresta Amazônica brasileira através do PRODES, que é um projeto de monitoramento do desmatamento com o uso de satélites. Nesta linha de pesquisa, estudos complementam o monitoramento do INPE com autores como Peres (2006) que identificou o raleamento da floresta pelo desmate seletivo na Amazônia brasileira; ou Laurence et al., (2002) que testou em modelos a possibilidade do desmatamento ter diminuído na Amazônia brasileira entre os anos de 1978 e 2000. 
Estudos sobre o desmatamento também vem sendo realizados na Amazônia ocidental, a exemplo de Viña et al (2004) que analisou as taxas de desmatamento entre os anos de 1973 e 1996, na faixa de fronteira entre a Colômbia e o Equador, zona produtora de coca e hidrocarbonetos.

\subsubsection{Programas de Recuperação de Áreas Degradadas - PRAD}

A recuperação deve considerar a sucessão primária como ponto de partida dos trabalhos. A resiliência do ecossistema foi rompida e o banco de sementes e os horizontes superficiais do solo foram eliminados. A área a ser restaurada apresenta um ambiente estéril: o solo está desprotegido, desestruturado, compactado, pouco poroso e desprovido de nutrientes. Minimizando, assim, as possibilidades de sucesso dos trabalhos de restauração pautados no fomento da sucessão secundária (NASCIMENTO, 2009).

A erosão influencia a regeneração das áreas degradadas que tem a técnica de restauração fundamentada na sucessão vegetal. Esta influência é recíproca, tanto a erosão influencia os processos sucessionais como é influenciada por eles. Este é um dos motivos do tímido sucesso obtido com o plantio de mudas visando à restauração das áreas degradas, na província petrolífera de Urucu (NASCIMENTO, 2009).

A compactação do solo é outro fator limitante da recuperação, pois minimiza a infiltração; potencializa o escoamento superficial; limita o estabelecimento das mudas cultivadas devido ao confinamento das raízes à cova; limita o estabelecimento das plântulas devido à reduzida disponibilidade hídrica e nutricional, além de favorecer a erosão pelas relações entre os fatores supracitados (NASCIMENTO, 2009).

A recuperação de uma área degradada pela mineração começa antes de se iniciar a abertura da lavra. A definição prévia do uso futuro do local degradado, o planejamento para a retirada da cobertura vegetal e da camada superficial do solo são medidas que reduzem os custos de controle ambiental (CORRÊEA, 2006).

A implementação de um PRAD é uma atividade complexa e duradoura, portanto, para a execução destes programas devem estar devidamente descritos os métodos de trabalhos a serem adotados, especificando as medidas mitigadoras dos impactos; o método para recuperação da fitofisionomia; as técnicas de conservação do solo; as técnicas de preparo do substrato para a cobertura vegetal; a proximidade com recursos hídricos; o plano de seleção de espécies; o plano de monitoramento dos tratos culturais e manutenção da área recuperada (CORRÊA, 2006). 
As diretrizes de um PRAD devem apontar seus procedimentos para alcançar como resultado a estabilização da paisagem em curto, médio e longo prazos. De maneira geral para o tratamento da paisagem é realizado o controle da erosão, a recomposição topográfica e as obras de engenharia necessárias. Em seguida deve ser feito um tratamento físico no substrato para escarificação, aração e incorporação de matéria orgânica; um tratamento químico para calagem, gessagem e aplicação de fertilizantes, e um tratamento biológico para inoculação de microorganismos e minhocas (CORRÊEA, 2006).

A chuva de sementes na área degradada é uma importante técnica do PRAD para a recuperação do banco de sementes do solo. A baixa taxa de novos aportes de sementes é um fator restritivo para a regeneração da área (REIS; TRES; SIMINSKI, 2006).

Yarranton \& Morrison (1972) verificaram que áreas em processo de formação do solo ao serem ocupadas por espécies arbóreas pioneiras resultaram em pequenos aglomerados de outras espécies em sua volta. Este fato acelerou o processo de sucessão primária, promovendo um avanço no compasso de alastramento das espécies a partir de uma espécie promotora. Este aumento no ritmo de colonização ficou conhecido como nucleação. Scarano (2000) tratou sobre a capacidade de uma espécie favorecer a colonização das demais espécies, usando o termo "planta focal".

O PRAD é que define a comunidade vegetal a ser aplicada, as espécies herbáceas, arbustivas e arbóreas, juntamente com a época mais adequada para a realização do plantio e a programação da irrigação. Após a execução das atividades operacionais deve ser executado o plano de manutenção e monitoramento de modo contínuo, realizando principalmente as ações de: adubação de cobertura; reposição de mudas mortas; capinas; coroamentos; aceiramentos; controle de pragas e patógenos; identificação de toxidez e deficiências nutricionais; reconstrução de terraços; a substituição de espécies pouco adaptadas e a emissão periódica de relatórios de acompanhamento para embasar as ações necessárias (CORRÊA, 2006).

Em 2009, a pesquisa realizada por Nascimento (2009) sobre a regeneração de 39 clareiras na província petrolífera de Urucu entre os anos de 1986 e 2007, mostrou que nenhuma das áreas voltou à classe de floresta após a intervenção e plantio para a recuperação. As melhores áreas foram onde ocorreram o adensamento de uma só espécie de grande capacidade de adaptação a insolação, solos compactados, pobre em nutrientes e estresse hídrico. A classificação digital supervisionada mostrou que em 2007 a superfície total com solo exposto era de 76,59\%. A pesquisa mostrou que em 
áreas maiores, e isoladas onde não houve plantio, após uma década de abandono a regeneração natural foi incipiente e com a colonização de uma única espécie (Vismia guiannensis (Alb) Choysi).

Ainda, segundo Nascimento (2009) na mesma pesquisa, as imagens de onde o plantio foi realizado não demonstraram crescimento progressivo das áreas de regeneração, pelo contrário, relatou uma redução das áreas florestadas que permaneceram após o plantio e uma tímida variação nas áreas em regeneração. Resultado, este, que deve ser analisado com cautela, pois a colonização por gramíneas e herbáceas transmitem uma falsa percepção de avanço da regeneração (resposta espectral em tons verde claro, com pouca rugosidade) no momento de leitura da imagem.

\subsection{SENSORIAMENTO REMOTO MULTIESPECTRAL}

Segundo Lillesand, Kiefer e Chipman (2008) sensoriamento remoto é a ciência e a arte de obter informações sobre objetos, áreas ou fenômenos através da análise de dados obtidos por um dispositivo que não está em contato direto com o objeto, área ou fenômeno sob investigação. Meneses \& Almeida (2012) menciona uma definição clássica: sensoriamento remoto é uma técnica de obtenção de imagens dos objetos da superfície terrestre sem que haja um contato físico de qualquer espécie entre o sensor e o objeto.

O Sensoriamento Remoto é definido como: um conjunto de atividades que caracterizam as propriedades dos objetos a partir da detecção, registro e análise do fluxo radiante emitido ou refletido por eles. Praticamente é necessário realizar a identificação e a discriminação dos alvos, visando deduzir as características das feições com base na radiação recebida pelo sensor (LATORRE, 2002).

Basicamente, o sensoriamento remoto constitui-se dos processos de aquisição e análise de dados para os quais são trabalhadas as informações relacionadas: da fonte de energia, da propagação da energia pela atmosfera, da interação da energia com as características da superfície, da sua retransmissão pela atmosfera, do sensor, da sua transmissão, recepção, gravação, interpretação e análise (RESENDE, 2010).

A fonte de energia ilumina o alvo ou a superfície de interesse na forma de radiação eletromagnética, a qual consiste de um campo elétrico e um campo magnético, que formam um ângulo reto entre si. Suas características em termos de comprimento de onda e frequência é que permitem extrair informações dos dados do sensoriamento 
remoto (RESENDE, 2010). A figura 09 demonstra o espectro eletromagnético e a variação do comprimento de onda.

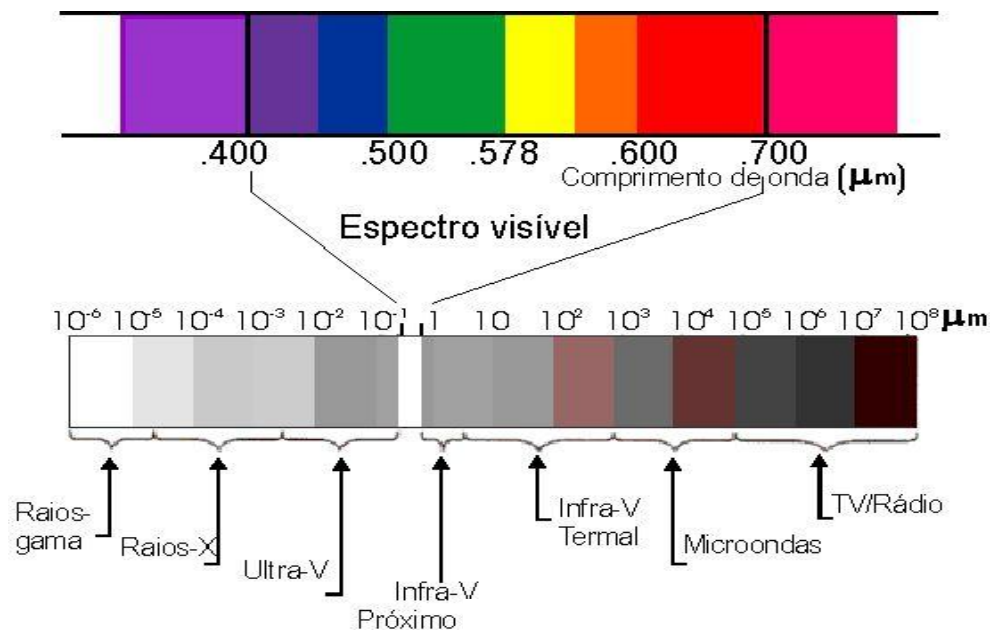

Figura 09 - Espectro eletromagnético (modificado de INPE, 2015)

$\mathrm{Na}$ interpretação do espectro eletromagnético para o sensoriamento remoto as faixas do ultravioleta, do visível, do infravermelho e das microondas são muito utilizadas (LILLESAND, KIEFER e CHIPMAN, 2008). Estas faixas são ainda divididas internamente: o espectro visível se divide em Azul (400nm a 500nm), Verde (500nm a 600nm) e Vermelho (600nm a 700nm) e o infravermelho é dividido em infravermelho próximo, médio e distante (RESENDE, 2010).

Segundo Lillesand, Kiefer e Chipman (2008) quando a energia eletromagnética incide sobre alguma feição da superfície terrestre existem três interações fundamentais possíveis da energia com estes elementos: reflexão, absorção e transmissão. Portanto, pelo princípio da conservação de energia podemos ver a inter-relação entre esses três tipos de interação energética como:

$$
E_{I}(\lambda)=E_{R}(\lambda)+E_{A}(\lambda)+E_{T}(\lambda), \text { onde: }
$$

$$
\begin{aligned}
\mathrm{E}_{\mathrm{I}} & =\text { energia incidente; } \\
\mathrm{E}_{\mathrm{R}} & =\text { energia refletida; } \\
\mathrm{E}_{\mathrm{A}} & =\text { energia absorvida; } \\
\mathrm{E}_{\mathrm{T}} & =\text { energia transmitida; }
\end{aligned}
$$


As diferentes características da Terra ocasionam uma variação na proporção de energia refletida, absorvida e transmitida segundo as peculiaridades e condições do material. Este fato possibilita a distinção das feições nas imagens (LILLESAND, KIEFER e CHIPMAN, 2008).

Dessa forma, é possível realizar a elaboração de um gráfico da reflectância espectral de um objeto. Assim, torna-se conhecida a curva espectral do objeto, conhecida como sua assinatura espectral. Esta informação prévia possibilita o reconhecimento e análise dos objetos na imagem (RESENDE, 2010).

O comportamento singular dos objetos mediante a radiação incidente é dependente de diversos fatores. As frações de energia transmitida, refletida e absorvida pelos objetos variam com suas propriedades físico-químicas, estrutura e posição em relação à fonte de radiação. $\mathrm{O}$ comportamento da sombra apresenta a absorção total da energia ou ausência de incidência da radiação, fato que resulta na falta de informação. Embora a reflectância nula, geralmente, não aconteça em decorrência da radiação difusa, ainda que haja algum impedimento do fluxo de iluminação. Todavia, a opacidade do material pode interferir na intensidade do sombreamento, variando o comprimento de onda. Situação que pode ocorrer com as folhas devido sua maior opacidade na região do Vermelho que no Infravermelho próximo (MOREIRA, 2000).

Em diferentes países o manejo sustentável de florestas, a partir do uso do sensoriamento remoto, é bastante utilizado e representa uma importante ferramenta para a análise espacial, baseia-se na aplicação das técnicas de classificação de imagens para obtenção de informações mais precisas sobre a floresta (NASCIMENTO, 2009).

O desmatamento em florestas tropicais úmidas vem sendo monitorado de forma crescente utilizando-se imagens de satélite, como destaca Hansen et al. (2008) em seu estudo sobre estoques de carbono, que entre os anos de 2000 e 2005 monitorou o desmatamento das florestas tropicais ocorrido em diferentes continentes.

A medida do desmatamento em áreas planas para mosaicos de até um hectare, utilizando imagens LANDSAT, alcançou uma exatidão de até 90 a $95 \%$ segundo os estudos Roy et al. (1991); Steininger (1996); Lelmgruber et al. (2005). Enquanto Defries et al. (2007) destacam a complexidade de se realizar o monitoramento da degradação da floresta e de sua regeneração devido a temporalidade. Todavia, Asner (2001) e Palace et al. (2008) indicaram o uso de imagens de alta resolução aliadas ao uso de séries históricas das imagens como alternativa para superar este problema. 
A utilização das imagens LANDSAT aplicadas ao mapeamento do desmatamento tem sido favorável, conforme os estudos feitos por Tardin et al. (1980), que mapearam áreas desmatadas em dois períodos da década de 70 a partir de imagens LANDSAT/MSS (ALVES, 2001).

\subsubsection{Características Espectrais da Vegetação e do Solo}

Para compreensão dessas características considere uma vegetação verde, na região do espectro eletromagnético da luz vermelha $(0,63-0,67 \mu \mathrm{m})$, a radiação eletromagnética (REM) é absorvida pela clorofila, com pouca transmissão e pouca reflexão, ao passo que no infravermelho próximo $(0,7-1,3 \mu \mathrm{m})$ a absorção é quase zero, já a reflectância e a transmitância são altas, devido à estrutura interna das folhas (RESENDE, 2010).

Desta maneira, à medida que aumenta a quantidade de vegetação, a reflexão na banda espectral do infravermelho próximo (IV) aumenta e a reflexão na banda do vermelho (V) diminui, fazendo com que o aumento da razão entre as bandas IV/V seja potencializado, realçando a vegetação. Quando várias camadas de folhas vão sendo sobrepostas num dossel, em desenvolvimento, concomitantemente vão ocorrendo aumentos nos níveis de reflectância nas porções espectrais do IV (EPIPHÂNIO \& FORMAGGIO, 1991).

Na região do visível $(0,4$ a $0,7 \mu \mathrm{m})$, os pigmentos existentes nas folhas dominam a reflectância espectral. Estes pigmentos, geralmente, encontrados nos cloroplastos são: clorofila (65\%), carotenos (6\%), e xantofilas (29\%). Os valores percentuais destes pigmentos existentes nas folhas podem variar grandemente de espécie para espécie. A energia radiante interage com a estrutura foliar por absorção e por espalhamento. A energia é absorvida seletivamente pela clorofila e é convertida em calor ou fluorescência e, também, convertida fotoquimicamente em energia estocada na forma de componentes orgânicos por intermédio da fotossíntese (CARVALHO JR, 2003c).

Já na região do infravermelho próximo $(0,7$ a $1,3 \mu \mathrm{m})$ existe uma absorção pequena da REM e considerável espalhamento interno na folha. A absorção da água é geralmente baixa nessa região e a reflectância espectral é quase constante. Na pesquisa de Gates et al. (1965) determinou-se que a reflectância espectral de folhas nessa região do espectro eletromagnético é o resultado da interação da energia incidente com a estrutura do mesófilo. 
No estudo da resposta espectral de folhas verdes, constatou-se que no intervalo de comprimentos de onda de 400 a 700 nm (faixa do VIS) a reflectância é baixa, da ordem de $10 \%$, com um suave aumento da resposta na região do verde $(550 \mathrm{~nm})$. Na faixa do infravermelho próximo (700 a $1300 \mathrm{~nm}$ - IVP), ocorre outro aumento na reflectância para valores próximos a 50\%. Daí em diante, até $2500 \mathrm{~nm}$ (infravermelho médio - IVM), há um gradual decréscimo, aparecendo algumas feições de absorção pelo conteúdo de água líquida. (MOREIRA, 2000).

Quanto ao solo observa-se um comportamento menos variável que a vegetação, em relação aos máximos e mínimos valores de reflectância. Alguns fatores que afetam a sua reflectância são o conteúdo de umidade, a textura (proporção de areia, silte e argila), a rugosidade da superfície, a concentração de óxidos de ferro e o conteúdo de matéria orgânica (decomposta ou não) (LILLESAND, KIEFER \& CHIPMAN, 2008).

A presença de umidade diminui a reflectância dos solos, sendo este efeito maior na faixa do IVM (LILLESAND, KIEFER \& CHIPMAN, 2008). A matéria orgânica tem uma forte influência diminuindo a reflectância em toda a região do visível (VIS) e do Infra-Vermelho Próximo (IVP). Os óxidos de ferro atuam no ultravioleta e no azul, gerando feições espectrais caracterizadas por uma depressão, presente na maioria dos espectros dos tipos de solo e podem produzir fracas absorções entre 700 e $870 \mathrm{~nm}$ (ferro férrico) e em 1000nm (ferro ferroso). Os óxidos de ferro e de titânio participam mais intensamente de interações macro e microscópicas com a radiação do visível e IVP, minerais de argila, carbonatos, sulfatos e fosfatos influenciam mais fortemente no IVM (IRONS et al., 1989).

Sanches et al. (2005) verificaram que quando as culturas de soja, cana-de-açúcar e milho estão em início de crescimento, a identificação das mesmas em imagens de satélite Landsat é bastante difícil, pois, a resposta espectral desses alvos é muito influenciada pelo solo. Ou seja, se cultivadas sob o mesmo solo, o comportamento de diferentes culturas, em imagens de satélite, será bastante semelhante nas primeiras fases de desenvolvimento. O mesmo é observado após a colheita das culturas, quando o solo volta a aumentar sua influência no comportamento espectral. À medida que as plantas crescem, diminui a influência do solo e crescem as possibilidades de diferenciação de culturas, tendo em vista aumentar a influência das características específicas de cada tipo de planta. 


\subsection{PROCESSAMENTO DIGITAL DE IMAGENS}

Segundo Alvarenga (2005) o processamento digital de imagens (PDI) é entendido como a análise e a manipulação de imagens por computador, cuja finalidade é identificar e extrair informações da imagem, para transformá-la de tal modo que a informação seja mais facilmente discernível por um analista humano.

\subsubsection{Pré-processamento Digital de Imagens}

As técnicas de pré-processamento objetivam melhorar a qualidade visual da cena. As correções dos diferentes tipos de erros que a imagem pode apresentar são modeladas de acordo com o tipo da estrutura dos erros e a partir da fonte de distorção. Portanto, essas técnicas são uma etapa importante para os processamentos subsequentes não realçarem essas imperfeições. Todavia, a ordem da correção da imagem depende dos objetivos da pesquisa e pode iniciar pela correção radiométrica, atmosférica e geométrica, ou a realização de todas (MENEZES, 2012).

A correção radiométrica consiste na normalização dos valores radiométricos das imagens adquiridas, em diferentes datas ou por diferentes sensores e em diferentes condições atmosférica. De acordo com Ya'allah \& Saradjian (2005) a normalização diminui as diferenças nas condições de imageamento, retificando radiometricamente as imagens como se elas tivessem sido adquiridas sob as mesmas condições.

A atmosfera interage com a radiação eletromagnética, provocando significativas alterações no fluxo radiante advindo do alvo. Essa interação ocasiona mudanças na sua propagação, denominadas espalhamento e absorção (LATORRE,2002). O software ENVI uniformiza estas interferências por meio de um módulo que transforma os valores dos números digitais em valores de reflectância, possibilitando, desta forma, a análise de imagens de uma mesma área adquiridas em datas diferentes (LOEBMANN, 2005).

A correção geométrica trata da remoção de erros sistemáticos que ocorrem na aquisição dos dados e devido às distorções geradas pela visada cônica dos sensores. $\mathrm{O}$ usuário deve inserir na imagem um sistema de projeção para se estabelecer um referencial de coordenadas que possibilite localizar, na imagem, a posição geográfica dos alvos. Este é o método de georreferenciamento, que utiliza transformações geométricas polinomiais para fazer vínculo entre as coordenadas da imagem e as coordenadas do sistema de referência (MENESES \& ALMEIDA, 2012). 


\subsection{ANÁLISE LINEAR DE MISTURA ESPECTRAL - ALME}

Segundo Carvalho Júnior (2003), a análise de imagens utilizando os procedimentos de classificação passou a ter um novo formato a partir do conceito de mistura espectral. Neste procedimento os dados são trabalhados visando identificar e quantificar os componentes presentes nos pixels. Para isso, foram definidas quatro fases de processamento a citar: (i) Minimum Noise Fraction MNF (inverse); (ii) detecção dos pixels puros; (iii) visualização no espaço $n$-dimensional; e (iv) identificação dos endmembers.

Os endmembers da imagem são os espectros mais puros presentes nos pixels. Contudo, muitas vezes a imagem não possui um pixel puro totalmente composto pelo material procurado, pois, estes correspondem a um sinal de uma área. Nesse caso, obtém-se um espectro de uma mistura, onde existe uma maior proporção do material de interesse, que difere do membro final obtido em laboratório utilizando unicamente o material. Os endmembers, depois, são analisados no visualizador $n$-dimensional para a identificação da imagem (CARVALHO JUNIOR, 2003b).

CARVALHO JR (2003b) demonstrou em seu estudo uma metodologia para a detecção dos endmembers a partir da geometria do simplex, em três etapas: redução da dimensão espectral utilizando a técnica de Minimum Noise Fraction (MNF), redução da dimensão espacial utilizando o método Pixel Purity Index (PPI) e identificação (utilizando o visualizador $n$-dimensional).

O Simplex é uma forma geométrica que dispõe os pixels da imagem em um arranjo espacial de maneira a auxiliar o entendimento da relação das misturas dos materiais presentes na imagem (CARVALHO JUNIOR, 2003a). O método simplex tem o objetivo de identificar os vértices de um conjunto convexo, com os quais é possível se definir uma solução adequada para questões de programação linear (CARVALHO JUNIOR, 2003b).

O Simplex é um procedimento que pode ser realizado em ambiente ENVI para reduzir o volume espectral e espacial dos dados existentes, bem como, extrair os membros finais em um visualizador n-dimensional de espectros. Assim, a dimensionalidade espectral dos dados, ou seja, o número de bandas é reduzido pela Transformação MNF - Minimum Noise Fraction (BOARDMAN, KRUSE \& GREEN, 1995). Nela a imagem é descorrelacionada e re-escalonada em seguida, concentrando as 
informações relevantes nas primeiras bandas, tornando as últimas descartáveis (LOEBMANN, 2005).

Em seguida é aplicado o Índice de Pixel Puro (PPI) que registra e contabiliza os pixels que são vértices nas diferentes projeções do simplex. Desta forma, os pixels mais puros tendem a se repetir nas diferentes projeções, na imagem de PPI as áreas claras correspondem aos pixels puros selecionados (CARVALHO, 2001).

O procedimento PPI gera uma imagem que apresenta, para cada pixel, o valor do número de vezes em que esse foi definido como vértice. Quanto maior for o valor do pixel na imagem PPI maior é o seu grau de pureza (CARVALHO JUNIOR, 2003b).

O índice PPI - Pixel Purity Index (BOARDMAN, KRUSE \& GREEN, 1995) identifica os pixels mais puros da imagem por meio da seleção dos pontos que são projetados iterativamente nos vértices do simplex, numa quantidade de vezes maior que o valor de corte estabelecido previamente pelo usuário (LOEBMANN, 2005).

$\mathrm{Na}$ etapa de identificação, os pixels puros são inseridos numa área de interesse e exportados para um visualizador de $n$ dimensões, em que $n$ corresponde ao número de bandas da imagem utilizada como dado de entrada. Neste ambiente, os membros finais com maior semelhança se agrupam em nuvens que representam as classes de uso. A média dos espectros de cada classe pode ser utilizada como parâmetro para a classificação das imagens (LOEBMANN, 2005).

De maneira geral, o modelo linear de mistura espectral é um procedimento eficiente para a análise do desmatamento na floresta amazônica. Na literatura encontramos diversos autores que usaram-no em seus estudos, como Pereira (1998) que fez a proporção de componentes decompostas por um modelo linear de mistura espectral, utilizando imagens Landsat TM, para classificar a cobertura da terra na região amazônica e alcançou 98,6\% de exatidão na classificação do uso da terra nesta região.

Carvalho Junior (2003) utilizou técnicas de classificação imagens Landsat TM para descrever padrões de vegetação na região de transição entre o cerrado e a floresta amazônica e, também, utilizou a metodologia de análise linear de mistura espectral proposta por Boardman \& Kruse (1994), encontrando resultados eficientes na discriminação da densidade de biomassa vegetal.

O mapeamento da cobertura vegetal natural e antrópica do bioma cerrado foi estudado por Sano e colaboradores (2009), que realizaram a segmentação por crescimento de regiões em imagens Landsat ETM, uma técnica semi-automatizada que gerou o mapa de cobertura vegetal natural e antrópica do bioma cerrado, em escala de 
semi-detalhe. Nesse estudo, os autores destacaram o desafio de separar áreas com pastagens plantadas de áreas com pastagens nativas, que foi solucionado com base no aspecto geométrico e em dados de elevação SRTM (Shuttle Radas Topography Mission).

A autora Renó (2010) avaliou o desflorestamento da várzea do Baixo Amazonas com imagens Landsat MSS e TM, a partir de classificação supervisionada do vizinho mais próximo, que permitiu a distinção dos alvos de interesse, contribuindo significativamente para a identificação e o mapeamento da cobertura vegetal da área de estudo.

Em Pinagé (2011) foi realizado o mapeamento e análise do corte seletivo no estado do Pará utilizando uma cena do Landsat TM, tendo como base ma operação aritmética aplicada ao modelo linear de mistura espectral, para a detecção do corte seletivo. Uma pesquisa exploratória, sem verdade de campo, concluiu que a intensidade de exploração pode ser diferenciada pelo grau de alteração do dossel, sustentando que este tipo de informação é importante no monitoramento dos planos de manejo florestal.

\subsection{CLASSIFICADORES - SAM \& SFF}

Segundo Carvalho Junior \& Meneses (2000) os métodos de classificação para feições espectrais tem como base comparações realizadas na imagem espectral com um espectro de referência (membros finais ou bibliotecas espectrais).

\subsubsection{Spectral Angle Mapper - SAM}

O classificador SAM é considerado um dos principais métodos de classificação. Avalia a similaridade do espectro de modo a reduzir a influência do sombreamento para acentuar as características de reflectância do alvo (KRUSE et al. 1993).

O mapeamento por ângulo espectral (SAM) é um algoritmo que determina a similaridade espectral entre dois espectros, calculando o ângulo entre eles em todas as bandas espectrais, tratando-os como vetores em um espaço de dimensionalidade igual ao número de bandas espectrais (BARBOSA, 2005).

A figura 10 apresenta uma representação simplificada desta operação considerando um espectro de referência ( $r$ ) e o espectro do pixel (t). As linhas conectando cada ponto do espectro com a origem contêm todas as posições possíveis para o material, em termos de iluminação. Desta forma, o ângulo $(\alpha)$ entre os vetores é o mesmo, indiferente do grau de sombreamento ou iluminação (BARBOSA, 2005). 


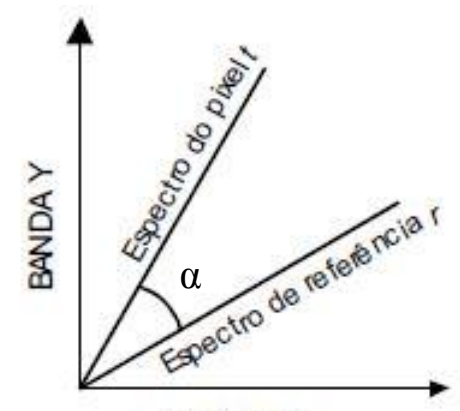

BANDAX

Figura 10 - Gráfico dos espectros de referência (r) e espectro do pixel (t) (modificado de KRUSE et al. 1993)

Carvalho Junior \& Meneses (2000) relataram que este algoritmo não consegue distinguir entre correlações negativas e positivas, pois considera apenas o valor absoluto. Estudos realizados por Smith \& Adams (1985) observaram que é necessário se obter certa precisão taxonômica dos diferentes tipos de vegetais, a qual pode ser alcançada através da classificação SAM.

Essa limitação é confirmada no estudo de Bias (2010) que descreve esta técnica de classificação supervisionada, baseada na disposição angular dos $n$-pixels num gráfico de dispersão, com dimensionalidade igual ao número de bandas. O algoritmo determina a similaridade espectral entre duas classes, calculando o ângulo entre eles e os tratando como vetores num espaço dimensional. Assim, quanto menor o ângulo de um pixel com o espectro de referência da classe, maior sua combinação com a mesma. Pixels localizados fora dos limites angulares, determinados para a classe, não são classificados e destaca que esta técnica, quando aplicada sobre uma imagem calibrada, é relativamente insensível aos efeitos de iluminação e albedo da imagem.

Em Loebmann (2005) foi demonstrado que a detecção dos membros finais e a posterior aplicação do Spectral Angle Mapper, complementadas com o algoritmo de vegetação fotossinteticamente ativa, possibilitaram o mapeamento da Bacia do Rio Jardim/DF. Entretanto, os resultados demonstraram que, provavelmente devido à pequena quantidade de bandas das imagens LANDSAT, o classificador não diferenciou as classes de agricultura irrigada e mata galeria. A separação entre as duas classes, de assinatura espectral muito semelhante, foi realizada utilizando-se um algoritmo elaborado por Carvalho Junior. et al. (2001) que, baseado na reflectância das bandas do espectro óptico, determinou a distribuição espacial das duas classes.

Em pesquisa realizada por Bias, Ramos e Ribeiro (2010) no estado de Goiás, apontava o mapeamento de oito feições e após a aplicação de métodos MNF, PPI e SAM os resultados apresentaram efetividade no mapeamento das feições propostas e, 
sobretudo na quantificação de suas áreas. Esses métodos indicaram uma boa aplicação em estudos multitemporais.

\subsubsection{Spectral Feature Fitting - SFF}

A partir de bibliotecas espectrais ou dos endmembers das imagens podem ser obtidos os valores do espectro da imagem (EI) e/ou do espectro de referência (ER), apoiado em sua comparação, os classificadores espectrais efetuam um critério de similaridade para a identificação do material. Assim, haverá a obtenção de duas curvas espectrais que permitem a identificação do material procurado de acordo com o ajuste obtido. Portanto, a probabilidade de ocorrência do material de referência no pixel da imagem é maior quanto melhor for o ajuste (CARVALHO JUNIOR et al., 2003c)

O ajuste linear é, basicamente, um procedimento para definir o grau de uma regressão linear com somente uma variável independente (equação 02). Para tal, se considera a variável independente (X) como o Espectro da Imagem (EI) e a variável dependente (Y) sendo o Espectro de Referência (ER) (CARVALHO JUNIOR et al., 2003c).

$$
\mathrm{ER}=\mathrm{a}+\mathrm{bEI} \text {, onde: }
$$

$$
\begin{aligned}
& \mathrm{a}=\text { coeficiente linear } \\
& \mathrm{b}=\text { coeficiente angular }
\end{aligned}
$$

Para realizar a regressão linear entre os espectros existem duas maneiras: considerando o ER como termo dependente ou o EI. Essas variantes, no modo de executar a regressão, denotam peculiaridades aos valores de erro médio, mas permanecem inalteradas para os valores de correlação (CARVALHO JUNIOR et al., 2003c).

Segundo Baptista (2012), existe uma relação linear, em grande parte dos alvos imageados, relacionando a intensidade de absorção e o conteúdo da matéria original. Assim, a medição das intensidades de absorção permite estimar o conteúdo dos materiais. O algoritmo SFF é um método utilizado para definir a intensidade da feição espectral, o seu cálculo se dá por meio do ajuste dos mínimos quadrados para comparar os endmembers com cada pixel da cena.

O recurso do Spectral Feature Fitting (SFF) é utilizado para comparar o ajuste dos espectros da imagem com os espectros de referência usando a técnica dos mínimos quadrados. O SFF é uma metodologia baseada na absorção de feições. Os espectros de 
referência são dimensionados para combinar com o espectro da imagem depois da remoção do contínuo espectral de ambos conjuntos de dados (ENVI, 2015).

Os resultados principais deste algoritmo são uma imagem scale, referente à medida de intensidade da feição em cada pixel, e uma imagem RMS (root mean square), referente ao erro médio quadrático do ajuste por mínimos quadrados. Com estas informações pode-se gerar um produto quanto à probabilidade do pixel conter o endmember, para isso basta calcular a divisão do scale pelo RMS, que trará um resultado conhecido como fit image (BAPTISTA, 2012).

O método SFF realiza as seguintes funções: (a) remoção do efeito do background; (b) cálculo da profundidade da banda de absorção, e (c) comparação de espectros. Para esta última função o SFF utiliza o erro do tipo $\mathrm{Y}=\mathrm{EI}$ (CARVALHO JUNIOR et al., 2003c). A técnica SFF foi aplicada por Meroni (2009) em imagens hiperespectrais para quantificar a fluorescência da vegetação a partir do ajuste espectral, revelando um erro muito pequeno e uma elevada acurácia no ajuste da feição.

\subsection{QUALIDADE DE DADOS: MATRIZ DE CONFUSÃO E ÍNDICE KAPPA}

O teste estatístico mais simples para se julgar a exatidão dos mapas, derivados de dados de sensores orbitais, consiste em determinar um número ótimo de amostras a serem tomadas no terreno e assumir uma margem de erro permissível. Então, pela comparação dos pontos amostrados no terreno com aqueles correspondentes obtidos no mapa, gerado pelo processo de classificação, o número de erro pode ser determinado. Se o número de erro é menor ou igual à margem assumida o mapa é aceito como exato, dentro dos intervalos de confiança especificados (CONGALTON \& GREEN, 2009).

Segundo Campell (1987), qualquer tipo de classificação apresenta erros, geralmente, ligados a associação incorreta das informações às relações espectrais. Todavia, existe uma maneira padrão para informar os erros acontecidos em determinados locais, por meio da aplicação de uma matriz de confusão. Nesta matriz são identificados o erro global da classificação por categoria e as confusões geradas em cada categoria. Uma Matriz de Confusão (erros) expressa à relação do número de unidades de amostras atribuídas a uma categoria particular de duas classificações. $\mathrm{Na}$ qual os dados de referências são representados pelas colunas e as linhas são o resultado advindo de algum método de classificação (CONGALTON, 1991).

Conforme Lillesand, Kiefer and Chipman (2008), a matriz de erros expressa uma série de características sobre o desempenho da classificação, como os erros de omissão 
(exclusão) e de comissão (inclusão). Todos os elementos, fora da diagonal principal da matriz, representam algum desses erros, quando estão presentes na coluna são erros de omissão, enquanto comissão corresponde à linha.

De acordo com Brites (1996), a natureza genérica dos erros existentes, normalmente, deve passar por uma investigação inicial e depois ter uma avaliação quantitativa da Matriz de Erros. A verificação quantitativa da Matriz de Erros, geralmente, é necessária após a realização de uma inspeção inicial para se detectar a natureza genérica dos erros presentes. Alguns dos procedimentos, que foram desenvolvidos para a análise de tabelas de contingência, podem ser aplicados ao exame da Matriz de Erros.

Lillesand, Kiefer and Chipman (2008) descrevem que a matriz de erros pode fornecer outras medidas descritivas como a exatidão global, que é calculada dividindose o número total de pixels classificados, corretamente, pelo número total de pixels de referência. A exatidão de cada categoria pode ser medida dividindo-se o número de pixels classificados, corretamente, pelo número total de pixels na respectiva linha ou coluna.

Duas outras importantes medidas descritivas citadas por Lillesand, Kiefer and Chipman (2008) tratam sobre a exatidão do produtor e do usuário. A exatidão do produtor gera um valor que indica a qualidade da classificação, obtida pelos pixels do conjunto de treinamento utilizado em determinada categoria. Esta é calculada a partir da divisão do número de pixels, corretamente, classificados em cada categoria (diagonal principal) pelo número que indica o conjunto de pixels de treinamento usados para aquela categoria (total da coluna).

Ainda segundo esses autores, a exatidão do usuário é a medida dos erros de comissão e indica a probabilidade de um pixel classificado em uma determinada categoria realmente representar aquela verdade terrestre. E é calculada pela divisão do número de pixels classificados corretamente em cada categoria pelo número total de pixels que foram classificados naquela categoria (total da linha).

Como sugerem Gong e Howarth (1990), um dos procedimentos utilizados para mensurar a exatidão das classificações temáticas é o índice Kappa e vem sendo recomendado como uma medida apropriada da exatidão por representar inteiramente a Matriz de Confusão. Pois, considera todos os elementos da Matriz de Confusão ao invés de selecionar apenas a diagonal da matriz, o que ocorre quando se calcula a exatidão global da classificação. 
A análise Kappa é uma técnica multivariada, discreta, utilizada na avaliação da precisão para determinar estatisticamente se uma matriz de erro é significativamente diferente da outra (BISHOP et al., 1975). O resultado de uma análise Kappa é uma estatística Khat (na verdade, $\mathcal{K}$, uma estimativa de Kappa), que é outra medida de acordo ou precisão (COHEN, 1960). Esta medida de concordância baseia-se na diferença entre o acordo real, na matriz de erro, e o acordo chance indicado pelos totais de linha e coluna (CONGALTON, 2009).

A análise Kappa é apropriada quando todos os erros na matriz podem ser considerados de igual importância. No entanto, é fácil de imaginar um sistema de classificação em que os erros podem variar na sua importância, o que é uma situação realmente mais realista (CONGALTON, 2009).

Em 2008, Lillesand, Kiefer and Chipman, trouxeram outro ponto importante sobre a interpretação da acurácia da classificação, onde mesmo uma atribuição completamente aleatória de pixels para classes vai produzir valores percentuais corretos na matriz de erro. Assim a análise Kappa é uma medida da diferença entre a conformidade real, comparando os dados de referência e um classificador automático e a concordância aleatória entre os dados de referência e um classificador aleatório (equação 03). Conceitualmente $\mathcal{K}$ pode ser definido como:

$$
\mathcal{K}=\frac{\text { exatidão observada }- \text { concordância aleatória }}{1-\text { concordância aleatória }}
$$

Segundo Lillesand, Kiefer and Chipman (2008) esta estatística serve como um indicador do grau em que os valores percentuais corretos de uma matriz de erro são devidos à concordância real perante a concordância aleatória. Geralmente, o valor de $\mathcal{K}$ varia de 0 a 01 , onde valores mais próximos a 01tem maior exatidão. O índice Kappa é calculado conforme a equação 04 .

Onde:

$$
\mathcal{K}=\frac{N \sum_{i=1}^{r} x_{i i}-\sum_{i=1}^{r}\left(x_{i+} * x_{+i}\right)}{N^{2}-\sum_{i=1}^{r}\left(x_{i+} * x_{+i}\right)}
$$

$\mathrm{r} \quad$ = número de linhas na matriz de erros;

$x_{i i}=$ número de observações na linhas $i$ e na coluna $i$ (na diagonal maior).

$x_{i+}=$ total de observações na linha $i$ (total na lateral direta da matriz);

$x_{+i}=$ total de observações na coluna $i$ (total embaixo na matriz). 
Ainda, segundo Lillesand, Kiefer and Chipman (2008), as medições realizadas com o índice Kappa e a matriz de erros, geralmente, apresentam divergências em seus resultados, pois cada uma das análises utiliza diferentes informações da matriz. A exatidão global analisa apenas os dados da diagonal principal e exclui os erros de omissão e comissão. Por outro lado, o índice Kappa insere todos os elementos, além da diagonal da matriz de erros, como o produto da linha e da coluna lateral. Entretanto, não há uma maneira restrita para quando aplicar estas medições, que devem ser calculadas e analisadas.

Landis \& Koch (1977) para manter a consistência da nomenclatura, quando se estiver descrevendo a intensidade de concordância da estatística Kappa, atribuíram seis rótulos para os valores de Kappa, que apesar serem claramente arbitrários provêm pontos de referência muito úteis para a interpretação dos valores de Kappa. Conforme demonstrado na tabela 01 .

Tabela 1 - Qualidade do mapa temático - índice Kappa

\begin{tabular}{c|c}
\hline Estatística Kappa & Intensidade de Concordância \\
\hline$<0,00$ & Péssimo \\
$0,00-0,20$ & Ruim \\
$0,21-0,40$ & Razoável \\
$0,41-0,60$ & Bom \\
\hline $0,61-0,80$ & Muito Bom \\
\hline $0,81-1,00$ & Excelente \\
\hline
\end{tabular}




\section{MATERIAL E MÉTODOS}

A identificação das áreas degradadas decorrentes das atividades de exploração e produção de petróleo e gás natural nas Bacias Sedimentares do Amazonas e Solimões/ AM foi realizada com a análise multitemporal de imagens de satélites, de média resolução, do sensor LANDSAT 5 e 8, os quais possuem um acervo temporal que atende o objetivo do estudo. Esta pesquisa não teve levantamentos de campo, os dados referentes à localização dos poços de perfuração e as coordenadas geográficas dos blocos de concessão foram obtidos no site da ANP, enquanto as imagens de satélites foram todas adquiridas no site do Serviço Geológico Americano (USGS).

O primeiro passo deste estudo identificou a localização geográfica dos blocos da Bacia Sedimentar do Amazonas e da Bacia Sedimentar do Solimões, realizando o delineamento das poligonais das áreas da pesquisa. As informações correlatas foram obtidas no site da Agência Nacional do Petróleo (ANP), no Banco de Dados de Exploração e Produção (BDEP), que além de outras informações também disponibiliza as coordenadas dos poços de perfuração e os arquivos shapefiles dos Blocos de Exploração, Produção e Devolvidos das concessionárias (Petrobras).

A aquisição das imagens LANDSAT passou por uma fase de intensas pesquisas nos sites do Instituto Nacional de Pesquisas Espaciais (INPE) e no site do Serviço Geológico dos Estados Unidos (USGS), visando encontrar as imagens com melhor qualidade e menor interferência atmosférica para fazer a combinação dos períodos.

Assim, foram levantadas as cenas referentes aos quadrantes da Área I (Bacia Sedimentar do Solimões): 01/063 e 02/063, bem como da Área II (Bacia Sedimentar do Amazonas): 230/62 e 229/62. Os limites das duas áreas de estudo aconteceram de modo a considerar integralmente os blocos de produção e exploração e, somente, a parte dos blocos devolvidos que estivessem presentes nestas quatro cenas. As figuras 11 e 12 mostram as áreas de estudos nos Blocos da Petrobras no Estado do Amazonas. 


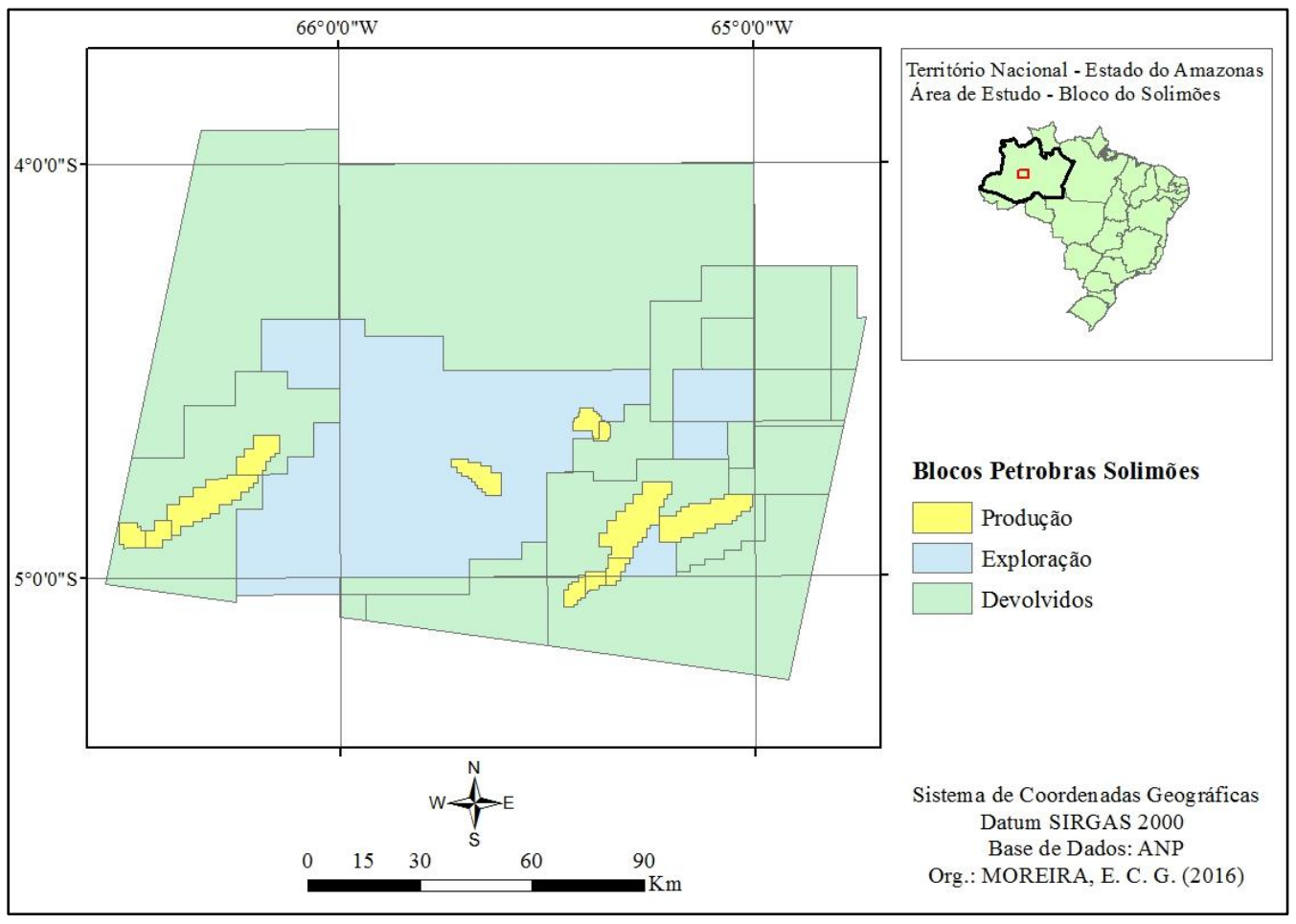

Figura 11 - Mapa dos Blocos de Concessão da Bacia do Solimões

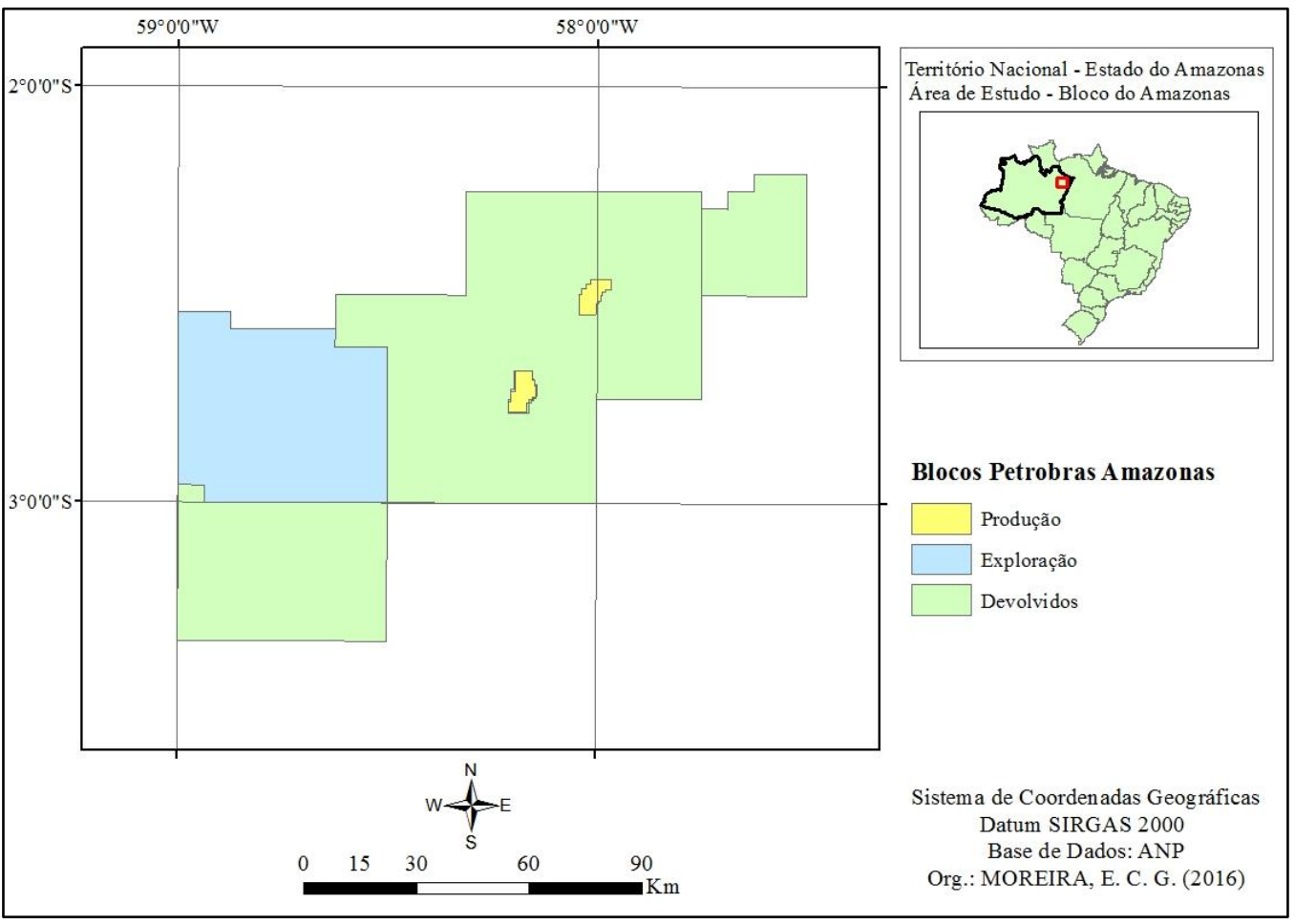

Figura 12 - Mapa dos Blocos de Concessão na Bacia do Amazonas

A concessão de exploração dos blocos aconteceram conforme rodada de licitação da Agência Nacional do petróleo (ANP). Assim, o Bloco do Solimões teve sua primeira concessão ocorrida em junho de 2002, para os blocos BT-SOL- 01 e 02 durante a $4^{\mathrm{a}}$ rodada de licitação e os demais blocos do Solimões tiveram sua concessão 
na $7^{\text {a }}$ rodada, ocorrida em outubro de 2005. Logo o Bloco do Amazonas teve sua primeira concessão ocorrida na $2^{\mathrm{a}}$ rodada de licitações, em setembro do ano 2000, com o bloco BT-AM-1 e os outros blocos do Amazonas tiveram sua concessão na $10^{\mathrm{a}}$ rodada, ocorrida em dezembro de 2008.

A pesquisa multitemporal das imagens deu preferência àquelas em que fossem encontradas as melhores condições atmosféricas e com a menor presença de nuvens, visando abordar um total de quinze anos e em quatro diferentes períodos. Logo, devido à disponibilidade das imagens e, mediante estas condições, não foi possível trabalhar com uma temporalidade regular para as duas áreas. Abaixo, a tabela 02 mostra a referência das imagens utilizadas, segundo sua localização e data de aquisição.

Tabela 2 - Coleção das Imagens

\begin{tabular}{c|c|c|c}
\hline \multirow{2}{*}{ Referência } & $\begin{array}{c}\text { Bacia Sedimentar } \\
\text { Solimões }\end{array}$ & \multicolumn{2}{|c}{$\begin{array}{c}\text { Bacia Sedimentar } \\
\text { Amazonas }\end{array}$} \\
\cline { 2 - 4 } & Área I & \multicolumn{2}{|c}{ Área II } \\
\hline \multirow{4}{*}{$\begin{array}{c}\text { Data das } \\
\text { Imagens }\end{array}$} & $08 / 08 / 2001$ & $15 / 07 / 1999$ & $08 / 09 / 1999$ \\
\cline { 2 - 4 } & $07 / 09 / 2006$ & $03 / 08 / 2006$ & $10 / 08 / 2006$ \\
\cline { 2 - 4 } & $17 / 08 / 2010$ & $17 / 08 / 2011$ & $08 / 08 / 2011$ \\
\hline
\end{tabular}

Após a escolha das cenas que seriam utilizadas aplicou-se os passos apresentados na figura 13, com o processamento digital das imagens e foi criado um mosaico das cenas do ano de 2010 para a Área I (002/63 e 001/063) e outros quatro mosaicos, um para cada período, com as cenas da Área II (230/62 e 229/62).

Os blocos de produção e exploração da Bacia Sedimentar do Solimões foram contemplados com apenas uma cena (001/063), mas a imagem obtida para o ano de 2010 apresentava um quadrante reduzido, o que provocou a criação de um mosaico para contemplar toda a área dos blocos de produção e exploração. Todavia, a área de estudo da Bacia Sedimentar do Amazonas foi composta utilizando-se duas cenas, portanto, quatro mosaicos diferentes. 


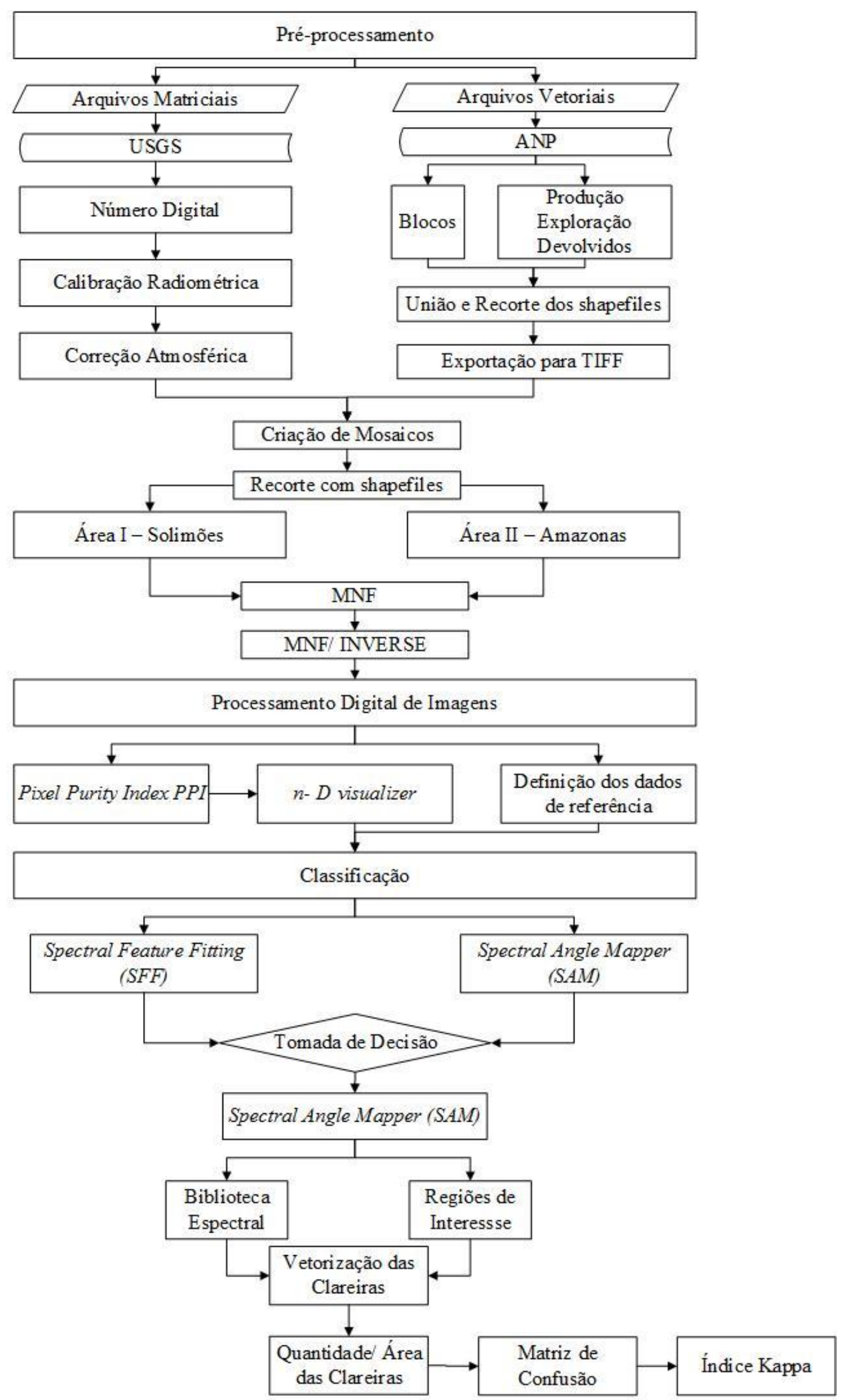

Figura 13 - Esquema Metodológico 
Posteriormente, os mosaicos foram recortados conforme a poligonal da sua área de localização com o auxílio da ferramenta clip no software ArcGis 10.2 e seus resultados exportados para o formato ENVI (.dat), para dar continuidade aos procedimentos de análise.

O tratamento da imagem iniciou-se com o pré-processamento digital, primeiramente, com a calibração radiométrica das imagens para a conversão do número digital para valores de radiância e, posteriormente, fez a correção atmosférica com o auxílio da ferramenta FLAASH (software ENVI 5.1) para a conversão da radiância em valores de reflectância de superfície. Esta ferramenta otimizou o processo de correção, pois fez a inserção de fatores específicos da imagem analisada como: a data de aquisição, altitude e o tipo de sensor.

As imagens utilizadas do USGS são geometricamente corrigidas e tiveram boa associação com os arquivos shapefiles dos blocos da Petrobras, obtidos no site da ANP. Contudo, cabe esclarecer que todos os dados foram convertidos para o sistema geodésico SIRGAS2000 (Sistema de Referência Geodésico das Américas), por ser base do Sistema Geodésico Brasileiro - SGB - e do Sistema Cartográfico Nacional - SCN (IBGE, 2014a).

Ao final do pré-processamento das imagens, ainda no software ENVI 5.1, a qualidade do sinal foi melhorada com a aplicação da técnica do MNF (Minimum Noise Fraction), acompanhada pelo MNF inverso. Neste momento as últimas bandas, que concentram a maior intensidade de ruídos, foram removidas melhorando a qualidade do sinal. Dessa forma, em decorrência da concentração do sinal nas bandas iniciais, os processamentos seguintes ocorreram com apenas quatro das seis bandas utilizadas dos sensores Landsat 5 e 8, com a composição RGB 5/4/3.

Sequencialmente, foi aplicado o Índice de Pixel Puro para isolar os endmembers e, assim, propor as classes de feições a serem analisadas no visualizador $n$-dimensional. Além disso, outros dois procedimentos complementaram a fase de identificação dos pixels: a criação de uma biblioteca espectral e a criação das regiões de interesse (ROI), ambos a partir dos pixels conhecidos da imagem, para serem utilizados como referência.

A aquisição dos dados de referência gerou duas bibliotecas espectrais, inicial e final. A biblioteca espectral inicial considerou seis classes na imagem (vegetação, corte raso, solo exposto, asfalto, rio Urucu e rio Tefé) no Bloco do Solimões e quatro classes (vegetação, corte raso, solo exposto e corpos d'água) no Bloco do Amazonas. E a biblioteca espectral final considerou quatro classes no Bloco do Solimões (vegetação, 
solo exposto, asfalto e corpos d'água) e três classes no bloco do Amazonas (vegetação, solo exposto e corpos d'água).

Em seguida, foi realizada a classificação com os algoritmos do Spectral Angle Mapper (SAM) e do Spectral Feature Fitting (SFF), visando comparar os resultados para uma tomada de decisão baseada no melhor delineamento das feições, otimizando a vetorização espacial das áreas degradadas e definindo o classificador a ser utilizado.

Finalmente, para conhecimento e aferição da qualidade da classificação, os dados foram validados com a aplicação de uma matriz de erros, obtendo-se o Índice Kappa e as medidas descritivas da Exatidão Global, Exatidão do Produtor e Exatidão do Usuário. 


\section{RESULTADOS E DISCUSSÕES}

Os métodos de classificação (SFF e SAM) adotados para a análise de mistura espectral trouxeram diferentes resultados, mas no geral as metodologias conseguiram encontrar os alvos dos objetivos propostos (clareiras de desmatamento para exploração de petróleo e gás natural), apesar das restrições decorrentes das condições atmosféricas e da mistura espectral da vegetação, conforme relatado nos tópicos a seguir.

\section{1 ÍNDICE DE PIXEL PURO - PPI \& VISUALIZADOR $N$-DIMENSIONAL}

O primeiro procedimento aplicado (PPI) teve o objetivo de isolar os pixels puros, por meio de uma rotação espectral e de acordo com seu nível de pureza. Dessa forma, obteve-se classes bem definidas e maior exatidão na fase de classificação. Entretanto, devido à grande mistura espectral houve a confusão das classes, impedindo a criação de uma biblioteca espectral mais precisa.

Este procedimento passou por uma série de experimentos na configuração dos parâmetros da ferramenta, tendo início com a configuração padrão do software (ENVI 5.1), com valor limiar de 2,5 e número de iterações de 10.000. Mas neste caso o resultado não conseguiu distinguir nenhum pixel puro na imagem, anulando a identificação das feições.

Outros testes foram realizados aumentando o valor limiar e variando o número de iterações. Este novo procedimento apresentou resultados mais positivos, mas somente a partir do valor limiar de 9.0. De forma paralela foi sendo configurado o número de iterações do algoritmo, analisando-se o comportamento das iterações mediante ao valor limiar.

A realização de diversas combinações de limite e número de iterações demonstrou uma boa discretização de clareiras nos valores limiares de 9.6, com iterações 10.000. Porém, o resultado do limiar de 9.8 apresentou o melhor delineamento das clareiras, apesar da maior presença de pixels na vegetação (impressão de "sal e pimenta"). A tabela 03 mostra as combinações testes que foram realizadas para a identificação dos pixels puros. 
Tabela 3 - Treinamentos realizados com o PPI

\begin{tabular}{r|c|r|l}
\hline No. & Limiar & Iterações & \multicolumn{1}{|c}{ Identificação de Pixel Puro } \\
\hline $\mathbf{1}$ & 2.5 & 10.000 & Resultado Vazio \\
\hline $\mathbf{2}$ & 3.0 & 10.000 & Resultado Vazio \\
\hline $\mathbf{3}$ & 4.0 & 10.000 & Resultado Vazio \\
\hline $\mathbf{4}$ & 8.0 & 1.000 & Resultado Vazio \\
\hline $\mathbf{5}$ & 8.0 & 5.000 & Resultado Vazio \\
\hline $\mathbf{6}$ & 8.0 & 10.000 & Resultado Vazio \\
\hline $\mathbf{7}$ & 9.0 & 1.000 & Resultado Vazio \\
\hline $\mathbf{8}$ & 9.0 & 5.000 & Resultado Vazio \\
\hline $\mathbf{9}$ & 9.0 & 10.000 & Resultado Vazio \\
\hline $\mathbf{1 0}$ & 9.4 & 1.000 & Surgimento de alguns pixels \\
\hline $\mathbf{1 1}$ & 9.4 & 5.000 & Surgimento de alguns pixels \\
\hline $\mathbf{1 2}$ & 9.4 & 10.000 & Surgimento de alguns pixels \\
\hline $\mathbf{1 3}$ & 9.4 & 15.000 & Surgimento de alguns pixels \\
\hline $\mathbf{1 4}$ & 9.6 & 1.000 & Início do delineamento das feições \\
\hline $\mathbf{1 5}$ & 9.6 & 5.000 & Início do delineamento das feições \\
\hline $\mathbf{1 6}$ & 9.6 & 10.000 & Início do delineamento das feições \\
\hline $\mathbf{1 7}$ & 9.8 & 1.000 & Delineamento das Feições \\
\hline $\mathbf{1 8}$ & 9.8 & 5.000 & Delineamento das Feições \\
\hline $\mathbf{1 9}$ & 9.8 & 10.000 & Delineamento das Feições \\
\hline $\mathbf{2 0}$ & 9.8 & 15.000 & Delineamento das Feições \\
\hline $\mathbf{2 1}$ & 9.9 & 10.000 & Aumento da mistura espectral \\
\hline $\mathbf{2 2}$ & 9.9 & 15.000 & Aumento da mistura espectral \\
\hline $\mathbf{0}$ & prof & & \\
\hline
\end{tabular}

O procedimento para a geração do índice de pixel puro consome um tempo significativo no processamento digital das imagens, a redução do número de iterações acelera o processo e apresentou uma pequena diferença ao ser comparada com o resultado usando iterações superiores a 10.000. Ao contrário do valor limiar que foi preponderante para a identificação dos pixels puros, mas seu aumento excessivo amplia a mistura espectral . Portanto, a redução do número de iterações foi uma estratégia utilizada para minimizar o tempo de investigação inicial para, posteriormente, se empregar a iteração padrão de 10.000 .

Nas figuras 14 e 15 é possível observar os resultados obtidos com o PPI usando valor limiar acima de 9.6 e 9.8, com iterações na ordem de 10.000. As setas em vermelho indicam a localização da clareira demonstrada no zoom da imagem. 


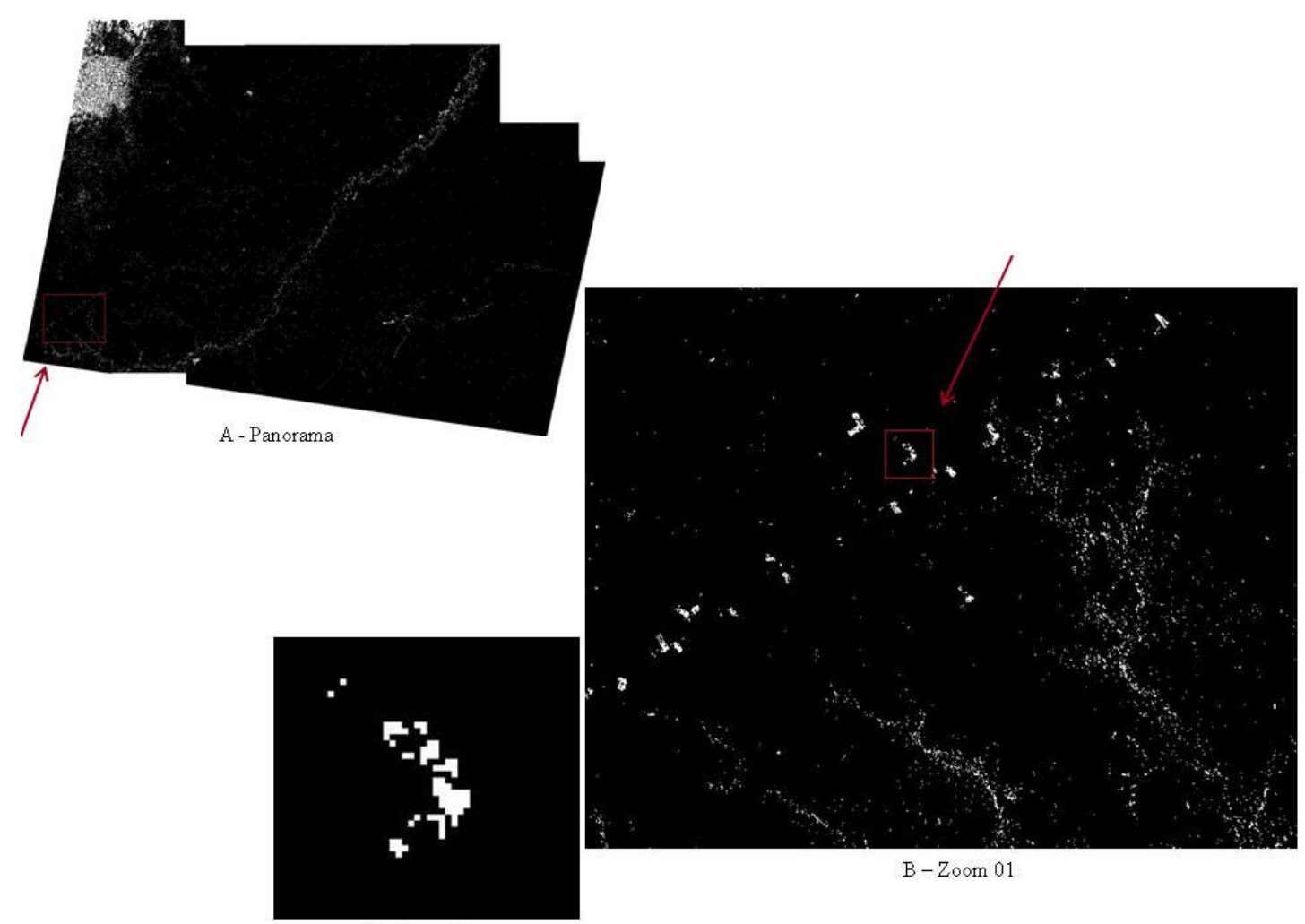

C-Zoom 02

Figura 14 - Resultado PPI com Valor limiar de 9.6 com 10.000 iterações

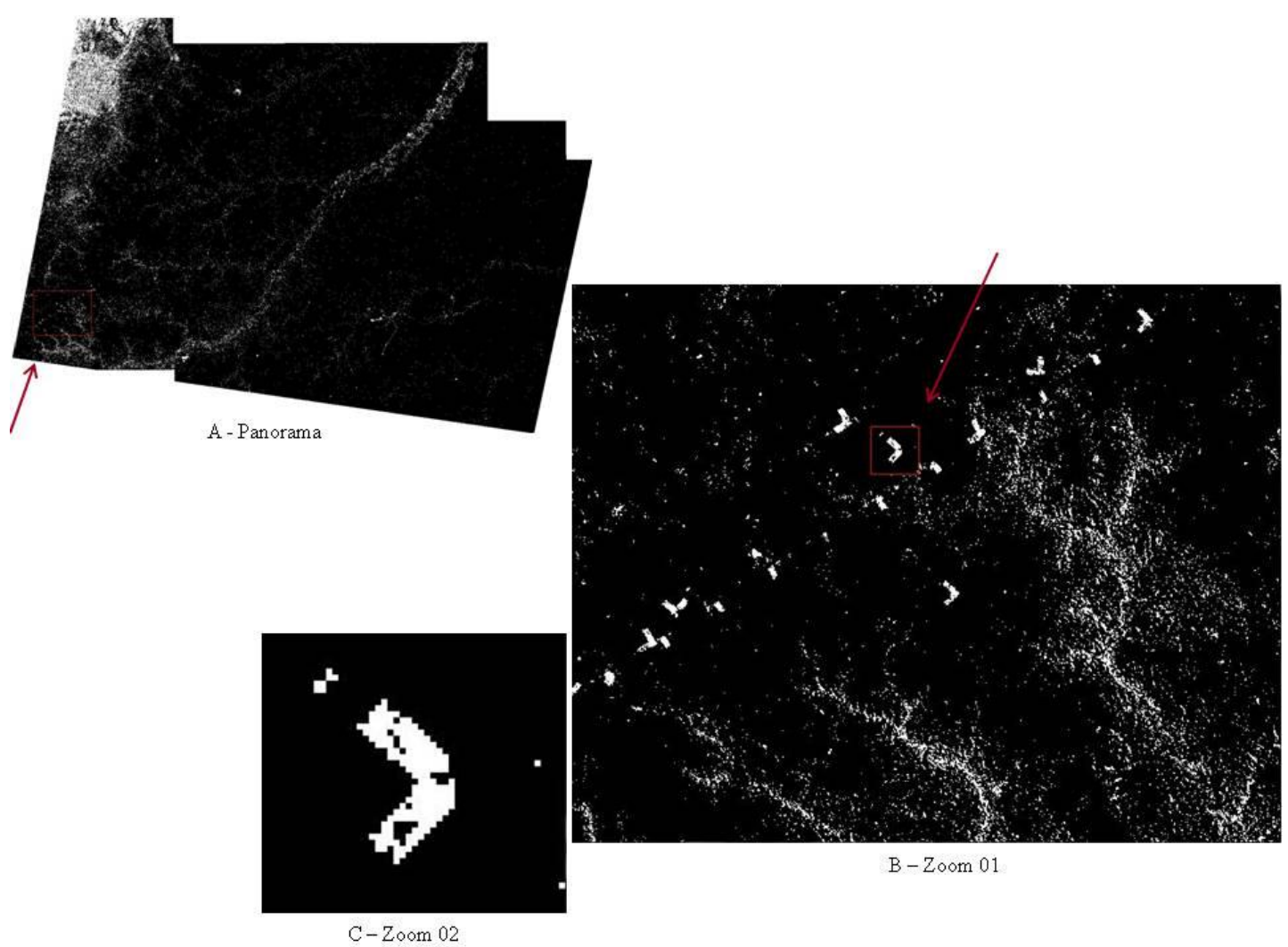

Figura 15 - Resultado PPI com Valor limiar de 9.8 com 10.000 iterações 
Os resultados obtidos com a aplicação do PPI não apresentaram uma boa identificação dos pixels puros das clareiras quando usado um valor limiar abaixo de 9.4, mesmo que o número de iterações variasse em 5000, 10000 ou 15000. Nestes casos, a identificação determinava apenas as feições maiores que as clareiras, como os rios Tefé e Urucu, a Base de Operações Geólogo Pedro de Moura e nuvens densas.

Portanto, para melhorar a identificação das clareiras foram utilizados valores limiares acima de 9.5 até 9.8 e, mesmo, utilizando iterações de 5.000, 10.000 ou 15.000, os resultados não apresentaram alterações determinantes. Portanto, a melhor discretização das clareiras apresentou-se vinculada à maior mistura espectral na vegetação. Quanto menor a 'impressão de sal e pimenta' na vegetação, menor o delineamento das clareiras, pois comprometeu mais a precisão da classificação.

Por conseguinte ao se exportar esses resultados para o visualizador $n$ dimensional do software ENVI 5.1, a formação da nuvem de pixels (clusters) apresentou aglomerados de 'pixels puros', que na verdade continha alta mistura espectral, conforme pôde ser constatado ao se trabalhar a coleta dos membros finais durante a montagem da biblioteca espectral. Fato que motivou o uso dos espectros de referência a partir da criação de bibliotecas espectrais de cada imagem.

As figuras 16 e 17 demonstram as bibliotecas espectrais adquiridas na imagem do ano de 2001 nos Blocos do Solimões, sendo que o procedimento semelhante foi adotado na aquisição dos espectros de referência nos Blocos do Amazonas.

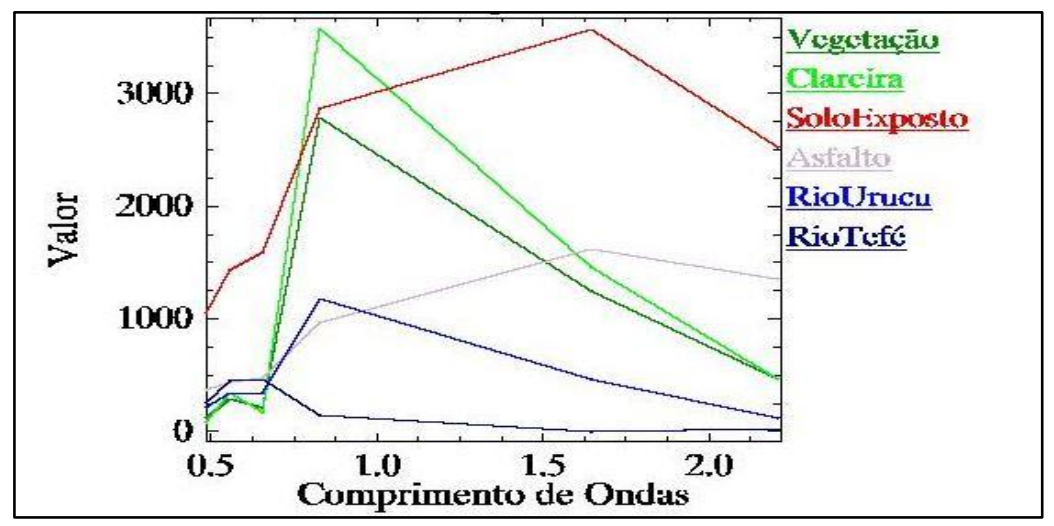

Figura 16 - Biblioteca Espectral Inicial 


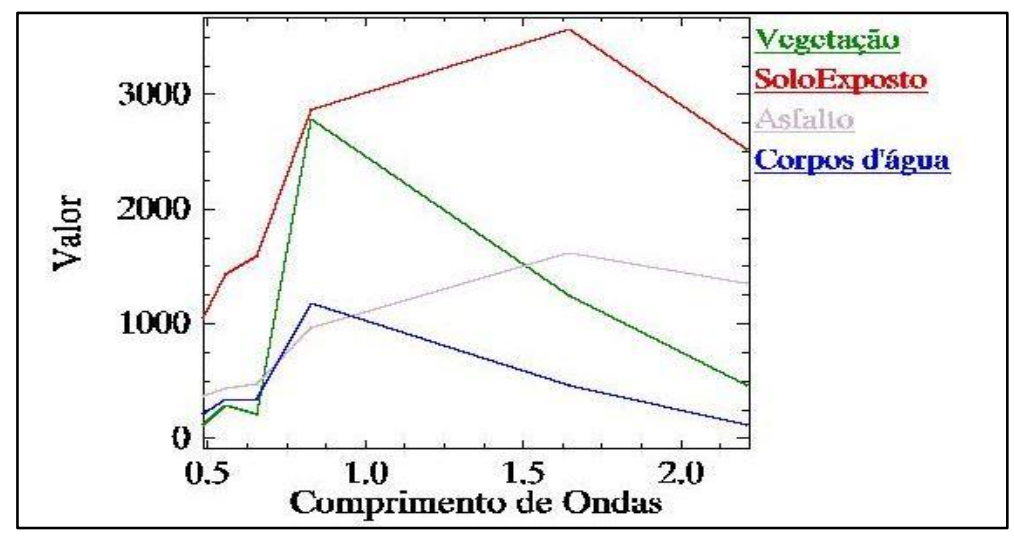

Figura 17 - Biblioteca Espectral Final

Foram amostrados os pixels de referência desses dois conjuntos amostrais, de cada uma das classes para a criação das bibliotecas espectrais, uma para cada cena e para cada ano e dessa mesma forma foram amostradas as regiões de interesse (ROI) para representar cada uma das classes. Esses dois procedimentos visaram constituir os dados de referência, para serem utilizados na fase de classificação das imagens.

Apesar do resultado insatisfatório com o uso do PPI, outros autores demonstraram bons efeitos utilizando o modelo linear de mistura espectral e comprovaram a eficiência na identificação do desmatamento na floresta tropical amazônica, conforme, evidenciado nos estudos dos autores ALVES (2001); PINAGÉ (2011) e RENÓ (2011), que analisaram imagens Landsat para o mapeamento da vegetação amazônica, bem como para a avaliação do desmatamento. Além dessa vertente em BIAS (2011) foi demonstrado a potencialidade desse modelo para, também, se analisar aspectos da água, identificando a dispersão de poluentes.

\subsection{CLASSIFICAÇÃO SPECTRAL FEATURE FITTING - SFF}

A classificação por meio do ajuste da feição espectral utiliza um critério de similaridade para a identificação do material, entretanto, devido às condições atmosféricas e a resolução espacial do sensor Landsat, a mistura espectral limitou a discretização das clareiras. Os testes realizados com este classificador alternaram o uso entre biblioteca espectral e regiões de interesse, visando aperfeiçoar o treinamento do algoritmo, contudo a resposta foi indiferente.

Portanto foi selecionado como exemplo o resultado de uma classificação SFF, nos Blocos do Solimões de Exploração, Produção e Devolvidos (SOL - EPD), referente à feição de vegetação, do ano de 2001 e com as feições dos poços em seus respectivos blocos: Blocos de Produção e Desenvolvimento (BPD); Blocos de Exploração e Produção (BEP) e, Blocos Devolvidos (BD), conforme ilustrado na figura 18. 


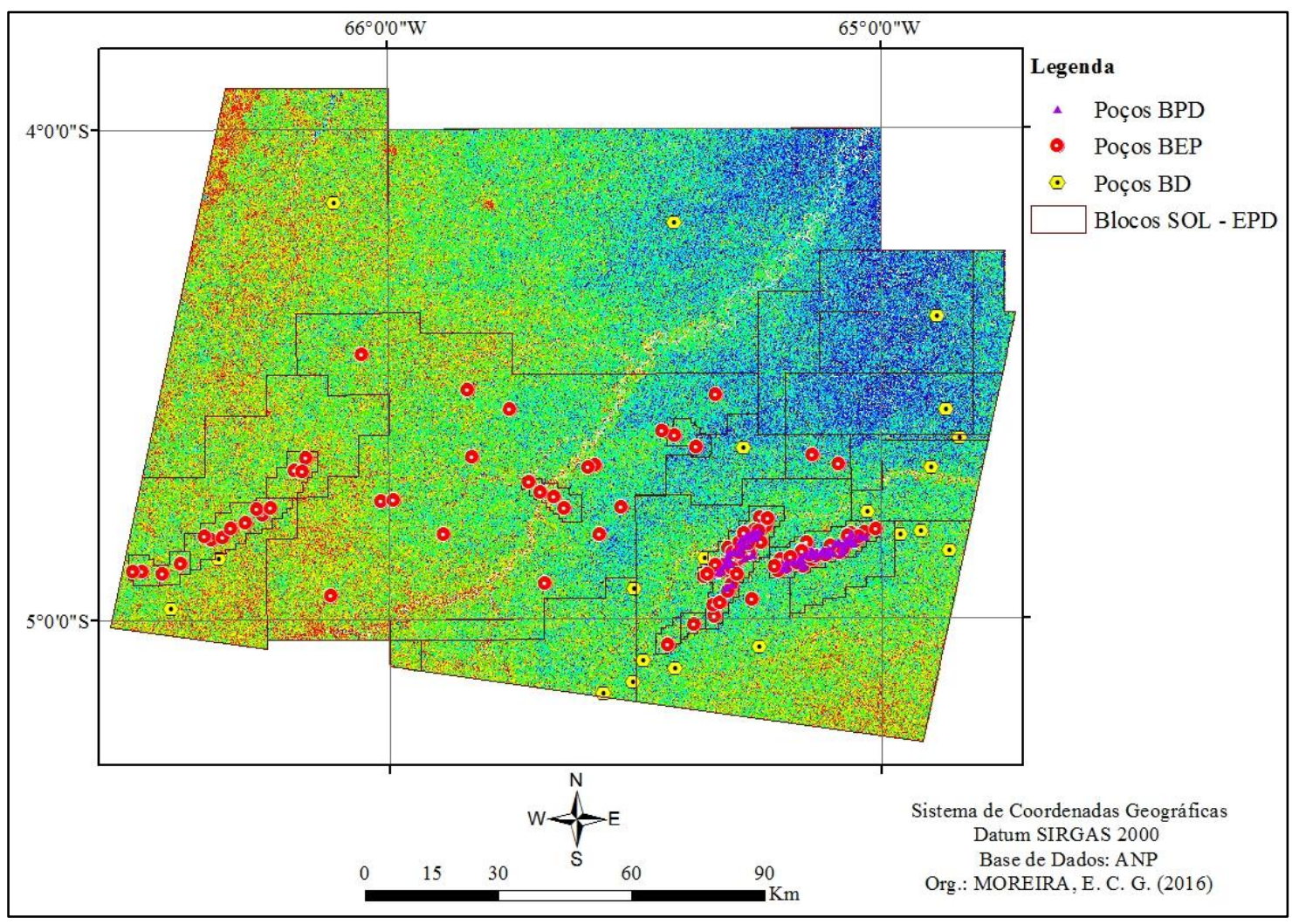

Figura 18 - Panorama do Resultado da Classificação SFF - vegetação

As feições analisadas tiveram foco na distinção da vegetação e do solo exposto, onde, apesar de ter sido possível realizar a identificação de áreas degradadas e de revegetação, a mistura espectral impossibilitou a discretização de algumas feições. Isto permaneceu, mesmo, após uma série de treinamentos de criação da biblioteca espectral e coleta das regiões de interesse.

Contudo, este classificador apresentou uma boa distinção entre áreas com vegetação e outras em estágio de revegetação, apesar de não solucionar a confusão nos pixels, geradas pela alta mistura espectral. As figuras 19 e 20 ilustram o resultado alcançado para as feições de vegetação (tons de azul, verde, amarelo e vermelho) e solo exposto (tom de preto).

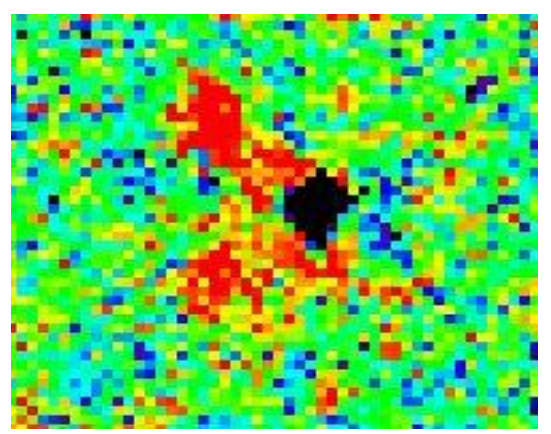

Figura 19 - Clareira RIT SFF Vegetação

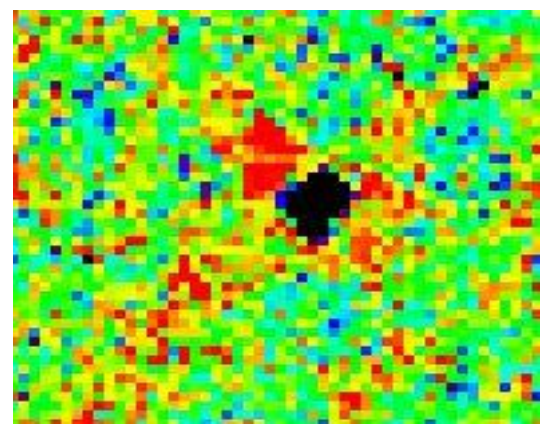

Figura 20 - Clareira RIT SFF Solo Exposto 
Os pixels não classificados, em preto, são referentes às áreas desmatadas, com remoção do horizonte superficial do solo e intensas alterações advindas de processos de compactação e terraplanagem. Enquanto os pixels em vermelho referem-se às áreas sujeitas apenas ao corte raso da vegetação, que serviram como 'perna de aproximação' para o pouso de helicópteros.

Segundo Meroni (2009) o método SFF demonstrou acurácia na estimativa dos valores de fluorescência da clorofila em situações de ruído. E os resultados do estudo de Kopackova (2014) comprovaram a sensitividade do Spectral Feature Fitting na distinção de minerais a partir de seu pH. Todavia neste estudo, devido à ocorrência de pixels não classificados nas áreas de maior alteração ambiental (solo exposto) e ao elevado nível de mistura espectral, este método também foi considerado limitado para a qualidade da pesquisa.

\subsection{CLASSIFICAÇÃO SPECTRAL ANGLE MAPPER - SAM}

A classificação por mapeamento de ângulo espectral possui uma análise com base na similaridade angular entre o pixel de referência e o pixel resultante do classificador. Este procedimento possui dois caminhos, por ângulos múltiplos ou ângulo singular e seus resultados estão demonstrados nos itens 5.3.1 e 5.3.2.

\subsubsection{Multiple Angles}

O mapeamento por meio de múltiplos ângulos espectrais possibilita a classificação espectral com base no ângulo referente a cada feição, este processo amplia a precisão do classificador devido à especificidade da resposta de cada alvo. Todavia, os resultados encontrados também apontaram para um alto nível de mistura espectral e com pixels não classificados.

Neste caso, o classificador não distinguiu entre as áreas com vegetação e áreas de revegetação, apesar de ter encontrado algumas clareiras de perfuração. Isto tornou o seu resultado limitado, pois inviabilizou a análise do crescimento de novas áreas no decorrer dos anos, reduzindo a precisão na quantificação de área desmatada. Portanto, a análise multitemporal dos resultados dessa classificação, também, apresentou limitações decorrentes da mistura espectral, reduzindo a discretização das classes pequenas. Portanto, apresentamos como exemplo o resultado da classificação SAM da feição de clareira, do ano de 2001, com a mesma legenda supracitada. Conforme pode ser visualizado na figura 21. 


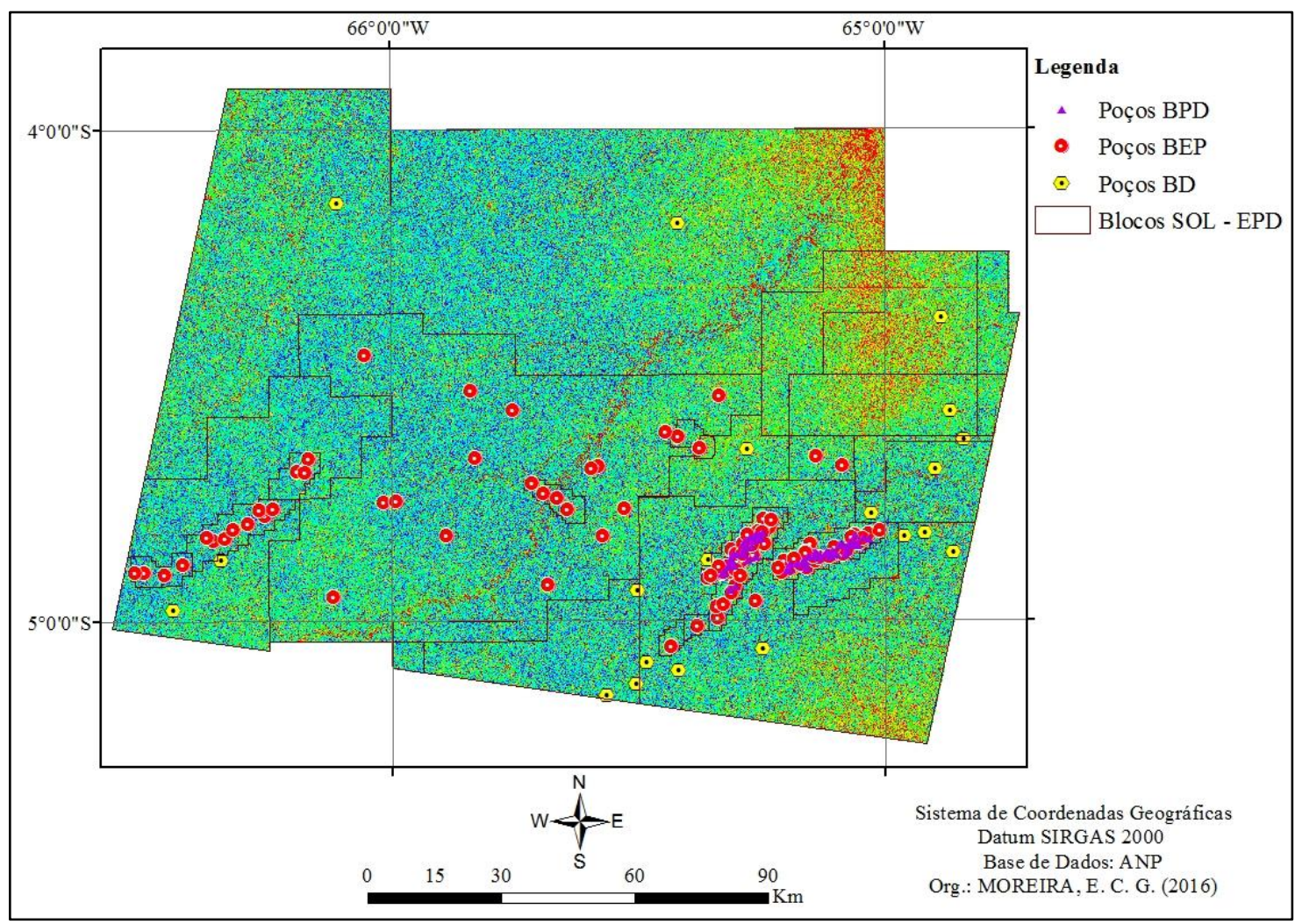

Figura 21 - Panorama do Resultado da Classificação SAM - vegetação

Ao se aproximar as imagens de vegetação e solo para comparação dos resultados percebemos o alto grau de mistura espectral existente na região onde houve a alteração da paisagem. Figuras 22 e 23.

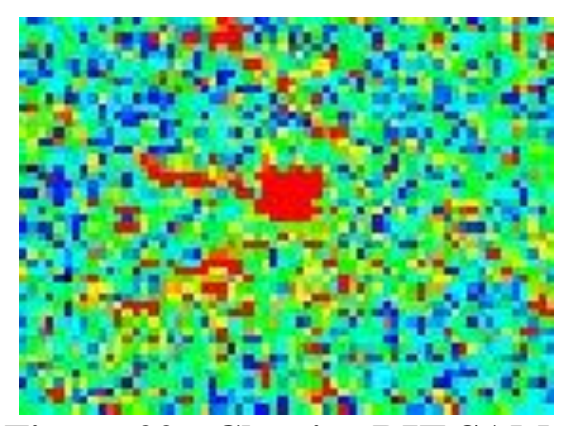

Figura 22 - Clareira RIT SAM Vegetação

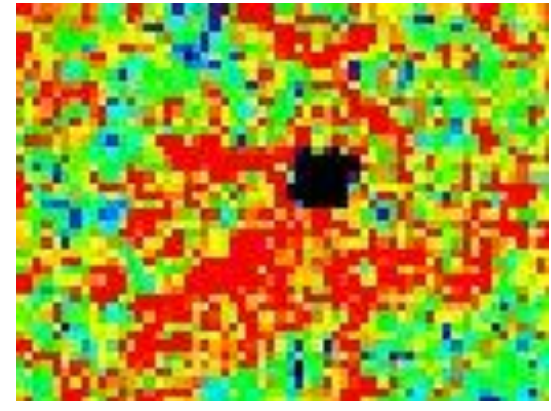

Figura 23 - Clareira RIT SAM Solo exposto

A baixa qualidade dos resultados do classificador SAM multiple angle, pode estar relacionada com fatores como o sombreamento provocado pelo dossel da vegetação, a diversidade fotossintética dos estágios sucessionais da flora e as condições atmosféricas no momento da aquisição dos dados, ou, ainda, com o tamanho do pixel de 30 metros do sensor Landsat, que absorve muito os efeitos da superfície terrestre e das condições atmosféricas, conforme citado por CARVALHO JUNIOR (2003). 
Outro fator importante de ser observado é a composição ocorrida na amostragem da classe de asfalto, que devido ao tamanho do pixel (30m) englobou a faixa de domínio das vias inserindo muito solo exposto na composição do pixel. E, por outro lado, houve muita mistura espectral entre os pixels de vegetação e revegetação, devido às suas assinaturas espectrais semelhantes.

\subsubsection{Single Angle}

O mapeamento espectral por ângulo singular utiliza apenas um coeficiente angular para determinar a similaridade espectral entre as bandas de dois espectros. Com sua aplicação foi possível reduzir o nível de mistura espectral gerado com a classificação SAM e, assim, alcançar delimitações mais precisas das áreas em estudo. A figura 24 apresenta o resultado da classificação obtida para o ano de 2001.

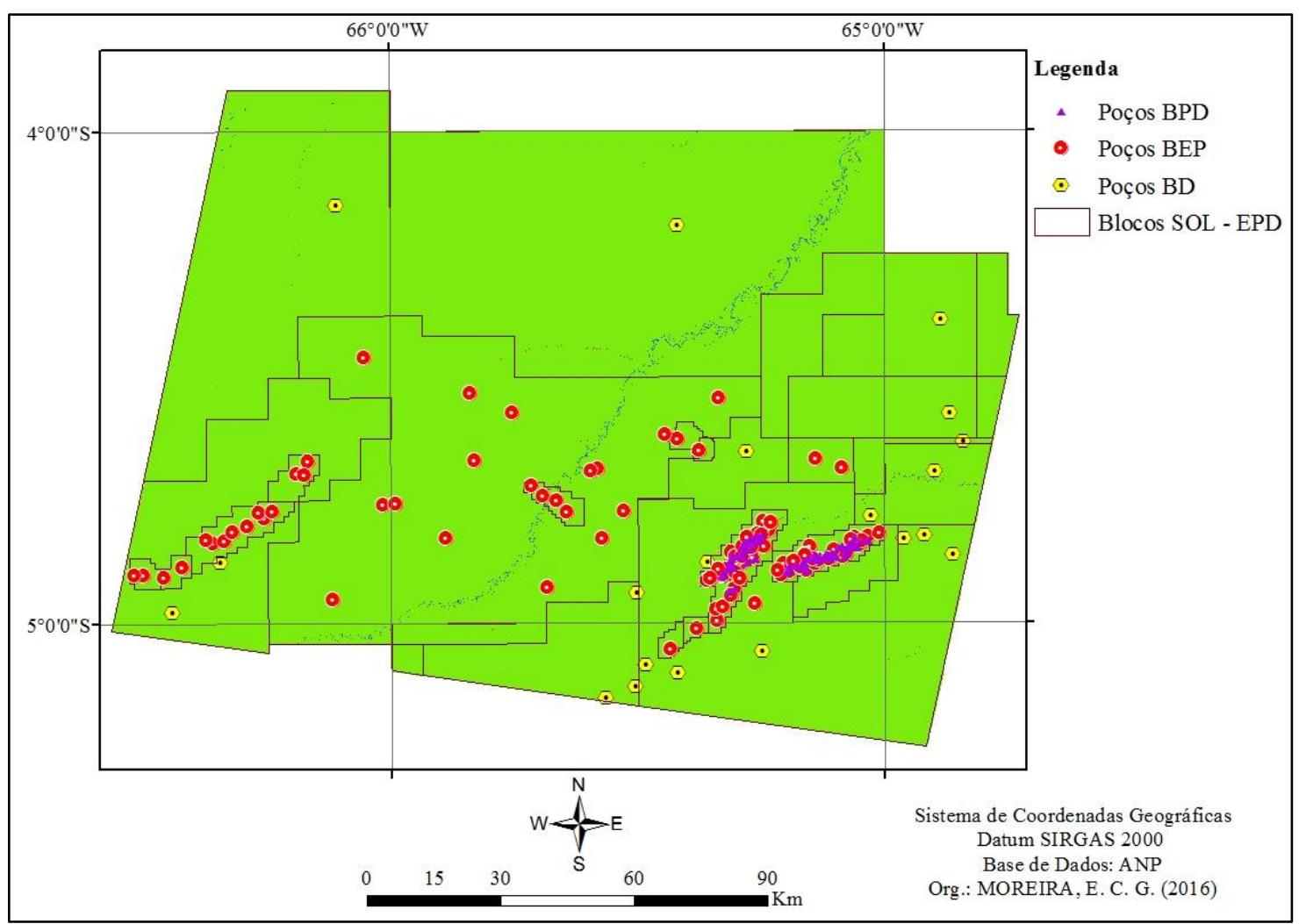

Figura 24 - Panorama do Resultado da Classificação SAM - Bloco Solimões

A análise dos resultados ocorreu com base nos Blocos da Petrobras no Estado do Amazonas (Bacia Sedimentar do Solimões e Bacia Sedimentar do Amazonas), identificando, pelo tipo de bloco (exploração, produção ou devolvido) e pelo status do poço (ativo ou inativo), onde as atividades estão acontecendo ou onde já foram encerradas. Dessa forma os resultados trazem duas abordagens distintas:

(I) A quantificação multitemporal das áreas das clareiras;

(II) O crescimento multitemporal do número total de clareiras. 
A quantificação multitemporal da área desmatada nos blocos das Bacias Sedimentares do Solimões e do Amazonas foi feita por meio da espacialização dos resultados da classificação SAM, single angle, e com o cálculo geométrico da área classificada. Nos Blocos de Produção e Desenvolvimento (BPD), situados na Base de Operações Geólogo Pedro de Moura (BOGPM), estão localizadas as clareiras dos poços ativos, que por sua vez ainda não iniciaram os seus PRADS, portanto, não estão no escopo deste estudo, mas foram retratadas para representar a realidade atual.

A primeira parte dos resultados analisou as áreas de clareiras dos poços abandonados e/ou arrazados (não-ativos) dos Blocos Devolvidos (BD) e, depois, realizou esta mesma análise nos Blocos de Exploração e Produção (BEP). Nestes locais subentende-se que, devido ao encerramento das atividades, o Programa Recuperação de Áreas Degradadas (PRAD) já deveria estar sendo executado. Principalmente, por se tratar de um item fundamental das condicionantes do licenciamento ambiental.

$\mathrm{Na}$ segunda parte dos resultados foi analisado o crescimento do número total de clareiras, a partir dos Blocos de Exploração e Produção, com poços ativos, comparando o número existente no decorrer dos anos e analisando o seu aumento. Nesta situação, não foi quantificada a área de revegetação, mas sim a expansão das frentes de desmatamento para novas perfurações, com o aumento do número de clareiras.

O processamento das imagens utilizou o classificador SAM, single angle, tendo em vista ter sido o que apresentou menor comprometimento dos resultados em virtude da mistura espectral. Dessa forma, foi possível realizar um bom delineamento das áreas desmatadas, para sua espacialização e cálculo geométrico. Contudo, a identificação dos níveis de revegetação não foi precisa e interferiu diretamente no aumento da mistura espectral, prejudicando a qualidade do resultado.

Por conseguinte, a solução encontrada foi agrupar as categorias de vegetação em apenas uma classe, para propiciar uma melhor discretização das áreas de solo exposto e a redução do nível de mistura espectral.

A figura 25 traz o resultado multitemporal das treze clareiras encontradas nos Blocos Devolvidos, onde o verde refere-se à vegetação, o amarelo ao asfalto e o vermelho ao solo exposto. 


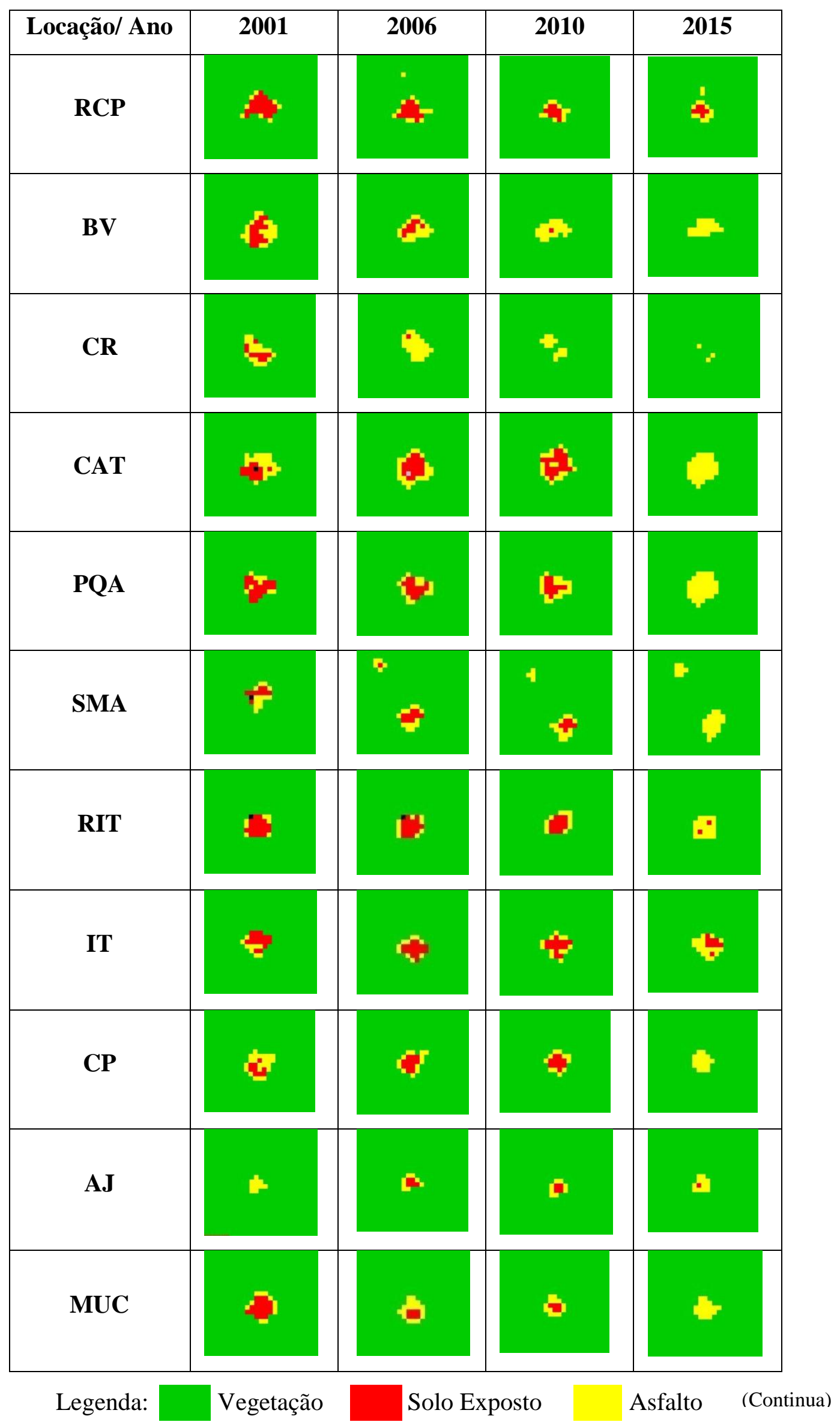




\begin{tabular}{|c|c|c|c|c|}
\hline $\begin{array}{c}\text { Locação/ Ano } \\
\text { (continuação) }\end{array}$ & 2001 & 2006 & 2010 & 2015 \\
\hline ANG & & & & \\
\hline IMA & & & & \\
\hline BRSA 372 & & & & \\
\hline BRSA 892 & & & & \\
\hline BRSA 1189 & & & & \\
\hline BRSA 985 & & & & \\
\hline
\end{tabular}

Figura 25 - Resultado Multitemporal da Classificação SAM nas clareiras

$\mathrm{O}$ resultado multitemporal A classificação SAM, single angle, identificou 20 clareiras de poços desativados nos Blocos Devolvidos e, dentre estas, 07 são clareiras mais recentes e 13 apresentaram ocorrência nos quatro períodos estudados. Assim, ao se analisar o desenvolvimento da recuperação das áreas não foi constatado um padrão de 
recuperação satisfatório, consequentemente, a partir deste grupo já se evidenciou a ineficiência dos PRADs na revegetação das clareiras.

O processamento digital ocorreu conforme a similaridade angular dos espectros de referência (biblioteca espectral e ROIs) e o comportamento espectral dos alvos. O resultado mostrou a presença predominante de solo exposto (vermelho) e asfalto (amarelo), estas feições foram utilizadas na composição da biblioteca espectral e obtidas a partir da imagem real, para atuar como valor de referência.

A classificação SAM, single angle, demonstrou similaridade espectral entre a imagem classificada e a de referência, utilizando uma biblioteca espectral criada a partir da imagem, corroborando com a metodologia proposta por KRUSE (1993) e CARVALHO (2001). Ainda, nesse contexto DUDLEY et al (2015) observaram que o desenvolvimento de uma biblioteca espectral multitemporal, para o mapeamento de espécies vegetais a partir de uma seleção interativa de endmembers, pode melhorar a exatidão da classificação.

Todavia, cabe observar que o asfalto da biblioteca espectral foi conseguido pelas vias da Base de Operações Geólogo Pedro de Moura (BOGPM), onde a largura média do asfalto mais a faixa de domínio variam em torno de $45 \mathrm{~m}$, figura 26. Esse fato, somado a resolução espacial de 30 metros do sensor Landsat corroboraram para a composição do pixel com muita presença de solo exposto e asfalto, explicando o aparecimento da feição asfalto (amarelo) nas áreas de clareiras.

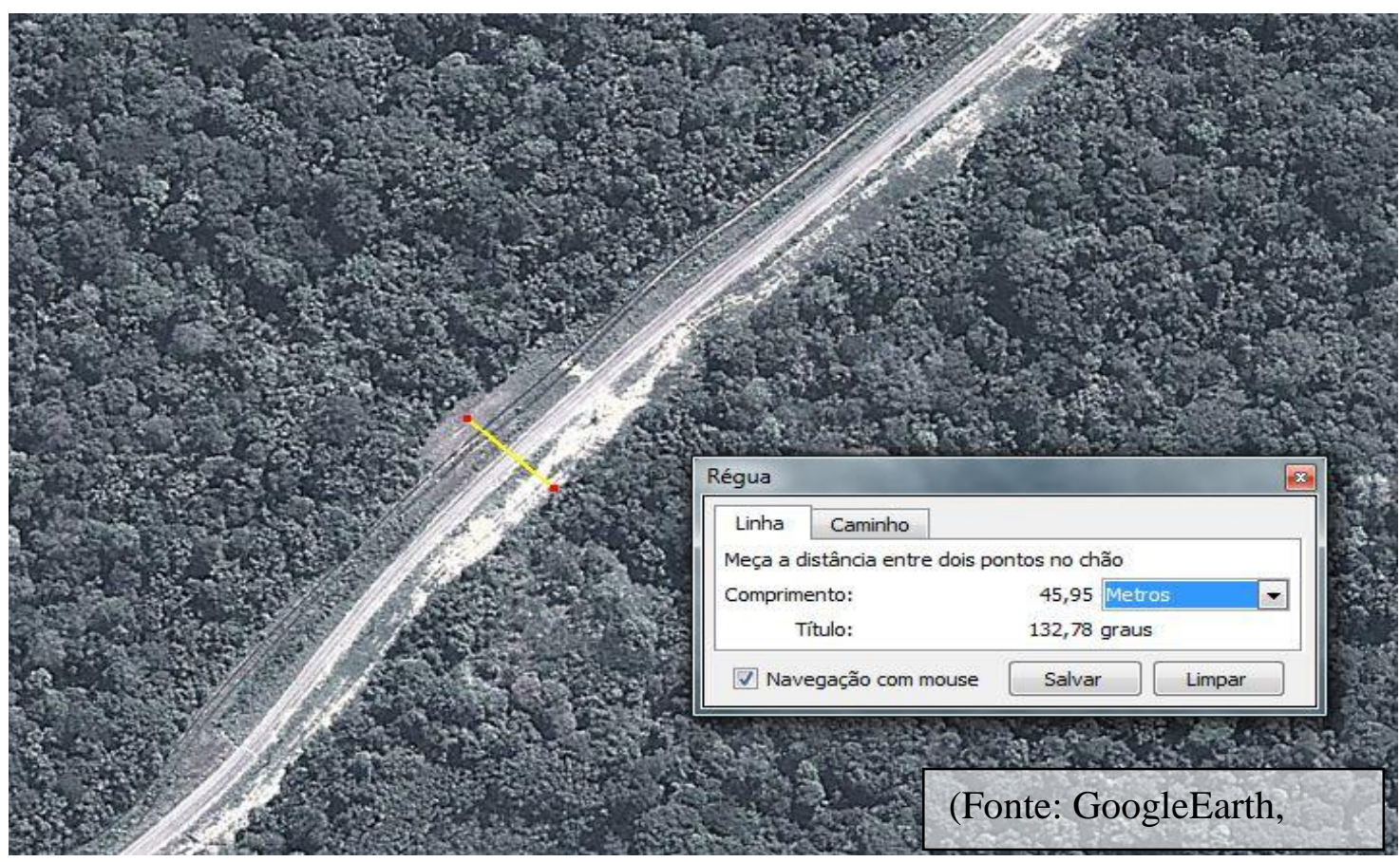

Figura 26 - Largura média das vias nas BOGPM 
O monitoramento do desmatamento realizado pelo projeto PRODES considera o valor de 6,25ha como a área mínima mapeada, mas ainda sim é possível se mapear áreas menores com a resolução de 30 metros do sensor Landsat, que corresponde a uma área de $900 \mathrm{~m}^{2}$ na superfície e aproximadamente a onze pixels na cena. Conforme demonstrado nos estudos de Renó (2010) e Pinagé (2011).

A tabela 04 apresenta o resultado multitemporal do processamento digital, com o qual foi realizado o cálculo de área, em hectares, viabilizando uma análise mais objetiva dos dados. Por meio desta é possível visualizar o crescente aumento no número de clareiras desativadas, principalmente, no período de 2010 a 2015, fato que reflete o avanço das frentes de trabalho e o aumento do número de clareiras. Contudo, esse tema será discutido no tópico 5.3.2, com foco nos poços inativos dos Blocos de Exploração e Produção. Abaixo, a tabela 04 apresenta as áreas desmatadas para a abertura de clareiras e sua situação no decorrer dos anos.

Tabela 4 - Resultado Multitemporal das Áreas das Clareiras dos Blocos Devolvidos

\begin{tabular}{|c|c|c|c|c|c|c|c|}
\hline \multirow{2}{*}{ No. } & \multirow{2}{*}{ Clareiras } & \multirow{2}{*}{ Conclusão } & \multicolumn{4}{|c|}{ Área (ha) } & \multirow{2}{*}{$\begin{array}{c}\text { Área } \\
\text { Recuperada }\end{array}$} \\
\hline & & & 2001 & 2006 & 2010 & 2015 & \\
\hline 1 & $1 \mathrm{IT}$ & 1982 & 2,43 & 2,14 & 2,34 & 2,44 & $0 \%$ \\
\hline 2 & $\mathbf{1 A J}$ & 1982 & 0,98 & 1,00 & 0,89 & 1,00 & $0 \%$ \\
\hline 3 & 1RIT & 1990 & 2,95 & 2,52 & 2,25 & 1,99 & $33 \%$ \\
\hline 4 & 1CR & 1992 & 3,08 & 2,28 & 1,13 & 0,18 & $94 \%$ \\
\hline 5 & $1 \mathrm{CAT}$ & 1992 & 3,89 & 3,98 & 3,79 & 3,66 & $6 \%$ \\
\hline 6 & 1PQA & 1992 & 3,21 & 2,86 & 2,83 & 2,64 & $18 \%$ \\
\hline 7 & 1SMA & 1992 & 5,54 & 2,35 & 2,05 & 2,54 & $54 \%$ \\
\hline 8 & 1ANG & 1993 & 4,19 & 4,19 & 3,77 & 3,31 & $21 \%$ \\
\hline 9 & 1BV & 1993 & 4,00 & 2,50 & 2,23 & 1,83 & $54 \%$ \\
\hline 10 & 1RCP & 1996 & 3,45 & 2,36 & 1,72 & 1,60 & $54 \%$ \\
\hline 11 & 1MUC & 1997 & 3,23 & 2,06 & 1,34 & 1,65 & $49 \%$ \\
\hline 12 & 1IMA & 1998 & 3,19 & 1,74 & 1,51 & 1,77 & $44 \%$ \\
\hline 13 & $1 \mathrm{CP}$ & 1999 & 3,40 & 2,11 & 1,78 & 1,60 & $53 \%$ \\
\hline 14 & 1BRSA 372 & 2005 & & 7,51 & 4,12 & 3,23 & $57 \%$ \\
\hline 15 & 1BRSA 892 & 2011 & & & 7,46 & 2,48 & $67 \%$ \\
\hline 16 & \begin{tabular}{|l|l|} 
1BRSA 985 \\
\end{tabular} & 2011 & & & & 3,86 & - \\
\hline 17 & 1BRSA 961 & 2011 & & & & 5,62 & - \\
\hline 18 & 1BRSA 984 & 2012 & & & & 4,10 & - \\
\hline 19 & HRT & 2012 & & & & 3,98 & - \\
\hline 20 & 1BRSA 1189 & 2013 & & & & 5,01 & - \\
\hline
\end{tabular}

As clareiras dos Blocos Devolvidos da Petrobras são, em sua maioria, áreas antigas onde a revegetação já deveria ter ocorrido. No entanto os resultados obtidos com 
a classificação SAM demonstraram a ineficácia dos PRADs mediante os valores encontrados. Os dados da Tabela 05 mostraram que apenas 01 de 13 clareiras apresentou uma área de revegetação acima de 94\% (1CR) e ainda mais drasticamente mostra que 05 das 13 clareiras não alcançaram sequer $20 \%$ de recuperação da área, no decorrer dos períodos (1CAT/ 1PQA/ 1IT/ 1AJ/ 1ANG). Neste cenário é importante destacar que todas essas 13 clareiras analisadas são anteriores ao ano de 1999.

As clareiras antigas levantadas nesta pesquisa, da década de 80 e 90, comprovam que, em áreas dispostas a esse tipo de intervenção, a regeneração natural não tem mais capacidade de se recuperar sozinhas, tornaram-se inertes e ainda comprometeram o ecossistema ao redor. Nascimento (2009) relata que onde o plantio foi realizado, observou-se pelas imagens de satélite (Landsat TM), que não houve o crescimento progressivo das áreas de regeneração e, inclusive, ocorreu à redução das áreas florestadas. Dessa forma foi destacado que a idade do plantio não é um fator determinante na presença de certa cobertura vegetal sobre o solo, as áreas que as mudas cultivadas melhor se estabeleceram foram onde ocorreram o adensamento de apenas uma espécie.

Cabe enfatizar que a localização remota das clareiras na Bacia Sedimentar do Solimões dificulta muito o acesso após a desmobilização da infraestrutura, o qual geralmente ocorre por meio fluvial (balsas) e/ou aéreo (helicópteros). Essa situação é bastante onerosa e morosa, dificultando a manutenção e o monitoramento das áreas em recuperação. Consequentemente, sem essas atividades periódicas, o desenvolvimento vegetal fica comprometido e o PRAD perde a sua eficácia, deixando áreas degradadas em meio à floresta e sem atingir os objetivos impostos na condicionante do Licenciamento Ambiental.

Prosseguindo na análise dos dados das áreas de clareiras dos Blocos Devolvidos foi encontrado um somatório das áreas desmatadas nos anos em estudo, que, também, colabora para a comprovação da ineficácia dos PRADs. As 13 clareiras em questão chegaram a somar uma área desmatada total de 43,54 hectares no ano de 2001 e apesar do ligeiro decréscimo ocorrido a revegetação até o ano de 2015 somente recuperou $40 \%$ da área total, restando 26,33 hectares degradados, conforme demonstrado na Tabela 05. 
Tabela 5 - Área Total das Clareiras dos Blocos Devolvidos

\begin{tabular}{|c|c|c|c|c|c|c|c|}
\hline \multirow{2}{*}{ No. } & \multirow{2}{*}{ Clareiras } & \multirow{2}{*}{ Conclusão } & \multicolumn{4}{|c|}{ Área (ha) } & \multirow{2}{*}{$\begin{array}{c}\text { Área } \\
\text { Recuperada }\end{array}$} \\
\hline & & & 2001 & 2006 & 2010 & 2015 & \\
\hline 1 & $1 \mathrm{IT}$ & 1982 & 2,43 & 2,14 & 2,34 & 2,44 & $0 \%$ \\
\hline 2 & 1A.J & 1982 & 0,98 & 1,00 & 0,89 & 1,00 & $0 \%$ \\
\hline 3 & 1RIT & 1990 & 2,95 & 2,52 & 2,25 & 1,99 & $33 \%$ \\
\hline 4 & 1CR & 1992 & 3,08 & 2,28 & 1,13 & 0,18 & $94 \%$ \\
\hline 5 & 1 CAT & 1992 & 3,89 & 3,98 & 3,79 & 3,66 & $6 \%$ \\
\hline 6 & 1PQA & 1992 & 3,21 & 2,86 & 2,83 & 2,64 & $18 \%$ \\
\hline 7 & 1SMA & 1992 & 5,54 & 2,35 & 2,05 & 2,54 & $54 \%$ \\
\hline 8 & 1ANG & 1993 & 4,19 & 4,19 & 3,77 & 3,31 & $21 \%$ \\
\hline 9 & $1 \mathrm{BV}$ & 1993 & 4,00 & 2,50 & 2,23 & 1,83 & $54 \%$ \\
\hline 10 & 1RCP & 1996 & 3,45 & 2,36 & 1,72 & 1,60 & $54 \%$ \\
\hline 11 & 1MUC & 1997 & 3,23 & 2,06 & 1,34 & 1,65 & $49 \%$ \\
\hline 12 & 1IMA & 1998 & 3,19 & 1,74 & 1,51 & 1,77 & $44 \%$ \\
\hline 13 & $1 \mathrm{CP}$ & 1999 & 3,40 & 2,11 & 1,78 & 1,60 & $53 \%$ \\
\hline \multicolumn{3}{|c|}{ Total } & 43,54 & 32,09 & 27,63 & 26,22 & $40 \%$ \\
\hline
\end{tabular}

O comportamento multitemporal das áreas das clareiras dos Blocos Devolvidos, no geral, apresentou uma tendência decrescente, ou seja, a revegetação aumentou no decorrer dos anos e a área de solo exposto reduziu. Todavia, algumas clareiras ainda chegaram a apresentar um aumento da área degradada em relação aos anos posteriores, como foi o caso de: 1SMA/ 1MUC/ 1IMA. Enquanto isso, somente a clareira 1CR conseguiu apresentar um nível de revegetação aceitável, reduzindo sua área degradada em $95 \%$, conforme pode ser visualizado na figura 27, que demonstra graficamente o comportamento multitemporal de cada clareira nos quatro anos analisados.

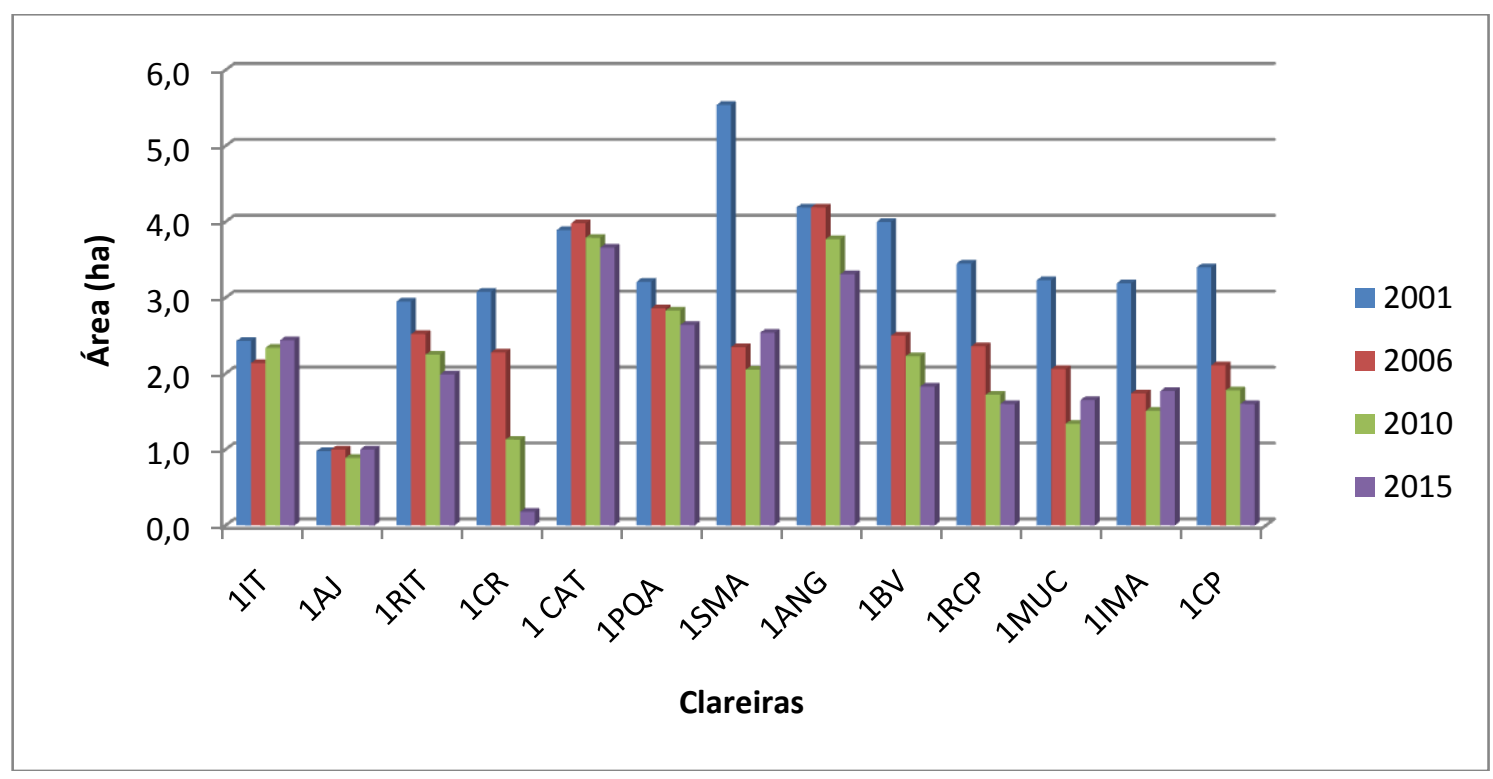

Figura 27 - Resultado multitemporal agrupado por clareira 
Para finalizar a demonstração dos resultados dos Blocos Devolvidos, abaixo são apresentados os gráficos de área (fig. 28 a 40), individualizados por clareiras, durante os quatro anos analisados, onde é visível o contraste do bom resultado do PRAD aplicado na clareira $1 \mathrm{CR}$ frente à ineficácia de recuperação da área das clareiras 1CAT, 1ANG, 1PQA. As figuras de 28 a 40 mostram os resultados multitemporais de cada clareira.

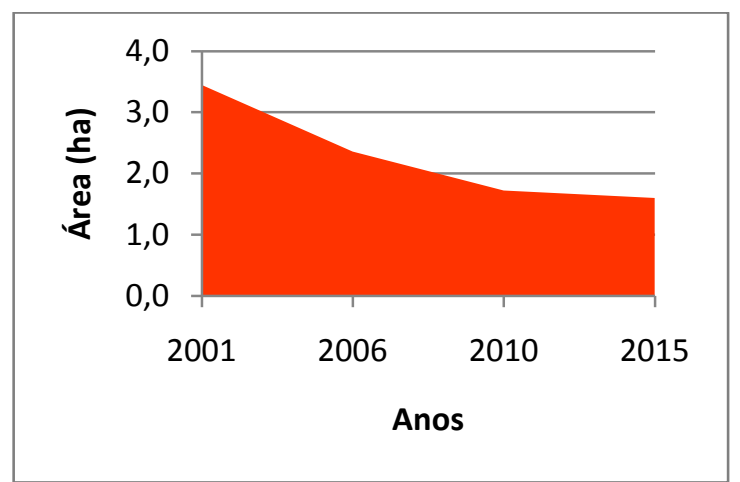

Figura 28 - Clareira 1RCP

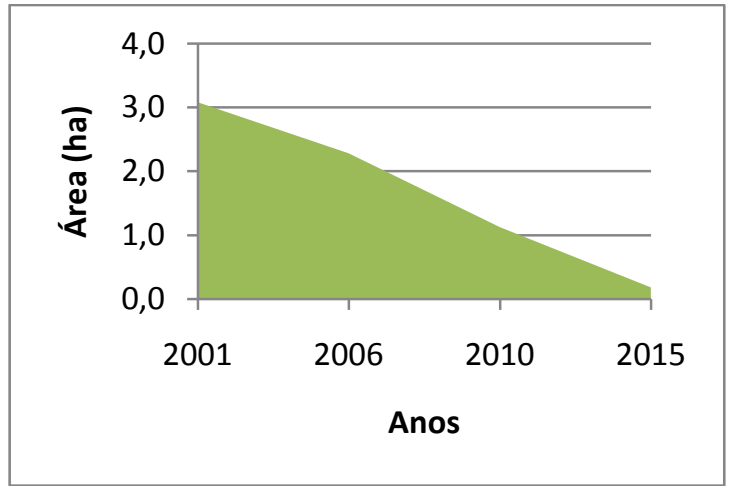

Figura 30 - Clareira 1CR

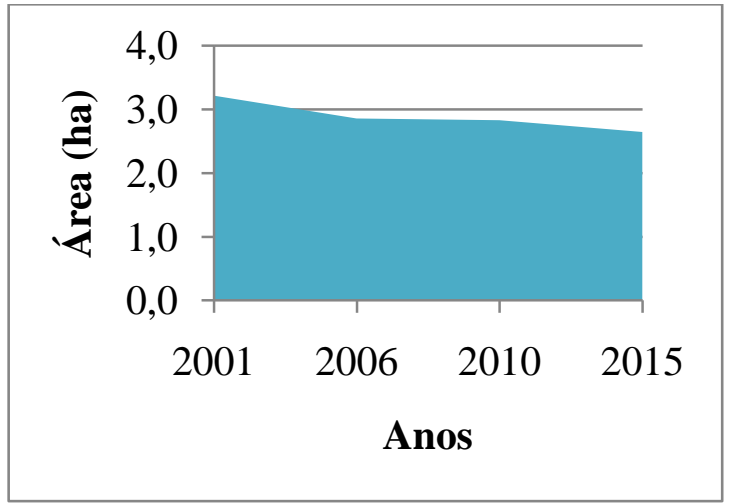

Figura 32 - Clareira 1PQA

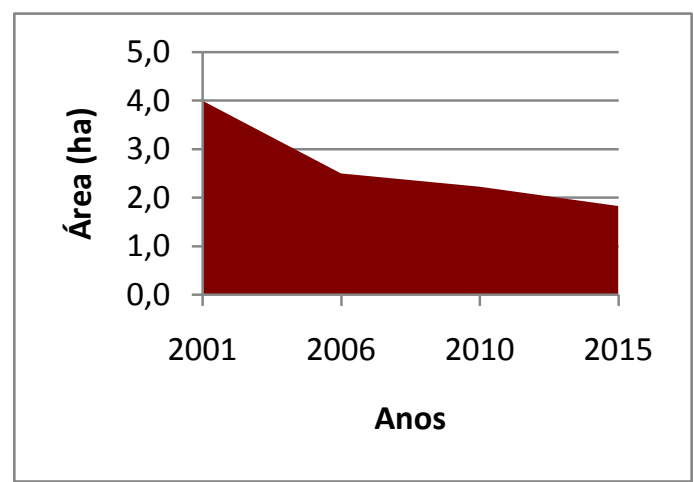

Figura 29 - Clareira 1BV

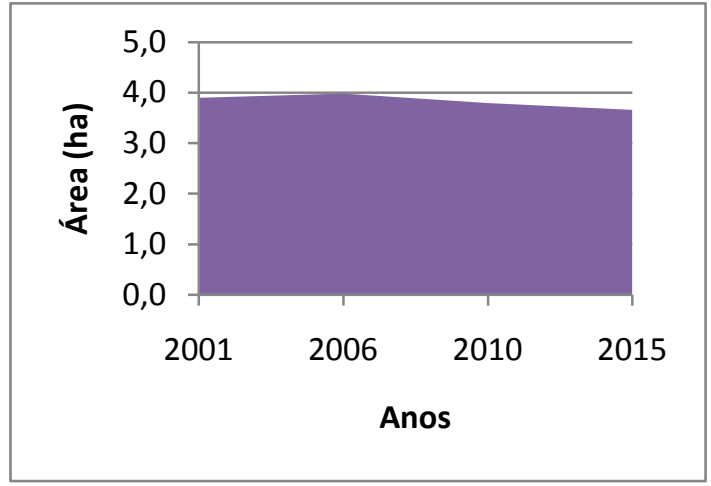

Figura 31 - Clareira 1CAT

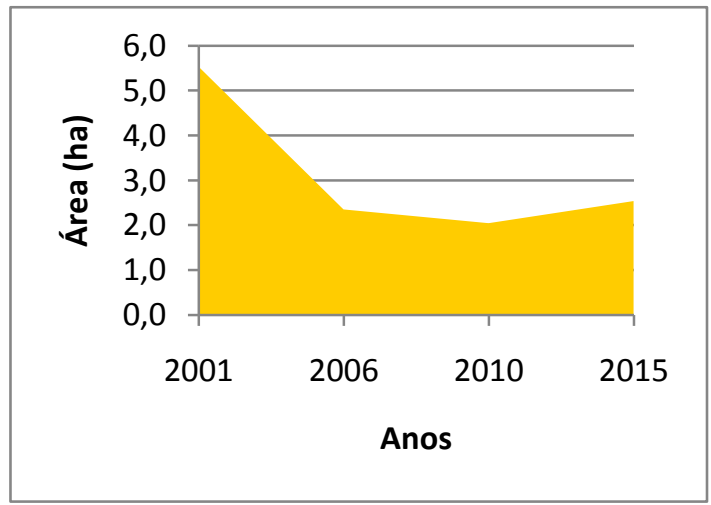

Figura 33 - Clareira 1SMA 


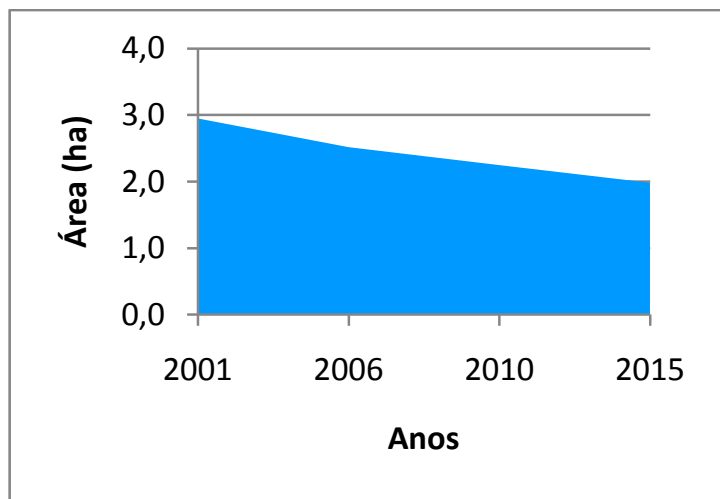

Figura 34 - Clareira 1RIT

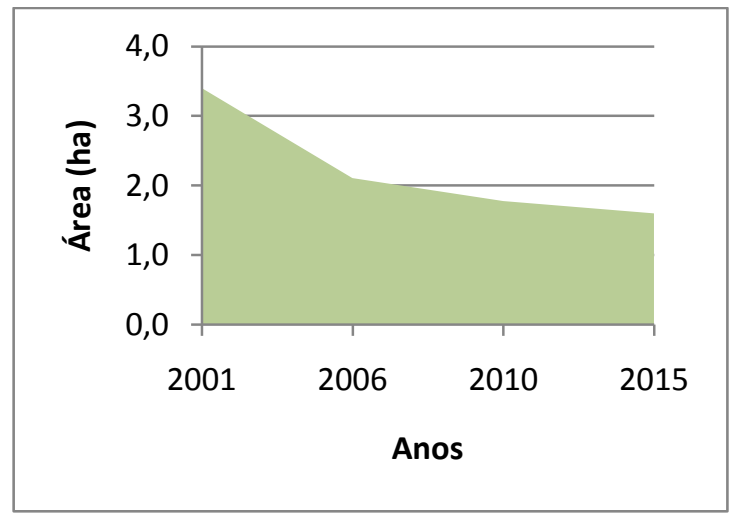

Figura 36 - Clareira 1CP

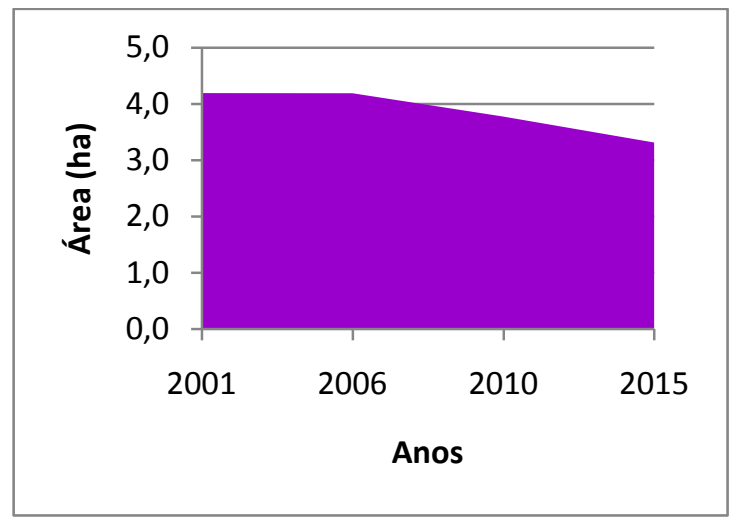

Figura 38 - Clareira 1ANG

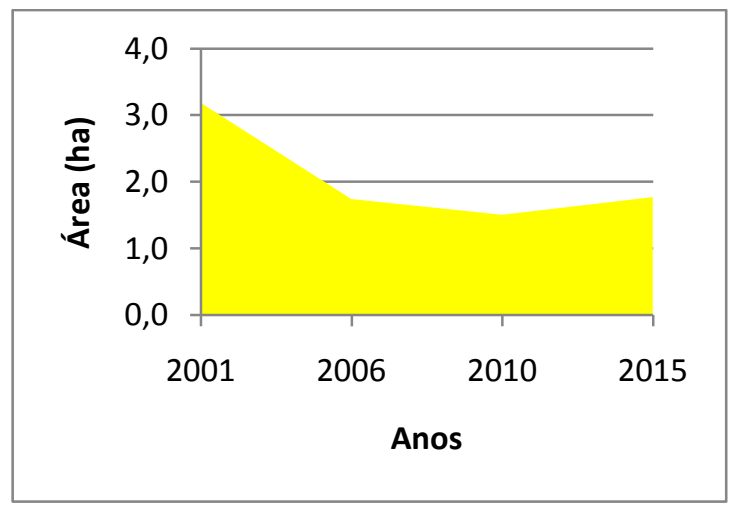

Figura 40 - Clareira 1IMA

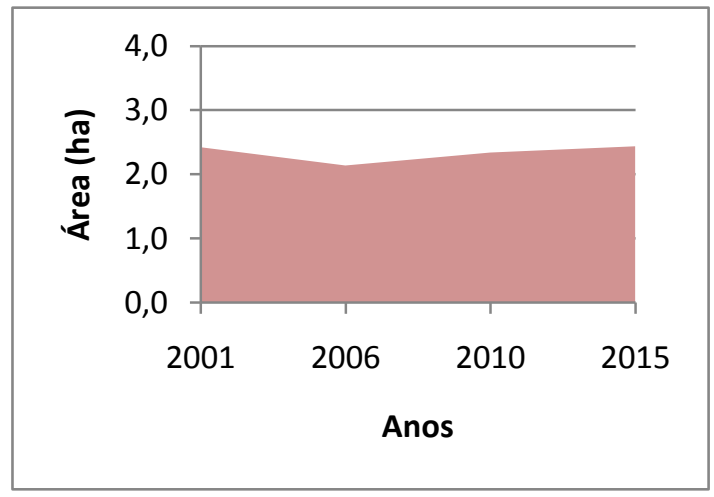

Figura 35 - Clareira 1IT

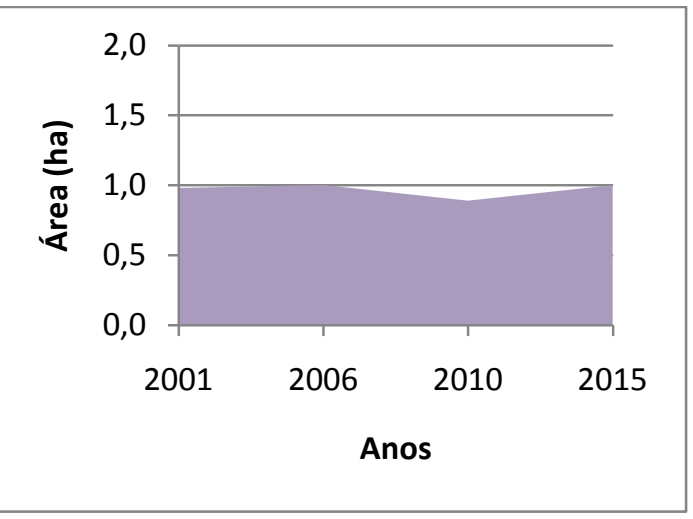

Figura 37 - Clareira 1AJ

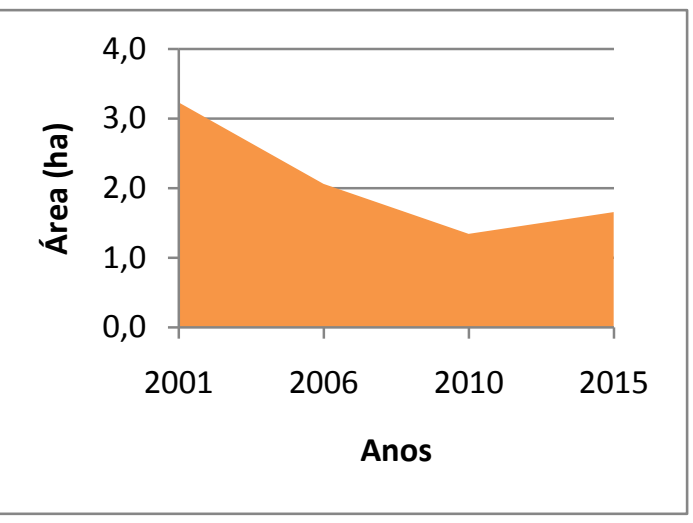

Figura 39 - Clareira 1MUC 
Por sua vez, os Blocos de Exploração e Produção possuem clareiras no estado ativo e não-ativo, mas, para a quantificação das áreas em recuperação as análises focaram as áreas desativadas, onde já ocorreu a execução do PRAD. Assim, foram analisadas 55 clareiras, conforme demonstrado na Tabela 06.

Tabela 6 - Resultado Multitemporal das Áreas de Clareiras Não-Ativas dos Blocos de Exploração e Produção

\begin{tabular}{|c|c|c|c|c|c|c|c|}
\hline \multirow{2}{*}{ No. } & \multirow{2}{*}{ Conclusão } & \multirow{2}{*}{ Clareiras } & \multicolumn{4}{|c|}{ Áreas das Clareiras (ha) } & \multirow{2}{*}{$\begin{array}{c}\text { Área } \\
\text { Recuperada }\end{array}$} \\
\hline & & & 2001 & 2006 & 2010 & 2015 & \\
\hline 1 & 2010 & 9LUC68 & 2,29 & 1,56 & 4,92 & 7,08 & $0 \%$ \\
\hline 2 & 2010 & 9RUC78 & 1,65 & 0,91 & 2,83 & 2,19 & $0 \%$ \\
\hline 3 & 2009 & 9RUC57 & 5,96 & 4,81 & 6,2 & 6,13 & $0 \%$ \\
\hline 4 & 2009 & 9LUC58 & 3,08 & 1,56 & 3,98 & 3,07 & $0 \%$ \\
\hline 5 & 2008 & 9LUC56 & 2,22 & 1,3 & 5,07 & 5,45 & $0 \%$ \\
\hline 6 & 2008 & 9RUC53 & 1,53 & 4,81 & 3,48 & 2,8 & $0 \%$ \\
\hline 7 & 2004 & 7RUC47 & 3,25 & 2,63 & 2,28 & 3,21 & $1 \%$ \\
\hline 8 & 2001 & 1BRSA55 & 11,74 & 4,2 & 3,7 & 3,22 & $73 \%$ \\
\hline 9 & 1999 & 1RT 0002 & 3,27 & 1,5 & 0,72 & 0,8 & $76 \%$ \\
\hline 10 & 1998 & 1NIT 0001 & 4,02 & 2,7 & 1,68 & 1,39 & $65 \%$ \\
\hline 11 & 1998 & 9RUC 0042 & 1,68 & 2,51 & 1,36 & 1,8 & $0 \%$ \\
\hline 12 & 1998 & 9LUC 0041 & 1,78 & 3,74 & 1,98 & 1,26 & $29 \%$ \\
\hline 13 & 1998 & 9LUC 0042 & 1,37 & 4,2 & 0,83 & 1,61 & $0 \%$ \\
\hline 14 & 1998 & 1LSM 0001 & 3,39 & 1,6 & 2,4 & 2,11 & $38 \%$ \\
\hline 15 & 1998 & 1JOB 0001 & 2,09 & 1,25 & 1,41 & 1,51 & $28 \%$ \\
\hline 16 & 1998 & 1RA 0002 & 3,35 & 2,38 & 2,32 & 2,26 & $33 \%$ \\
\hline 17 & 1997 & 1SSM 0001 & 3,16 & 2,16 & 2,04 & 1,79 & $43 \%$ \\
\hline 18 & 1997 & 9RUC 0040 & 2,62 & 0,9 & 1,84 & 2,69 & $0 \%$ \\
\hline 19 & 1997 & 9LUC 0034 & 2,3 & 1,39 & 2,54 & 2,15 & $7 \%$ \\
\hline 20 & 1997 & 9LUC 0037 & 2,47 & 1,81 & 1,42 & 2,02 & $18 \%$ \\
\hline 21 & 1997 & 1NSM 0001 & 3,05 & 2,45 & 1,72 & 1,52 & $50 \%$ \\
\hline 22 & 1997 & 1TAQ 0001 & 1,8 & 2,6 & 1,02 & 1,14 & $37 \%$ \\
\hline 23 & 1996 & 9LUC 0030 & 1,66 & 1,61 & 1,44 & 1,82 & $0 \%$ \\
\hline 24 & 1996 & 9LUC 0031 & 1,89 & 2,53 & 1,84 & 2,65 & $0 \%$ \\
\hline 25 & 1996 & 3RUC 0038 & 1,92 & 2,43 & 0,72 & 3,82 & $0 \%$ \\
\hline 26 & 1995 & 3LUC 0028 & 2,6 & 0,7 & 1,34 & 1,34 & $48 \%$ \\
\hline 27 & 1995 & 1SMT 0001 & 3,31 & 3,02 & 2,07 & 0,91 & $73 \%$ \\
\hline 28 & 1994 & 4RUC 0032 & 3,52 & 1,85 & 2,89 & 4,57 & $0 \%$ \\
\hline 29 & 1994 & 7RUC 0035 & 4,66 & 2,62 & 1,07 & 1,51 & $68 \%$ \\
\hline 30 & 1993 & 7LUC 0018 & 3,63 & 2,01 & 2,88 & 1,64 & $55 \%$ \\
\hline 31 & 1993 & 7LUC 0021 & 1,84 & 2,45 & 1,65 & 1,57 & $15 \%$ \\
\hline 32 & 1993 & 3LUC 0016 & 2,55 & 1,24 & 2,34 & 1,9 & $25 \%$ \\
\hline
\end{tabular}

(Continua) 
Tabela 6 (continuação) - Resultado Multitemporal das Áreas de Clareiras NãoAtivas dos Blocos de Exploração e Produção

\begin{tabular}{|c|c|c|c|c|c|c|c|}
\hline \multirow{2}{*}{ No. } & \multirow{2}{*}{ Conclusão } & \multirow{2}{*}{ Clareiras } & \multicolumn{4}{|c|}{ Áreas das Clareiras (ha) } & \multirow{2}{*}{$\begin{array}{c}\text { Área } \\
\text { Recuperada }\end{array}$} \\
\hline & & & 2001 & 2006 & 2010 & 2015 & \\
\hline 33 & 1993 & 7RUC 0031 & 1,43 & 1,68 & 2,95 & 3,1 & $0 \%$ \\
\hline 34 & 1992 & 3LUC 0011 & 1,56 & 1,98 & 1,8 & 3,78 & $0 \%$ \\
\hline 35 & 1992 & 7RUC 0030 & 3,07 & 1,41 & 1,76 & 2,97 & $3 \%$ \\
\hline 36 & 1991 & 4RUC 0025 & 0,84 & 1,63 & 1,1 & 1,96 & $0 \%$ \\
\hline 37 & 1991 & 7RUC 0023 & 2,11 & 3,02 & 2,25 & 3,54 & $0 \%$ \\
\hline 38 & 1991 & 3IMT 0002 & 3 & 3,3 & 2,23 & 2,78 & $7 \%$ \\
\hline 39 & 1990 & 3RUC 0022 & 0,66 & 2,35 & 1,72 & 1,75 & $0 \%$ \\
\hline 40 & 1990 & 1RA 0001 & 2,88 & 2,27 & 2,89 & 2,95 & $0 \%$ \\
\hline 41 & 1989 & 3LUC 0007 & 3,92 & 1,65 & 3,16 & 2,71 & $31 \%$ \\
\hline 42 & 1989 & 4RUC 0015 & 3,14 & 2,36 & 2,71 & 4,13 & $0 \%$ \\
\hline 43 & 1988 & 3LUC 0002 & 2,49 & 2,43 & 3,6 & 3,4 & $0 \%$ \\
\hline 44 & 1984 & 1RT 0001 & 1,93 & 1,6 & 2,07 & 1,77 & $8 \%$ \\
\hline 45 & 1983 & 1ICT 0001 & 1,17 & 0,91 & 1,19 & 0,95 & $19 \%$ \\
\hline 46 & 1982 & 3IP 0002 & 0,99 & 2,64 & 1,75 & 1,21 & $0 \%$ \\
\hline 47 & 1982 & 3JI 0004 & 1,69 & 2,12 & 9,65 & 3,99 & $0 \%$ \\
\hline 48 & 1982 & 3JR 0004 & 2,07 & 2,19 & 8,52 & 3,24 & $0 \%$ \\
\hline 49 & 1981 & 1IP 0001 & 1,76 & 2,82 & 1,4 & 1,08 & $39 \%$ \\
\hline 50 & 1981 & 3JI 0002 & 0,49 & 2,88 & 7,21 & 0,72 & $0 \%$ \\
\hline 51 & 1981 & 3JI 0003 & 1,89 & 2,73 & 1,99 & 1,85 & $2 \%$ \\
\hline 52 & 1980 & $1 \mathrm{JI} 0001$ & 1,72 & 3,32 & 2,36 & 2,3 & $0 \%$ \\
\hline 53 & 1979 & 3JR 0002 & 1,34 & 2,26 & 1,99 & 1,78 & $0 \%$ \\
\hline 54 & 1979 & 3JR 0003 & 1,1 & 1,27 & 1,75 & 1,43 & $0 \%$ \\
\hline 55 & 1978 & 1JR 0001 & 2,5 & 2,22 & 2,57 & 2,92 & $0 \%$ \\
\hline \multicolumn{3}{|c|}{ Total } & 139,4 & 121,7 & 142,6 & 135,3 & $03 \%$ \\
\hline
\end{tabular}

As clareiras presentes nos Campos de Produção da BOGPM (RUC/ LUC) tem a característica do acesso viário, portanto a manutenção do PRAD é mais acessível e poderia trazer resultados mais eficazes e eficientes. Mas, em algumas áreas mais recentes chegou a ser constatado um aumento da área degrada inicial. Esses dados comprovam que o tempo de desativação antigo não foi suficiente para proporcionar a regeneração da área, bem como, o benefício da acessibilidade viária, também, não resolveu o problema de eficácia do PRAD.

A análise do número de clareiras desativadas, nos Blocos de Exploração e Produção (E\&P), avaliou o resultado da classificação SAM para a quantificação das áreas que permaneceram em estado degradado, ou seja, onde houve um baixo percentual de revegetação, devido à falta de eficácia dos PRADs. Conforme pode ser visualizado na figura 41. 


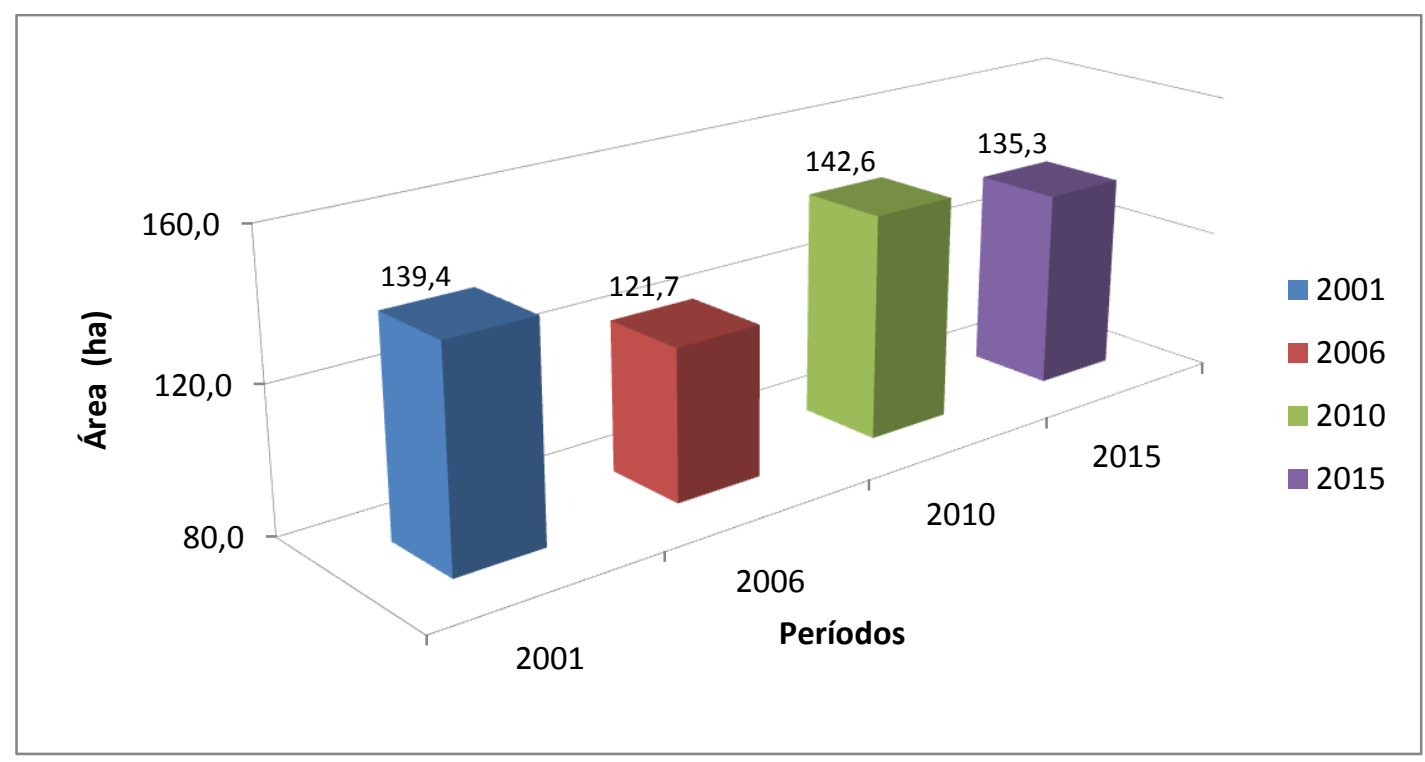

Figura 41 - Áreas das Clareiras Desativadas nos Blocos de E\&P

Cabe observar que esta análise ocorreu com o número fixo de 55 clareiras desativadas, que tiveram sua área analisada por meio do classificador SAM, single angle, em quatro períodos, assim, as colunas no gráfico representam a área total desmatada por ano e estão demonstrando pouca variação de recuperação. Isso significa que uma pequena área foi revegetada e os PRADs não estão atingindo seus objetivos, pois a revegetação alcançou apenas $3 \%$ da área total.

Nascimento (2009) fez uma pesquisa em 39 clareiras na Província Petrolífera de Urucu com imagens orbitais e levantamentos de campo, os resultados mostraram que a área ocupada pela regeneração era somente de 18,6\% e que nenhuma dessas áreas voltou à classe floresta após a intervenção e o plantio, também, realizou o acompanhamento da regeneração com imagens de satélite destacando restrições, mesmo com o plantio de 875.271 árvores ao longo de 21 anos, as 39 áreas permaneceram com $76,59 \%$ do solo exposto, correspondendo a 86,05 hectares.

Foi observado que o comportamento geral das clareiras no decorrer dos anos não apresentou um padrão definido de recuperação em nenhum dos casos analisados. Pelo contrário, a análise dos dados da Tabela 06 mostrou que apenas 05 de 55 clareiras apresentaram uma área de revegetação acima de $60 \%$, como podermos ver:

1BRSA55;

1RT 0002;
1NIT 0001;

1SMT 0001;

E, ainda, mais drasticamente mostrou que 38 das 55 clareiras não alcançaram sequer $20 \%$ de recuperação da área desmatada, a citar: 


\begin{tabular}{ccc} 
9LUC68 & 9LUC 0031 & 3LUC 0002 \\
9RUC78 & 3RUC 0038 & 1RT 0001 \\
9RUC57 & 4RUC 0032 & 1ICT 0001 \\
9LUC58 & 7LUC 0021 & 3IP 0002 \\
9LUC56 & 7RUC 0031 & 3JI 0004 \\
9RUC53 & 3LUC 0011 & 3JR 0004 \\
7RUC47 & 7RUC 0030 & 3JI 0002 \\
9RUC 0042 & 4RUC 0025 & 3JI 0003 \\
9LUC 0042 & 7RUC 0023 & 1JI 0001 \\
9RUC 0040 & 3IMT 0002 & 3JR 0002 \\
9LUC 0034 & 3RUC 0022 & 3JR 0003 \\
9LUC 0037 & 1RA 0001 & 1JR001 \\
9LUC 0030 & 4RUC 0015 & \\
\hline
\end{tabular}

Cabe destacar que 47 das 55 clareiras tiveram suas atividades concluídas antes do ano 2000, entrementes, o percentual de recuperação das áreas degradadas permaneceu muito baixo. Outros fatores como a severa compactação do solo, a presença de solos muito argilosos ou arenosos, a alta pluviosidade anual e a perda do banco de sementes do solo impactaram negativamente e de maneira muito significativa, causando a ineficácia dos PRADs.

As alterações ambientais necessárias à perfuração de um poço de petróleo têm um processo de reversão muito complicado, a remoção do horizonte superficial do solo, a intensa compactação e aterramento são exemplos de fatores que ao serem combinados tornam ainda mais difícil a recuperação dessas áreas. Arruda (2005) e Goch (2007) sinalizaram em suas pesquisas realizadas na Base de Operações Pedro de Moura (BOGPM, Urucu) que a existência de grandes superfícies com solo exposto e elevadas taxas de perda de solo comprometem a restauração das áreas degradadas e dos canais fluviais nas imediações. Outros autores como Leal Filho et al. (2000), Ezawa et al. (2006) e Molinaro (2005) também destacaram as dificuldades decorrentes de fatores 
ambientais como a compactação do solo, processos erosivos, dessecamento e competição de espécies.

Arruda (2005) e Molinaro (2005), também, destacaram a importância das características físico-químicas do solo na limitação do estabelecimento e desenvolvimento de vegetação nestas áreas. Mesmo diante dos diferentes agentes dispersores de propágulos, mudas adaptadas a região, disponibilidade de água e luminosidade, a sucessão ecológica perde seu potencial de desenvolvimento.

As figuras de 42 a 96 ilustram o comportamento da área degradada nas clareiras no período de 2001 a 2015, onde é possível notar a inexistência de um padrão de recuperação, com uma redução constante da área degradada no decorrer do tempo. Em alguns casos, nota-se uma instabilidade na revegetação, que mesmo após re-ocupar a área desmatada sofre um caimento e expõe novamente o solo exposto do desmatamento, aumentando a área degrada representada no gráfico.

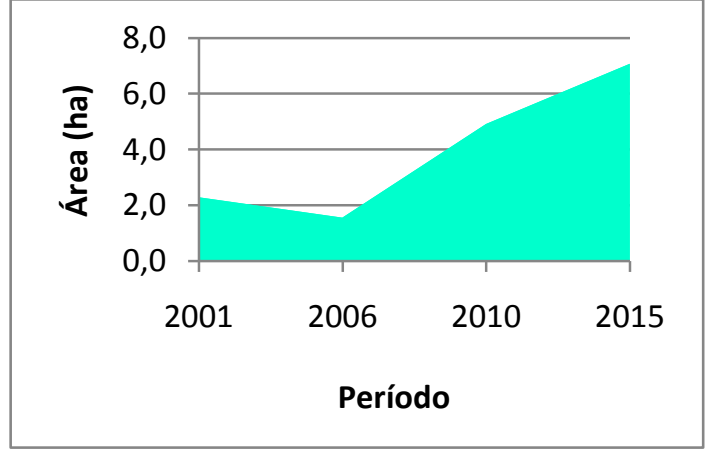

Figura 42 - Clareira 9LUC68

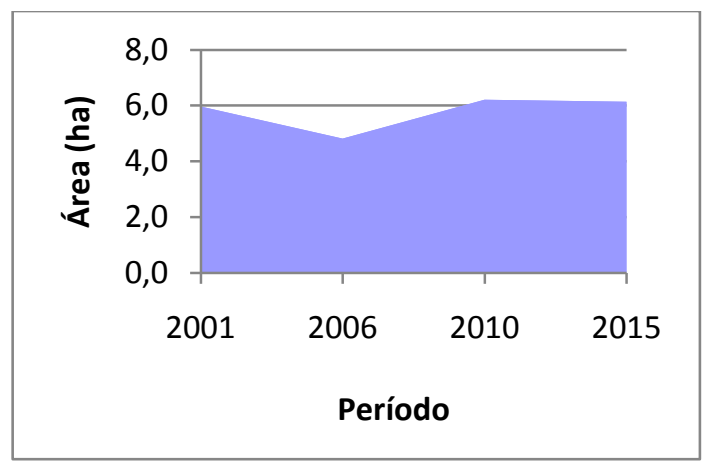

Figura 44 - Clareira 9RUC57

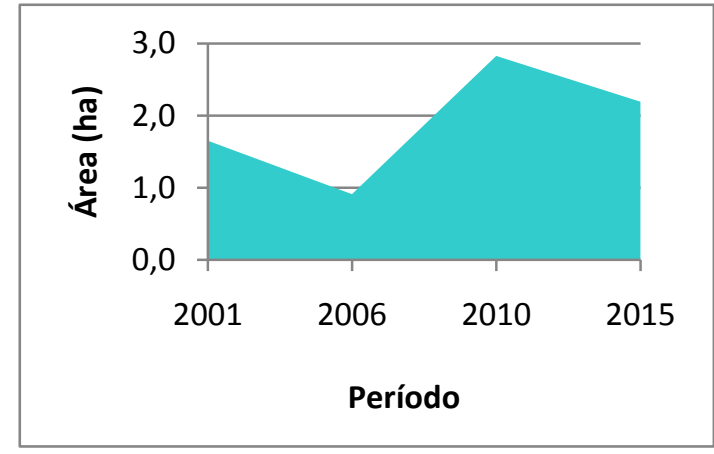

Figura 43 - Clareira 9RUC78

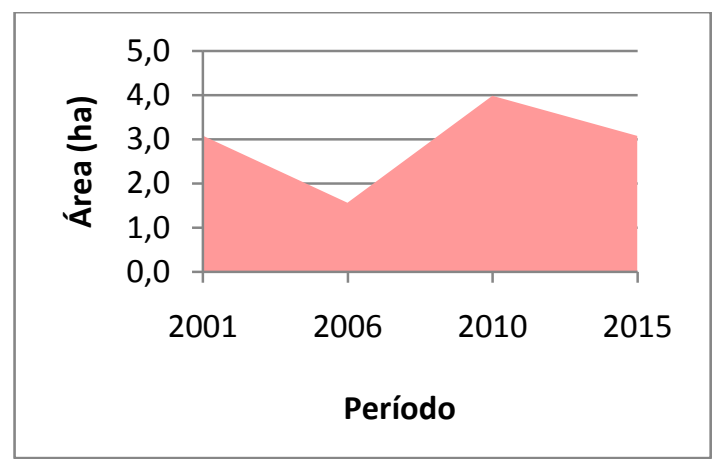

Figura 45 - Clareira 9LUC58 


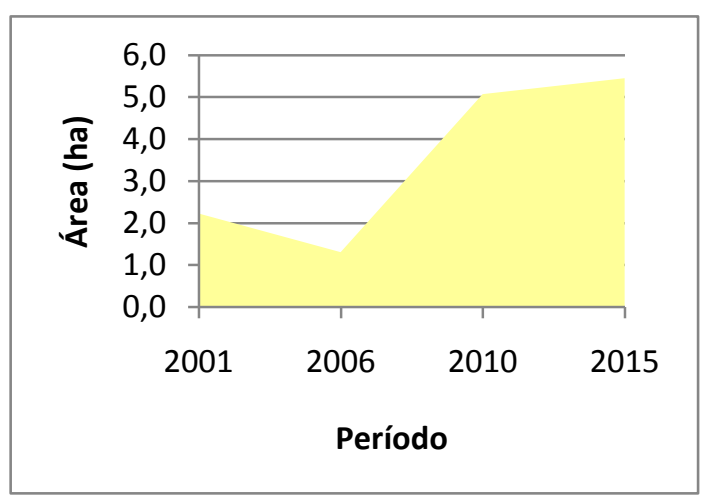

Figura 46 - Clareira 9LUC56

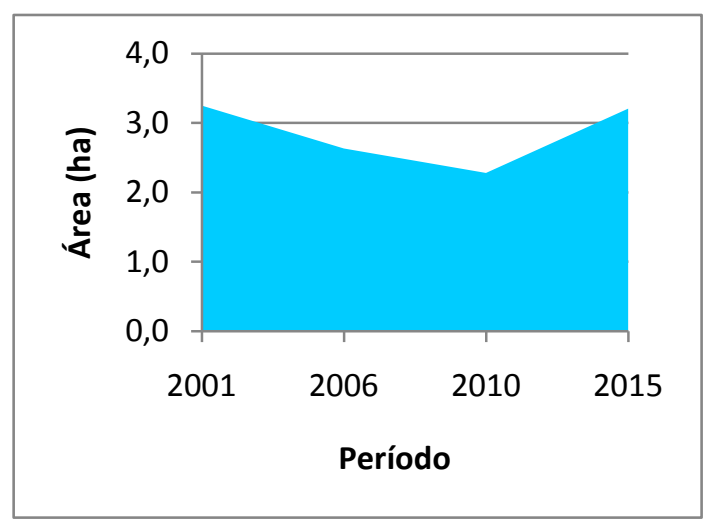

Figura 48 - Clareira 7RUC47

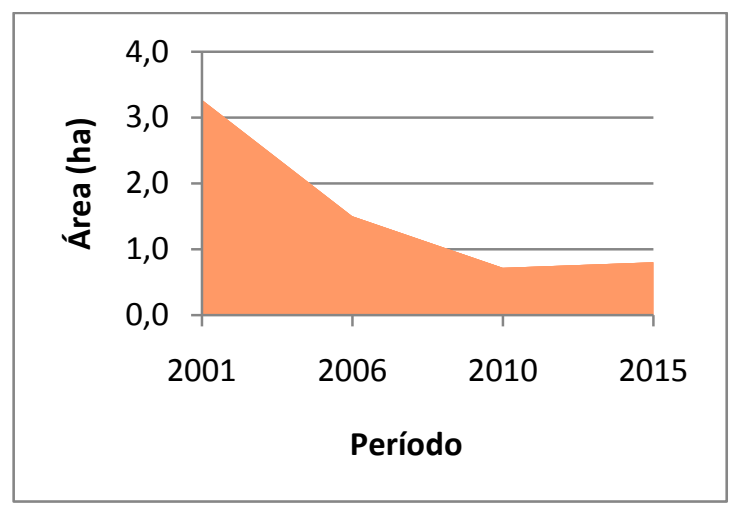

Figura 50 - Clareira 1RT0002

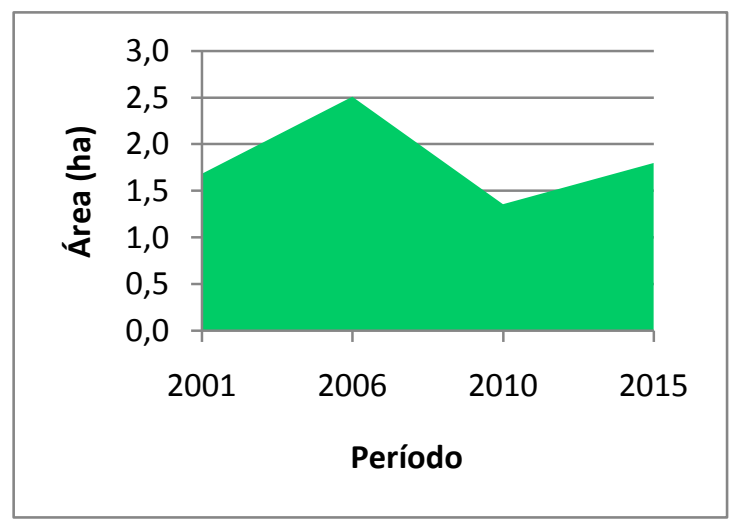

Figura 52 - Clareira 9RUC0042

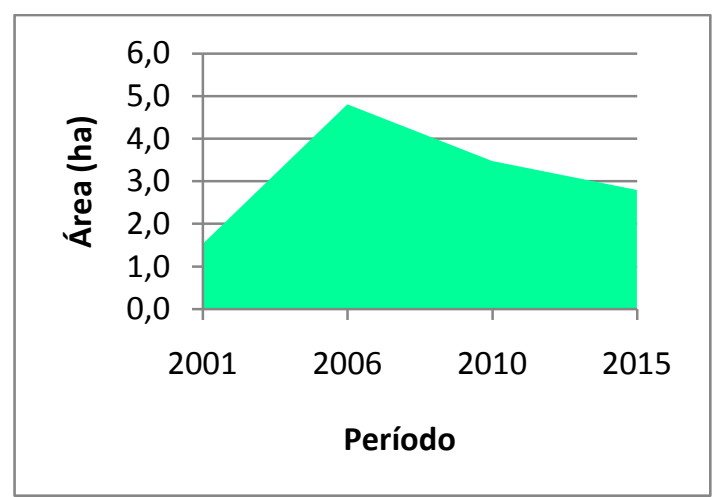

Figura 47 - Clareira 9RUC53

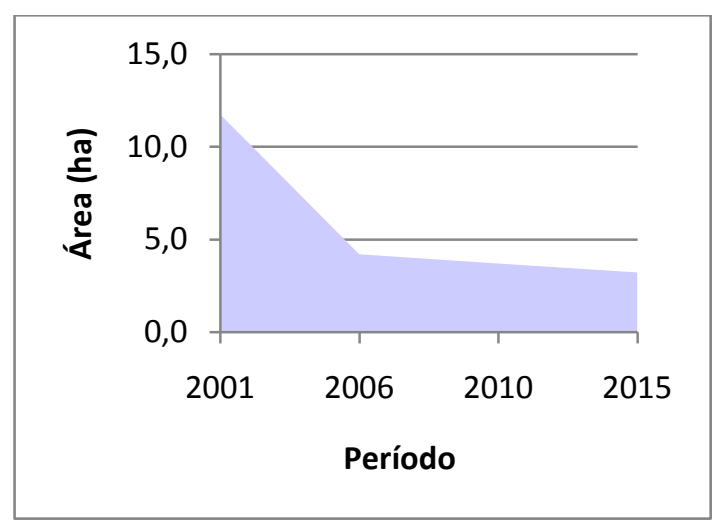

Figura 49 - Clareira 1BRSA55

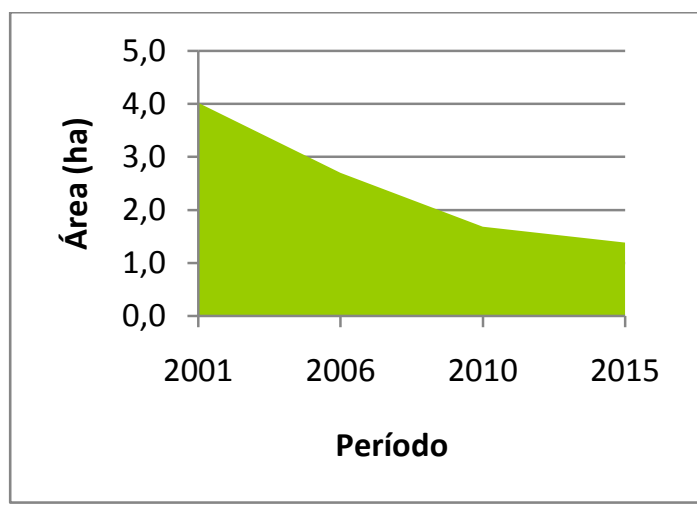

Figura 51 - Clareira 1NIT0001

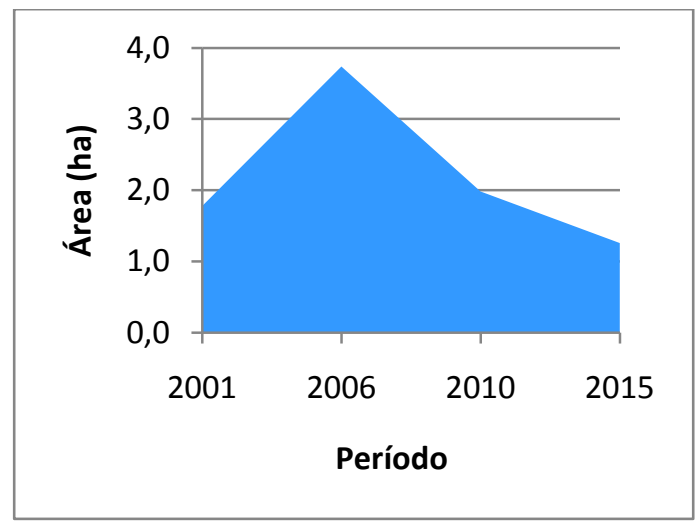

Figura 53 - Clareira 9LUC0041 


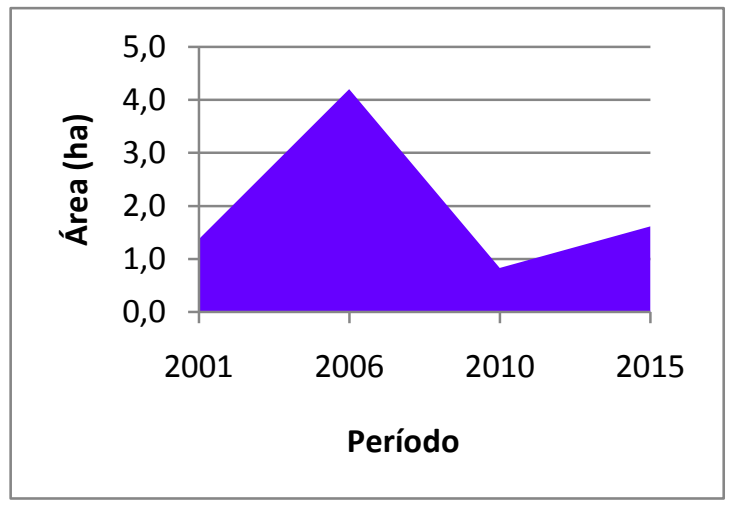

Figura 54 - Clareira 9LUC0042

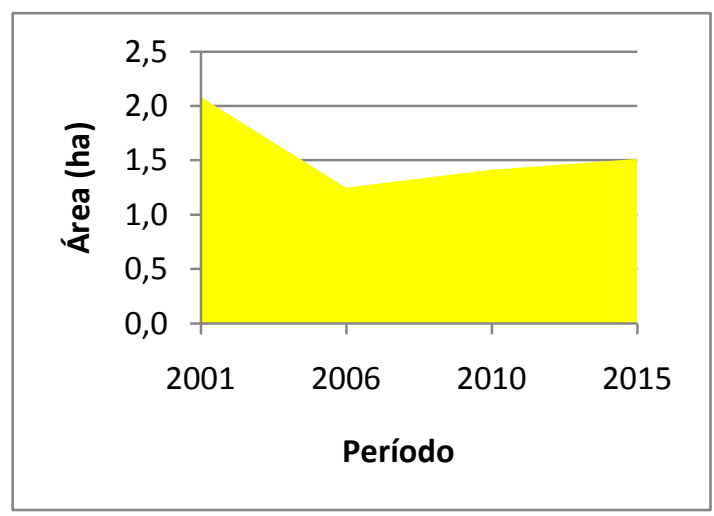

Figura 56 - Clareira 1JOB0001

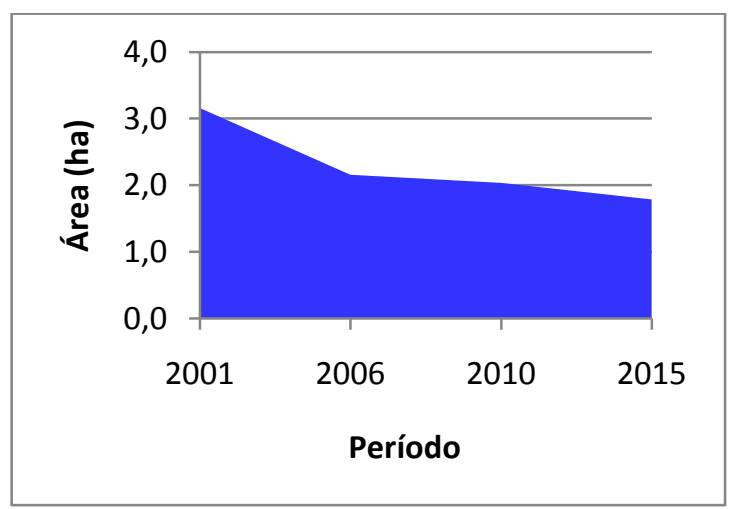

Figura 58 - Clareira 1SSM0001

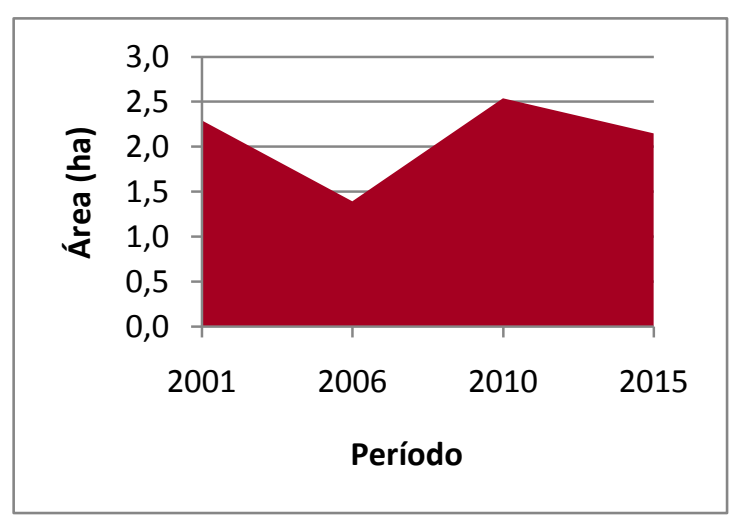

Figura 60 - Clareira 9LUC0034

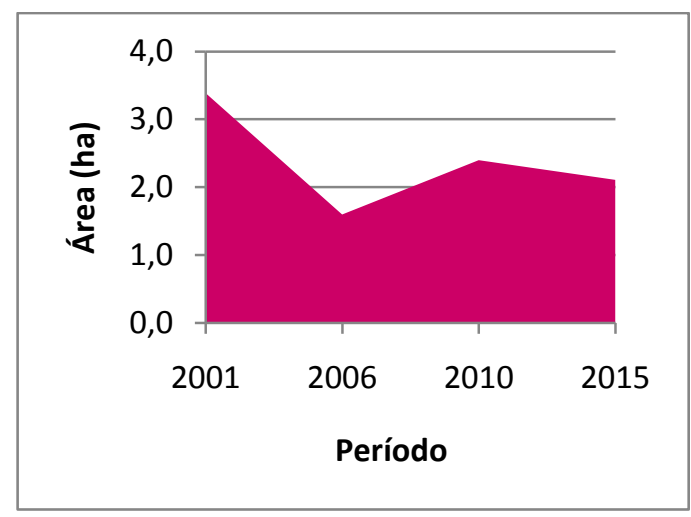

Figura 55 - Clareira 1LSM0001

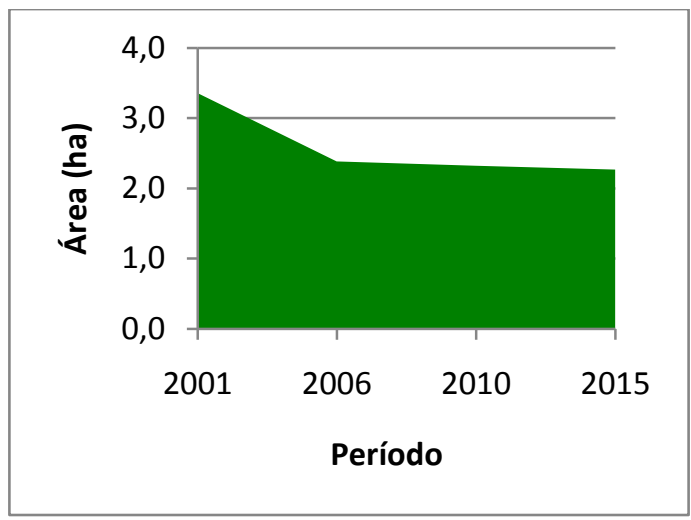

Figura 57 - Clareira1RA0002

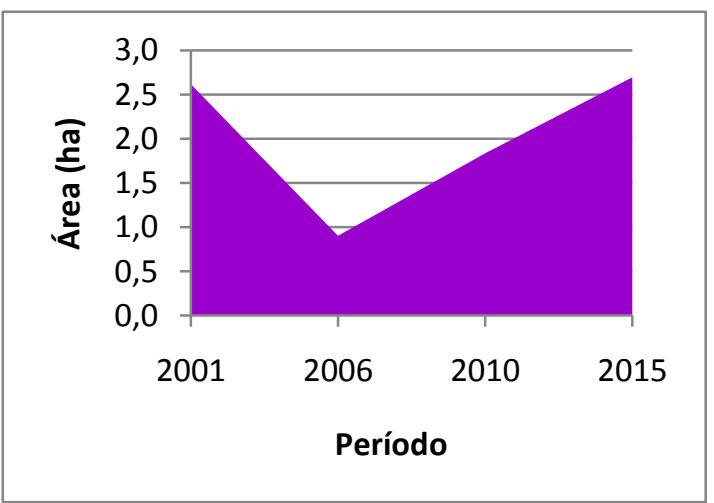

Figura 59 - Clareira 9RUC0040

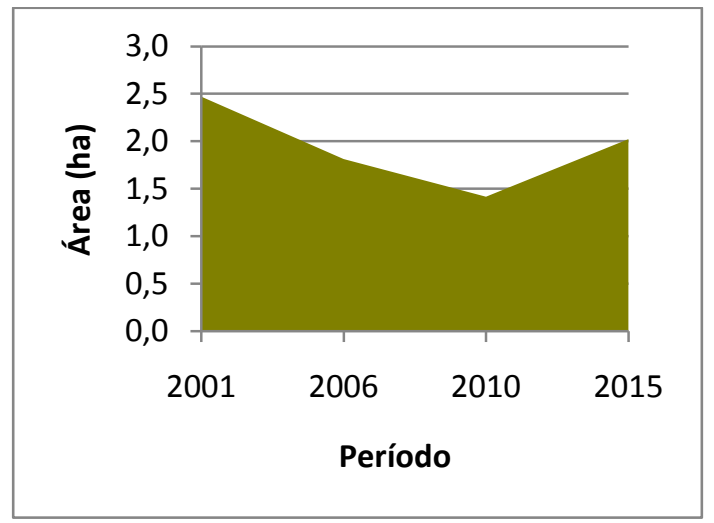

Figura 61 - Clareira 9LUC0037 


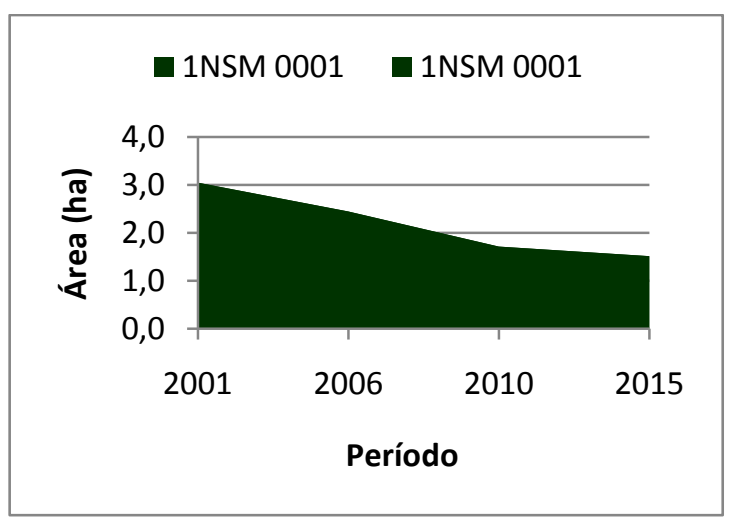

Figura 62 - Clareira 1NSM0001

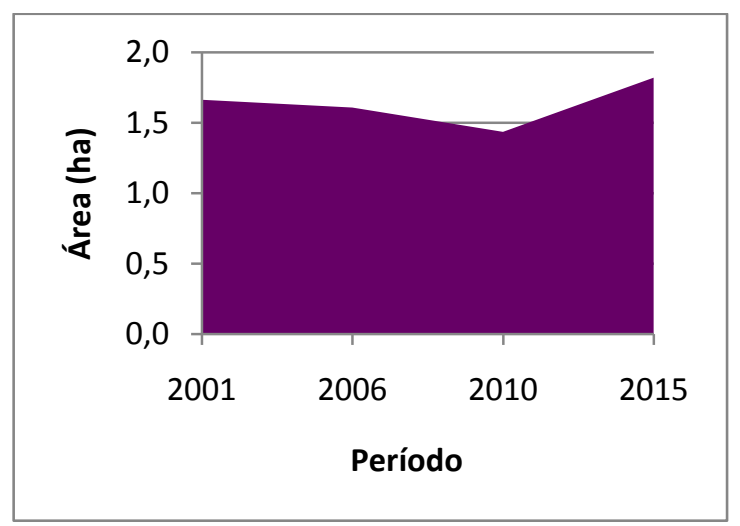

Figura 64 - Clareira 9LUC0030

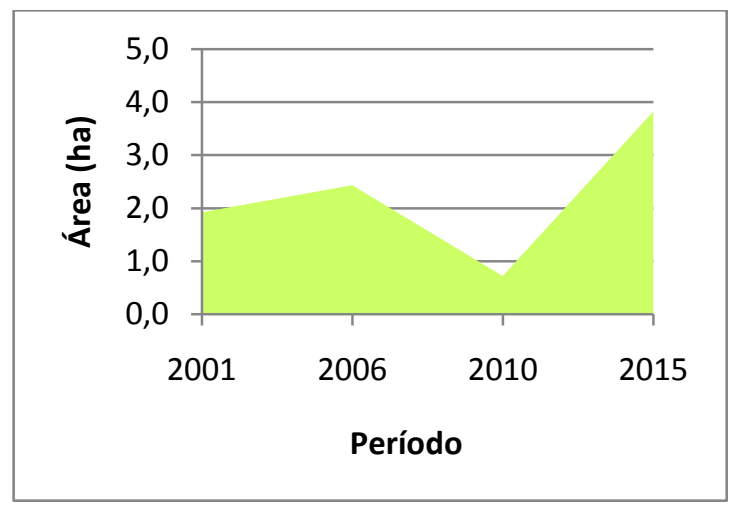

Figura 66 - Clareira 3RUC0038

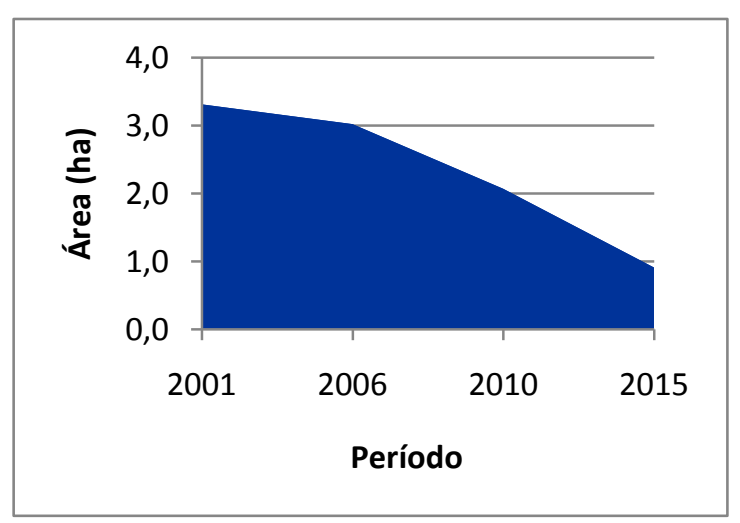

Figura 68 - Clareira 1SMT 0001

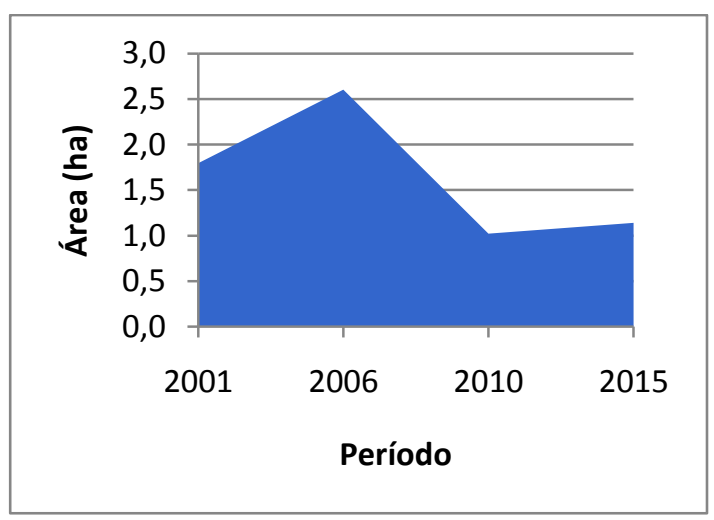

Figura 63 - Clareira 1TAQ0001

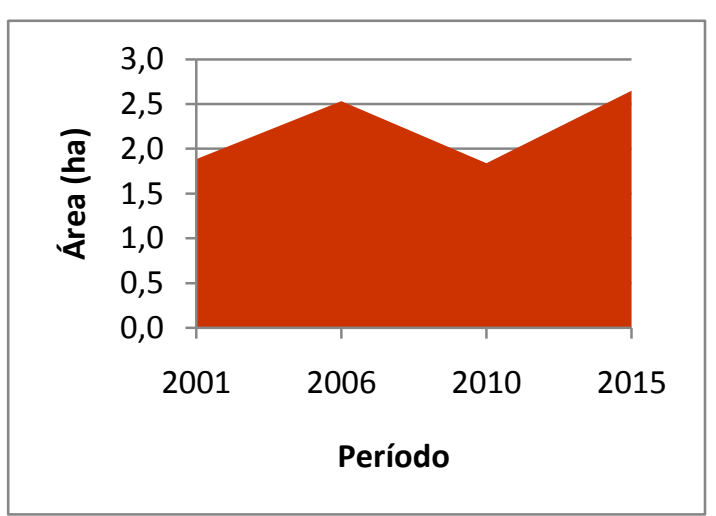

Figura 65 - Clareira 9LUC0031

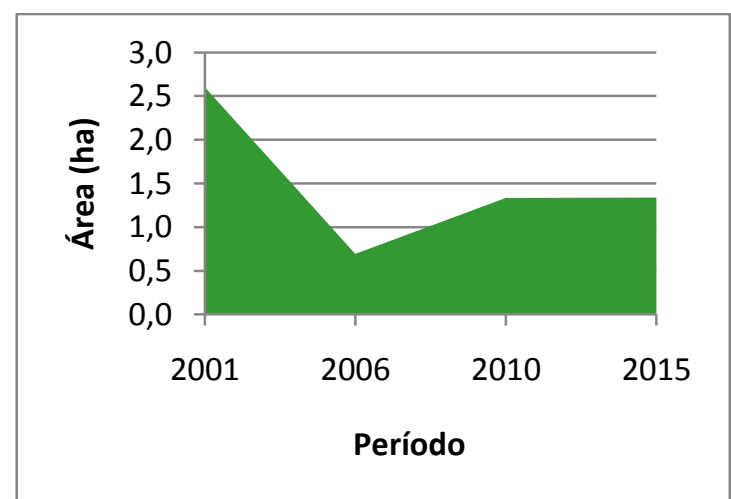

Figura 67 - Clareira 3LUC0028

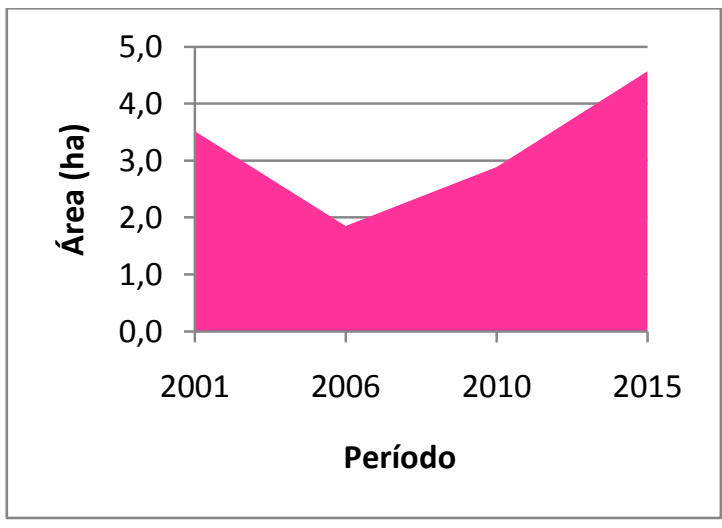

Figura 69 - Clareira 4RUC0032 


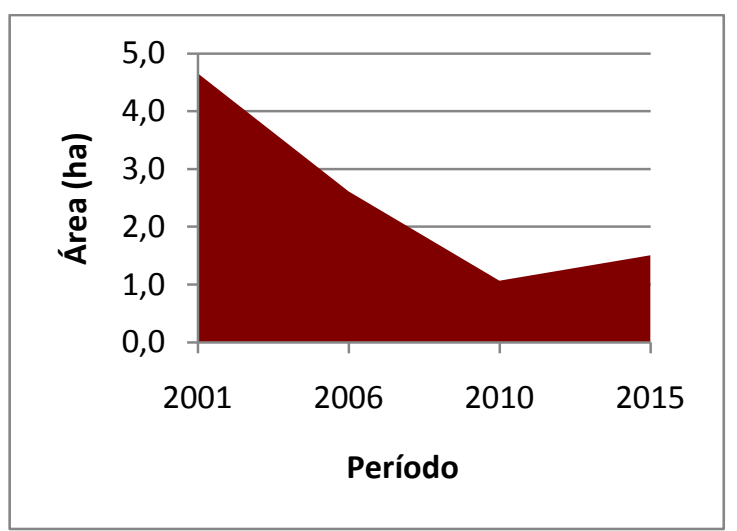

Figura 70 - Clareira 7RUC 0035

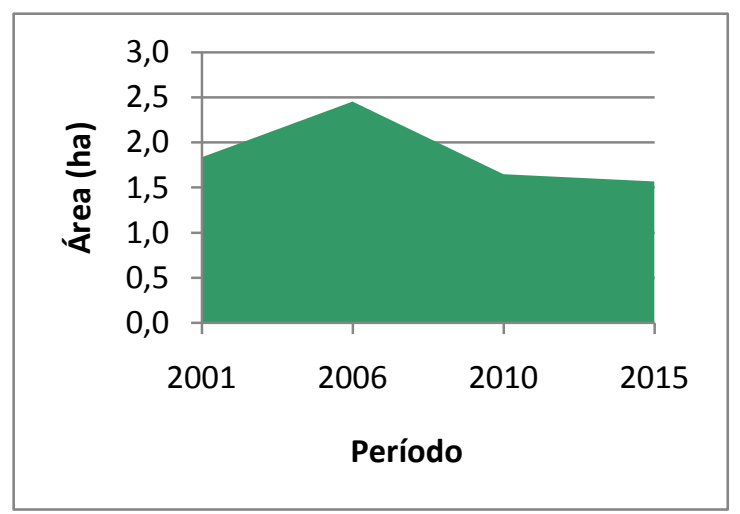

Figura 72 - Clareira 7LUC 0021

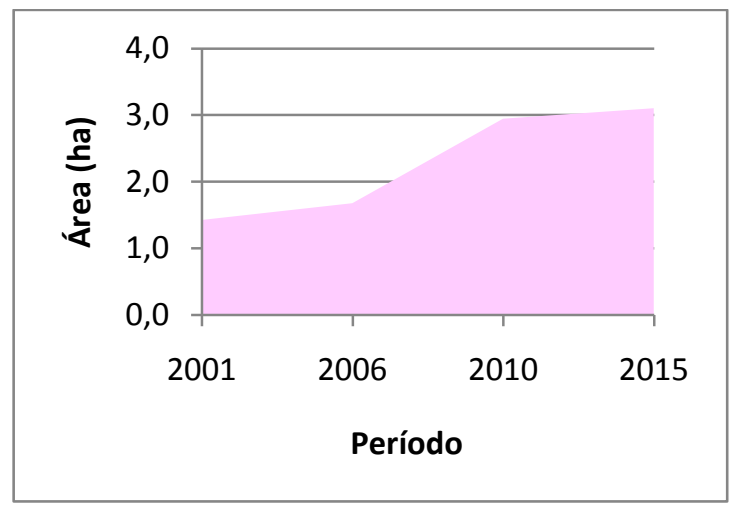

Figura 74 - Clareira 7RUC0031

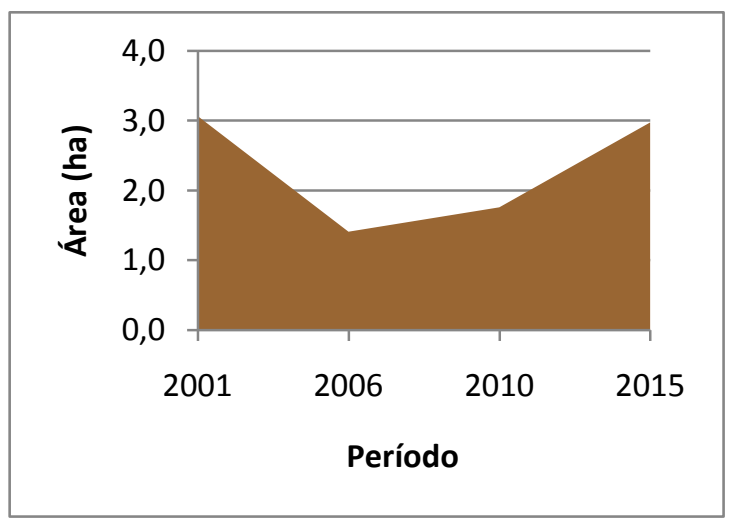

Figura 76 - Clareira 7RUC0030

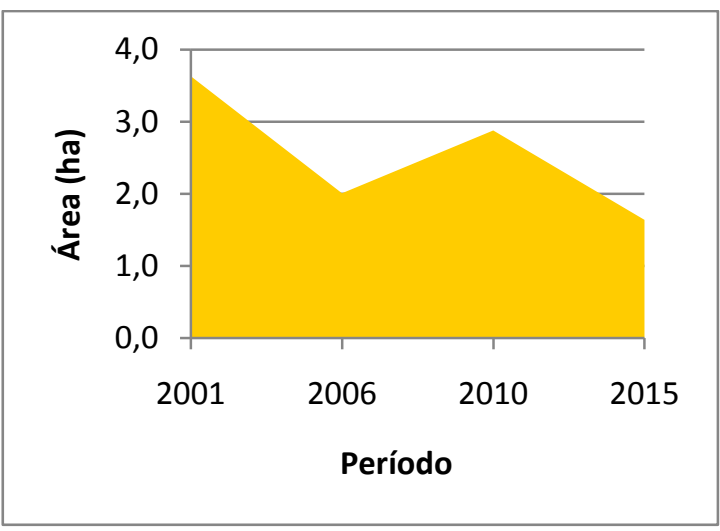

Figura 71 - Clareira 7LUC 0018

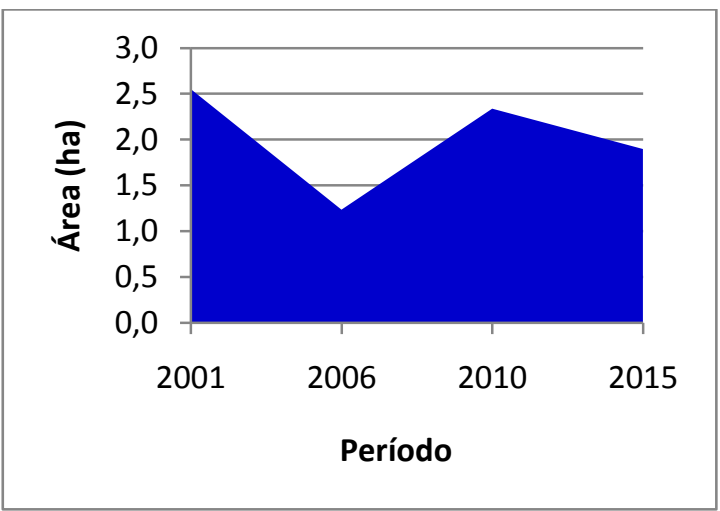

Figura 73 - Clareira 3LUC 0016

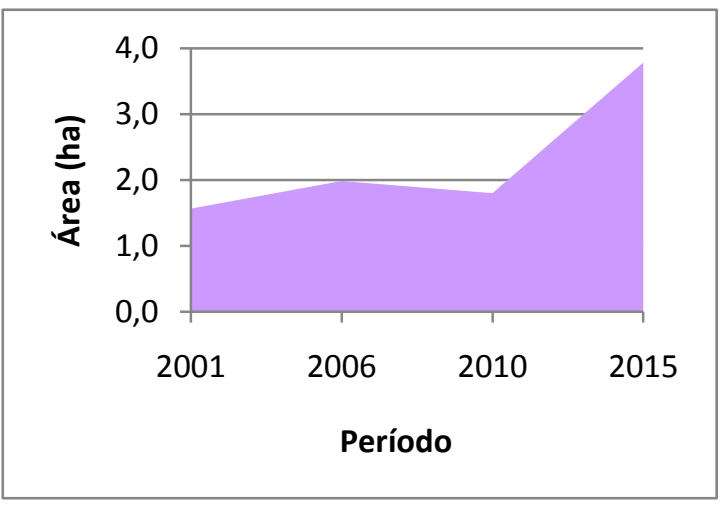

Figura 75 - Clareira 3LUC0011

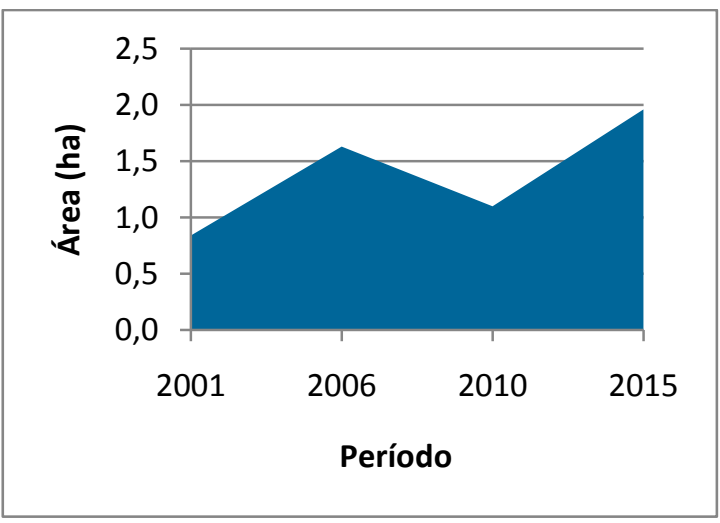

Figura 77 - Clareira4RUC0025 


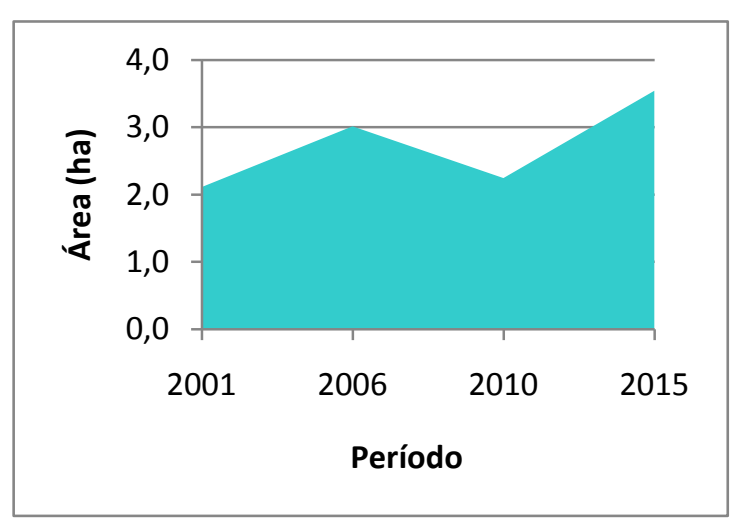

Figura 78 - Clareira 7RUC0023

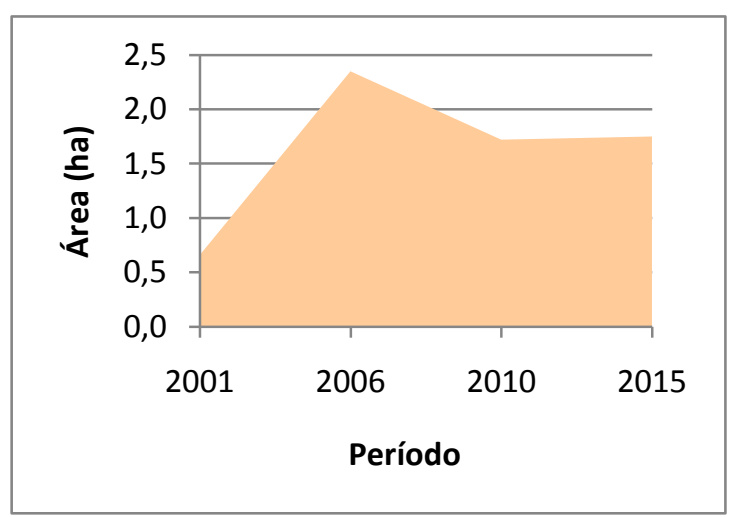

Figura 80 - Clareira 3RUC0022

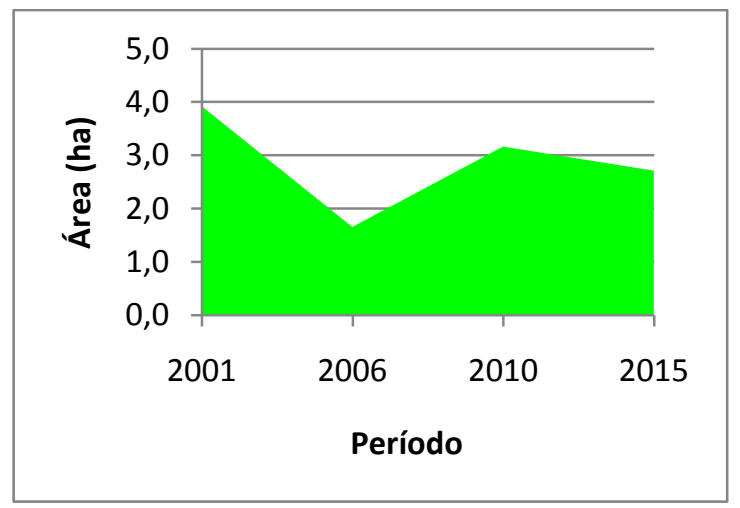

Figura 82 - Clareira 3LUC0007

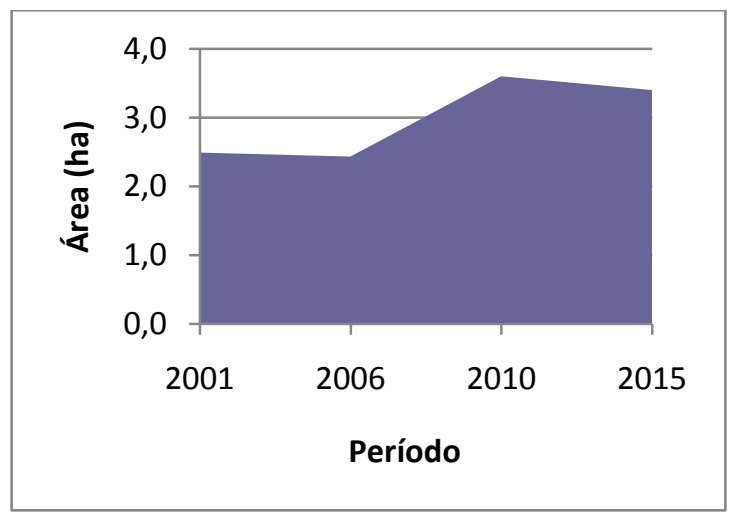

Figura 84 - Clareira 3LUC0002

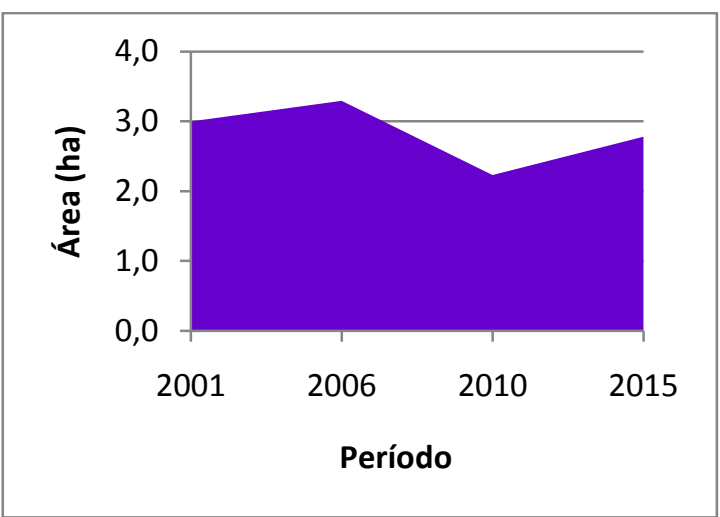

Figura 79 - Clareira 3IMT0002

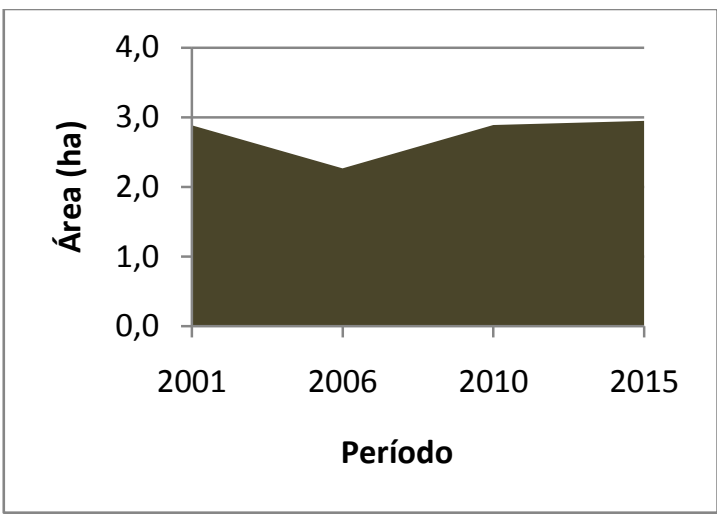

Figura 81 - Clareira 1RA0001

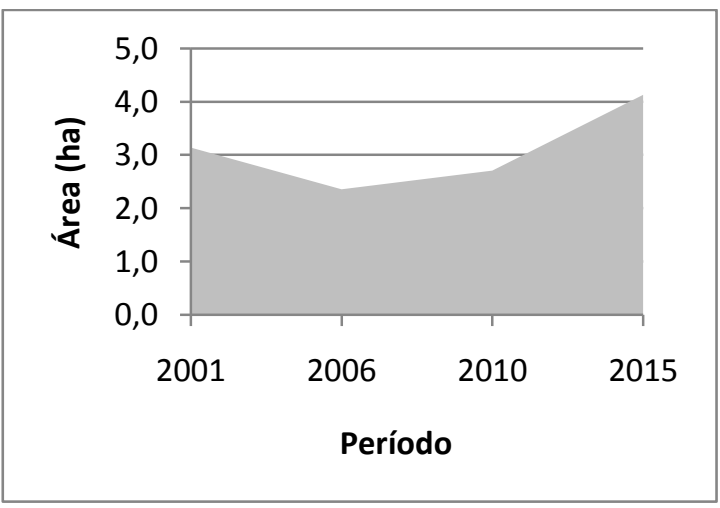

Figura 83 - Clareira 4RUC0015

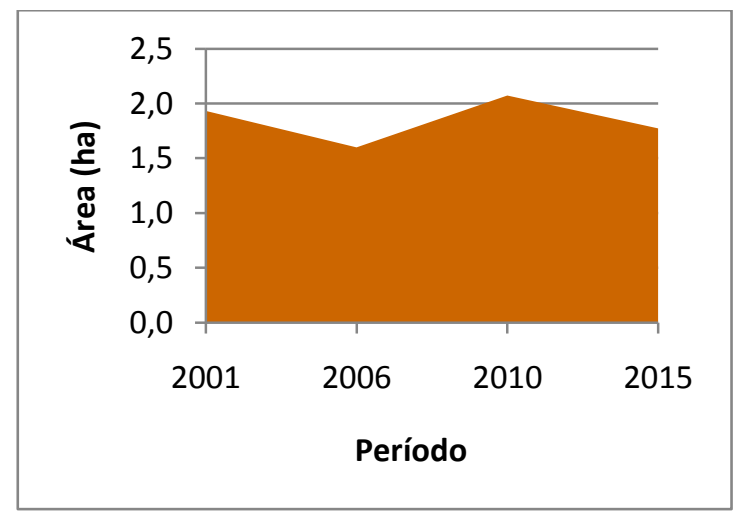

Figura 85 - Clareira 1RT0001 


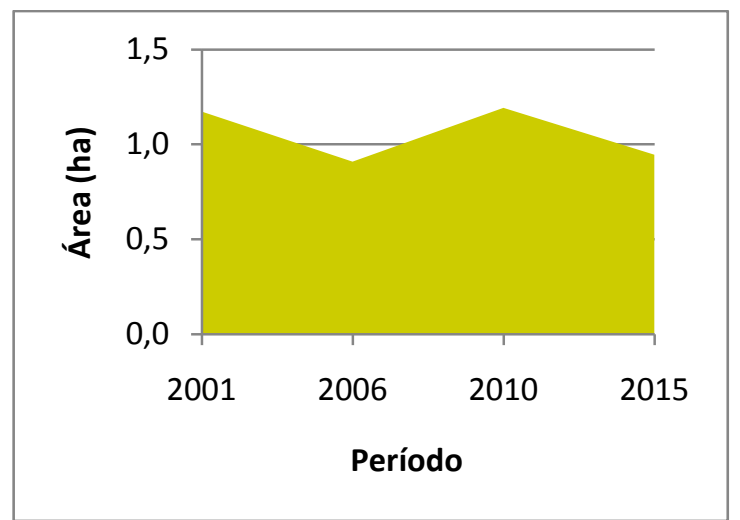

Figura 86 - Clareira 1ICT0001

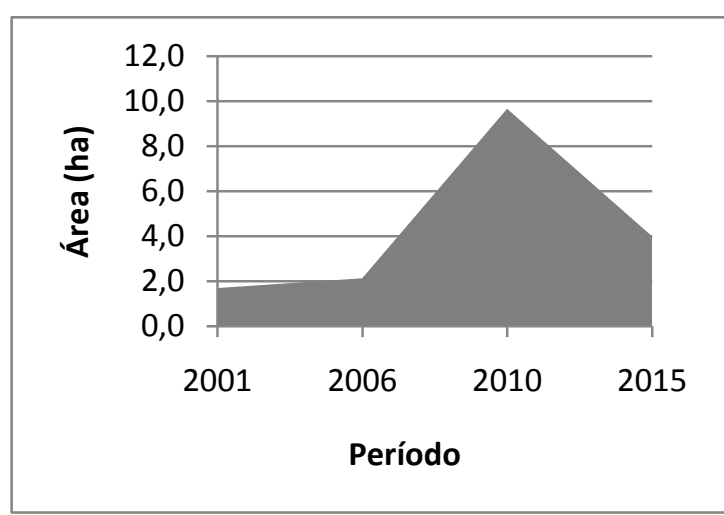

Figura 88 - Clareira 3JI0004

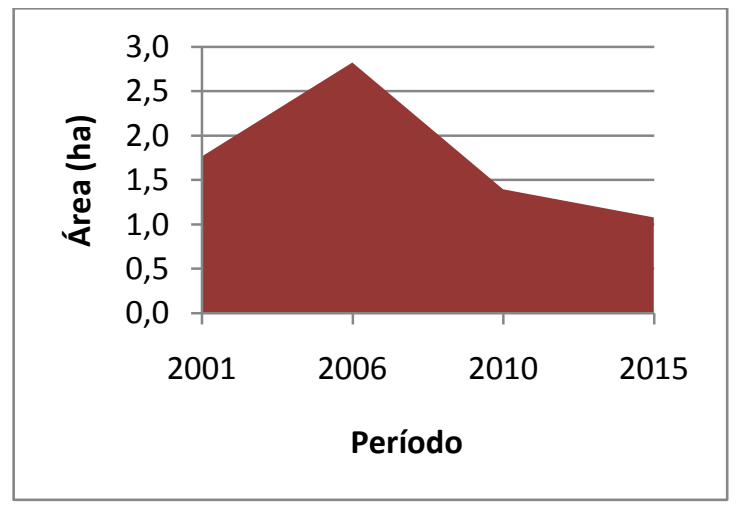

Figura 90 - Clareira 1IP0001

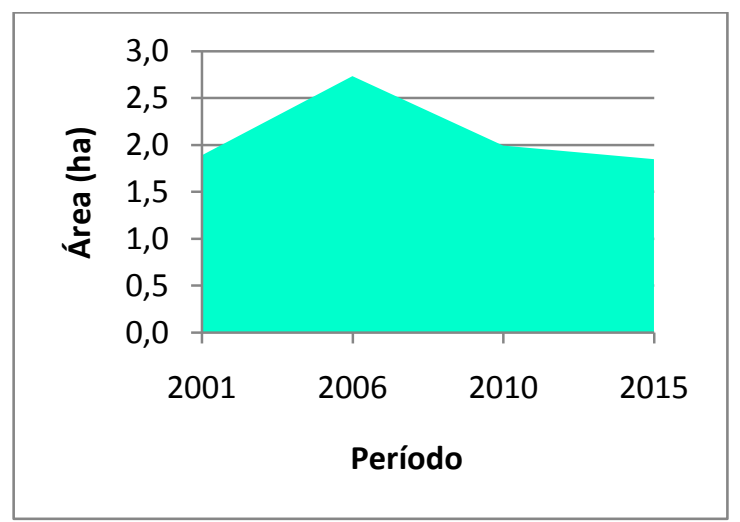

Figura 92 - Clareira 3JI0003

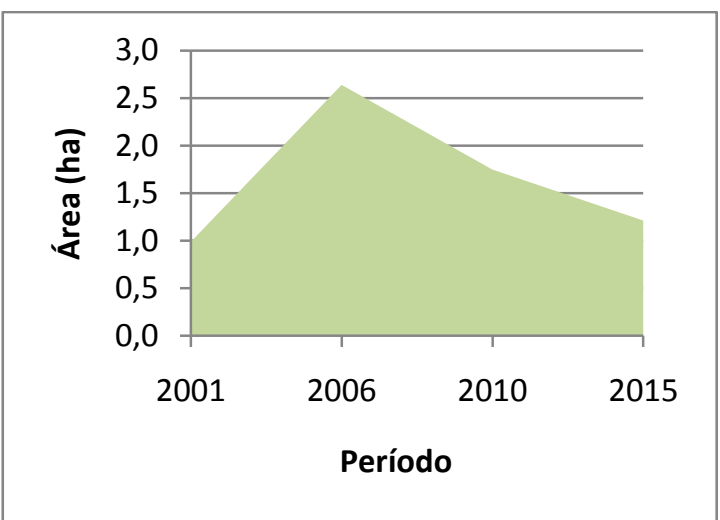

Figura 87 - Clareira 3IP0002

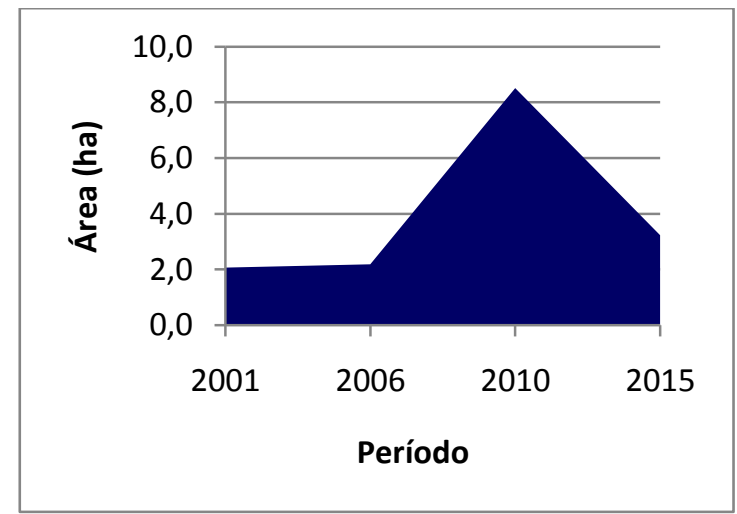

Figura 89 - Clareira 3JR0004

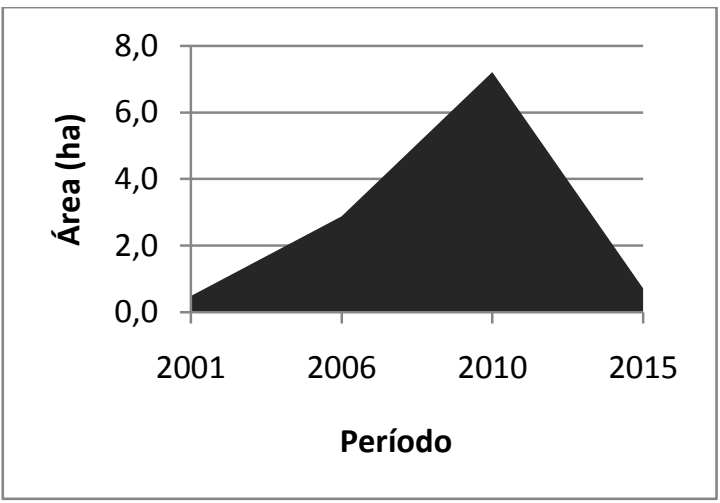

Figura 91 - Clareira 3JI0002

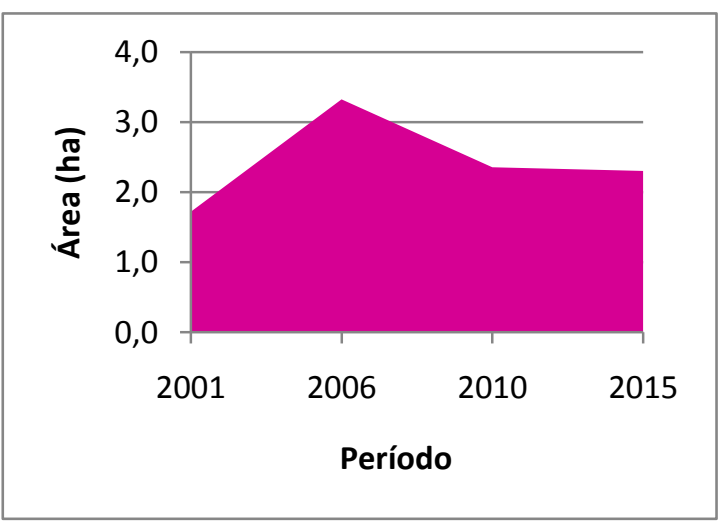

Figura 93 - Clareira 1JI0001 


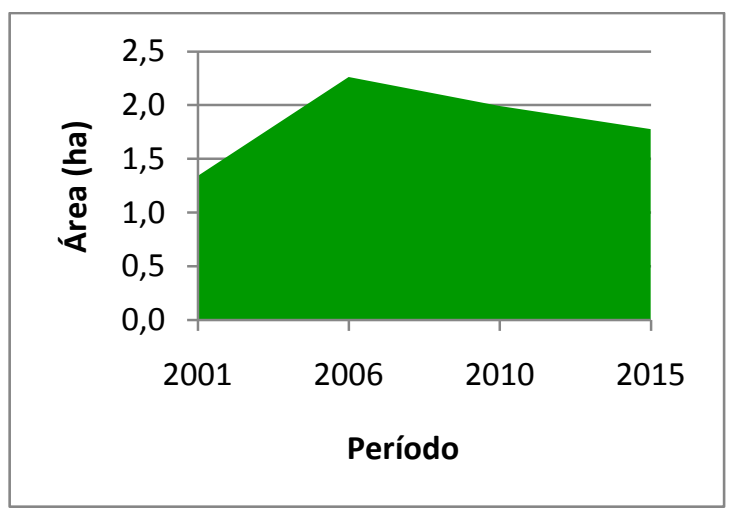

Figura 94 - Clareira 3JR0002

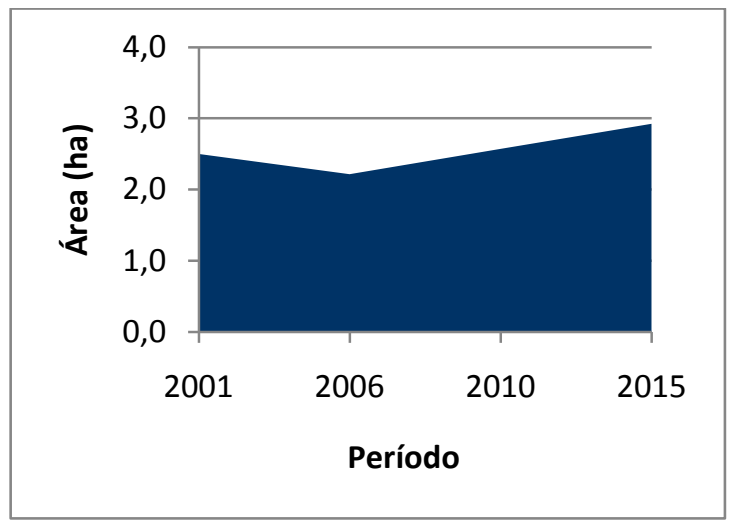

Figura 96 - Clareira 1JR0001

Além das condições ambientais, os métodos de manejo utilizados na recuperação das áreas também podem comprometer muito os resultados, pois devem seguir corretamente as instruções técnicas recomendadas nos PRADs. Nascimento (2009) observou problemas no processo de adubação das clareiras de Urucu, por falta de acompanhamento técnico durante a aplicação nas áreas e devido há falhas na contratação quantitativa do produto pelas prestadoras do serviço. Outro fator crítico é o emprego da técnica de regeneração natural assistida, indicada em áreas onde a sucessão natural já está em progresso, o que não é o caso das áreas degradadas de Urucu.

A segunda parte dos resultados sobre a Bacia Sedimentar do Solimões tratou dos Blocos de Exploração e Produção (BEP) e demonstrou o crescimento multitemporal do número total de clareiras considerando somente as áreas ativas. A Tabela 07 apresenta o desenvolvimento multitemporal do número de clareiras ativas.

Tabela 7 - Desenvolvimento multitemporal do número de clareiras ativas

\begin{tabular}{c|c|c}
\hline Períodos & No. Clareiras & Total de Clareiras \\
\hline $1970-1979$ & 1 & \\
\hline $1980-1989$ & 22 & \multirow{2}{*}{$\mathbf{1 2 3}$} \\
\hline $1990-1999$ & 42 & \\
\hline $2000-2009$ & 21 & \\
\hline $2010-2015$ & 37 & \\
\hline
\end{tabular}


O número de clareiras apresentou um crescimento contínuo no decorrer dos anos, sendo que das 123 áreas, 58 referem-se àquelas concluídas após o ano 2000, isto corresponde a um percentual de 47,2\%, ou seja, duplicou-se o número de clareiras nos últimos quinze anos. Vale, ainda, destacar que das 123 áreas, 37 foram abertas somente no período entre 2010 e 2015, o que representa $30 \%$ do número total de clareiras abertas desde a década de 80. Conforme demonstrado na Figura 97.

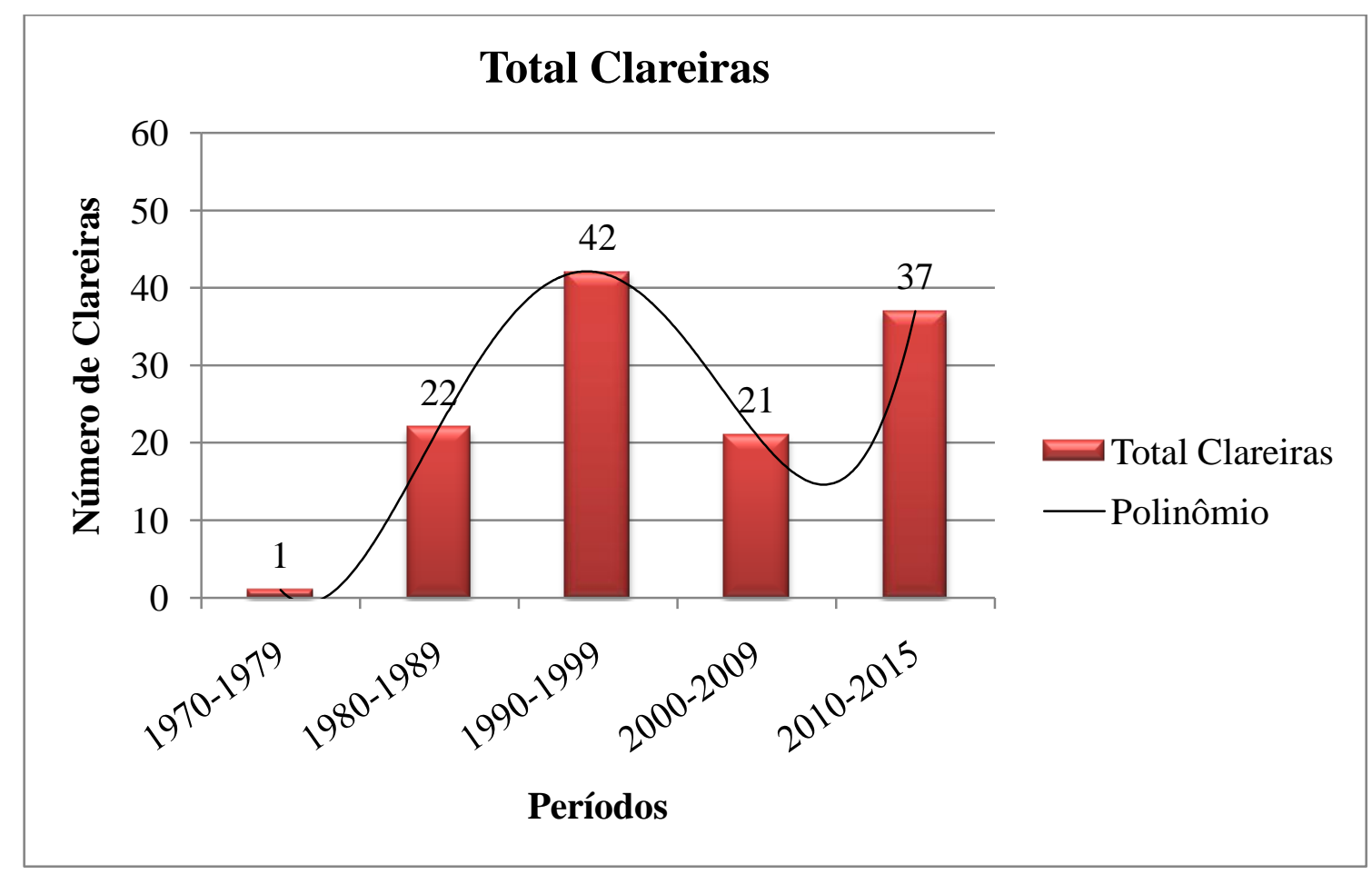

Figura 97 - Número de Clareiras Ativas

Tendo em vista o início da operação do poliduto Urucu-Coari (final da década de 90) e, principalmente, a inauguração do gasoduto Coari-Manaus (final do ano de 2009), o aumento dessas clareiras se tornou uma tendência estabelecida devido à busca contínua por novos poços produtores de petróleo e gás natural. Logo, seguindo o comportamento encontrado na análise da série histórica, haverá um crescimento exponencial das frentes de desmatamento e o aumento das áreas degradadas.

$\mathrm{Na}$ Bacia Sedimentar do Amazonas existe uma situação de desmatamento peculiar, que a difere da Bacia do Solimões, devido a sua proximidade com núcleos urbanos. Portanto, existem diversos tipos de uso e ocupação do solo visíveis nas margens dos rios Amazonas e Uatumã. Esse fato descaracteriza a geometria das clareiras, tornando-as irregulares e impossibilitando o reconhecimento das áreas dos poços por meio da forma geométrica com base em imagens de satélite. 
Dessa maneira, apesar do classificador SAM ter identificado as áreas degradadas, foi necessária uma informação complementar como referência para a localização das clareiras da Petrobras. Por isso, foram utilizadas as coordenadas geográficas dos poços disponibilizadas pelo BDEP (ANP), que permitiram definir precisamente os locais para a análise da área de desmatamento e do crescimento do número de poços, nos quatro períodos determinados. As figuras 98 a 100 ilustram um detalhe dessa área de estudo, mostrando o uso e ocupação humana.

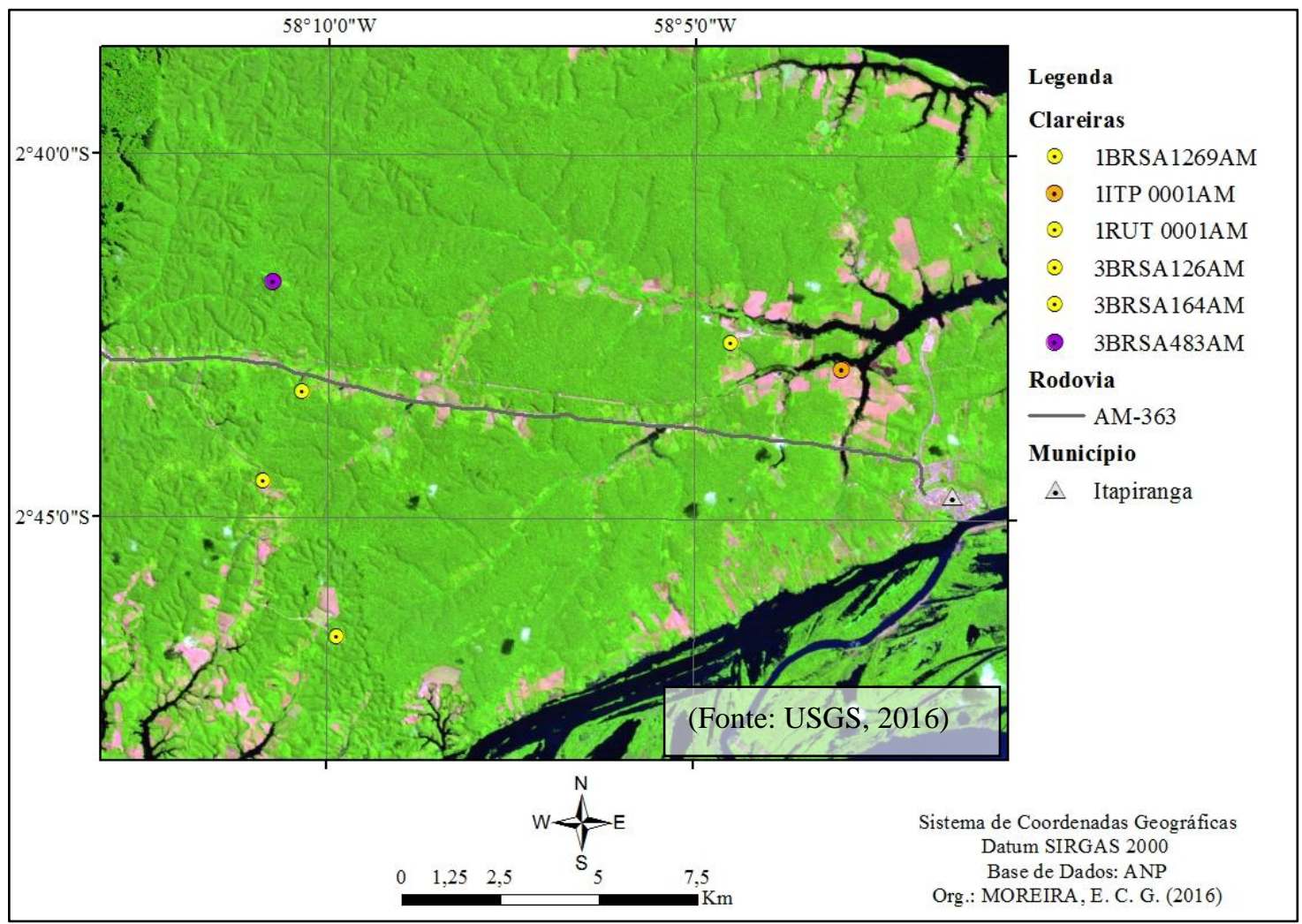

Figura 98 - Aproximação das clareiras do Bloco do Amazonas

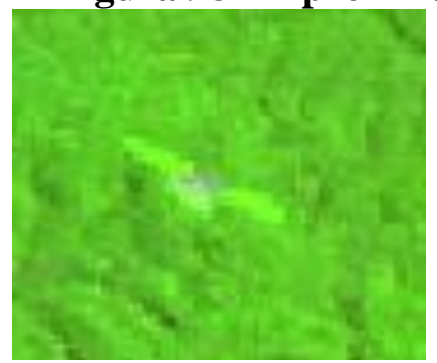

Figura 99 - Zoom Clareira BRSA483

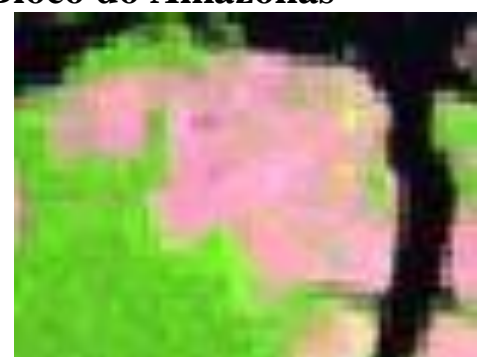

As áreas de legenda amarela são exemplos comuns da irregularidade das clareiras presentes nas áreas dos Blocos do Amazonas, a legenda em laranja destaca uma clareira com área muito superior a média e a legenda em roxo representa um exemplo da geometria regular das clareiras encontradas na Bacia do Solimões. Com isso foi encontrado um total de 13 clareiras distribuídas nos Blocos de Exploração, Produção e Devolvidos. Destas apenas duas ainda estão ativas (em Bloco de Produção) e as 
restantes estão não-ativas (em Blocos de Exploração e Devolvidos), como demonstradas na Figura 101.

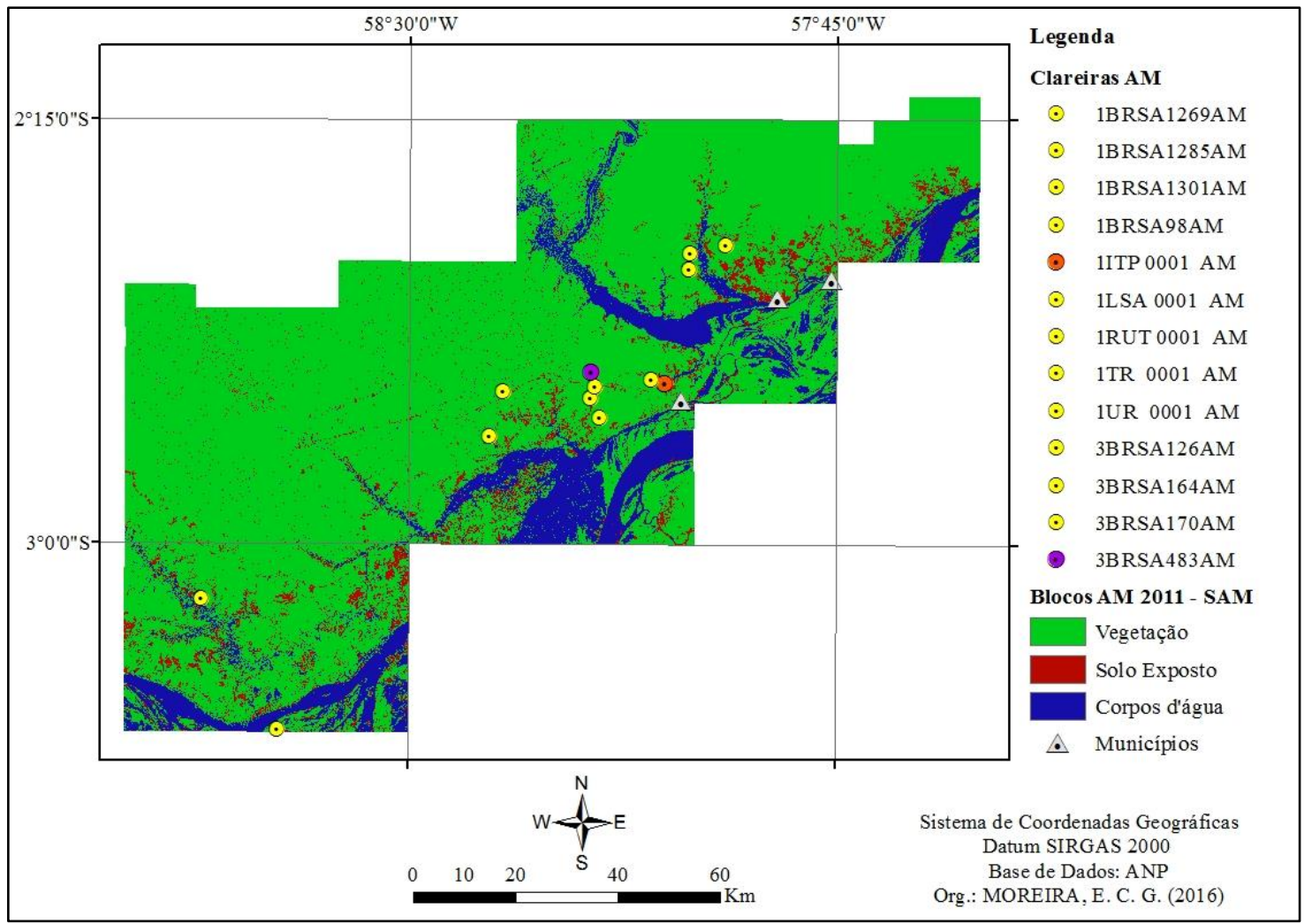

Figura 101 - Blocos da área de estudo da Bacia do Amazonas

A figura 101 é o resultado de uma classificação SAM, single angle, do ano de 2011, com coeficiente angular de 0.31 , usando ROIs como referência espectral. A tabela 08 demonstra as áreas, em hectare, encontradas para as 13 clareiras presentes nos Blocos de Exploração, Produção e Devolvidos, nos quatro períodos analisados.

Tabela 8 - Total de Clareiras na Bacia Sedimentar do Amazonas

\begin{tabular}{c|l|c|c|r|r|r|r}
\hline \multirow{2}{*}{ No. } & \multirow{2}{*}{ Clareira } & \multirow{2}{*}{ Conclusão } & \multirow{2}{*}{ Situação } & \multicolumn{4}{|c}{ Área (ha) } \\
\cline { 6 - 8 } & & & $\mathbf{1 9 9 9}$ & $\mathbf{2 0 0 6}$ & $\mathbf{2 0 1 1}$ & $\mathbf{2 0 1 5}$ \\
\hline $\mathbf{1}$ & 1BRSA1285 & 2015 & Abandonado & & & & 3,67 \\
\hline $\mathbf{2}$ & 1BRSA1301 & 2015 & Abandonado & & & & 3,40 \\
\hline $\mathbf{3}$ & 1BRSA1269 & 2014 & Abandonado & & & & 5,25 \\
\hline $\mathbf{4}$ & 3BRSA483 & 2007 & Abandonado & & & 0,49 & 0,18 \\
\hline $\mathbf{5}$ & 3BRSA170 & 2002 & Equipado & & 45,79 & 51,22 & 59,63 \\
\hline $\mathbf{6}$ & 3BRSA126 & 2002 & Abandonado & & 7,00 & 0,40 & 0,71 \\
\hline $\mathbf{7}$ & 3BRSA164 & 2002 & Abandonado & & 2,11 & 1,75 & 0,71 \\
\hline $\mathbf{8}$ & 1BRSA98 & 2001 & Equipado & & 2,47 & 4,07 & 2,76 \\
\hline $\mathbf{9}$ & 1ITP 0001 & 1999 & Arrazado & 61,59 & 63,98 & 61,64 & 46,32 \\
\hline $\mathbf{1 0}$ & 1RUT 0001 & 1999 & Abandonado & 4,21 & 8,67 & 8,88 & 2,21 \\
\hline $\mathbf{1 1}$ & 1UR 0001 & 1998 & Arrazado & 32,7 & 23,99 & 8,46 & 14,50 \\
\hline $\mathbf{1 2}$ & 1LSA 0001 & 1998 & Arrazado & 4,12 & 0,62 & & \\
\hline $\mathbf{1 3}$ & 1TR 0001 & 1957 & Arrazado & 2,20 & & & \\
\hline
\end{tabular}


Os dados das áreas das clareiras desativadas não demonstraram um padrão de recuperação vegetal no passar dos anos. Destacando o caso das clareiras 1ITP/ 1RUT e 1UR, que são áreas antigas e até hoje não conseguiram se recuperar. Ao se observar o caso da área 1ITP, detentora da maior área desmatada deste estudo, a revegetação recuperou apenas 25\%, enquanto em 1RUT a regeneração da área atingiu $48 \%$ e em 1UR, apresentou a melhor resposta com uma recuperação de 55\% da clareira. As figuras 102 a 104 ilustram o desenvolvimento das clareiras nos períodos.

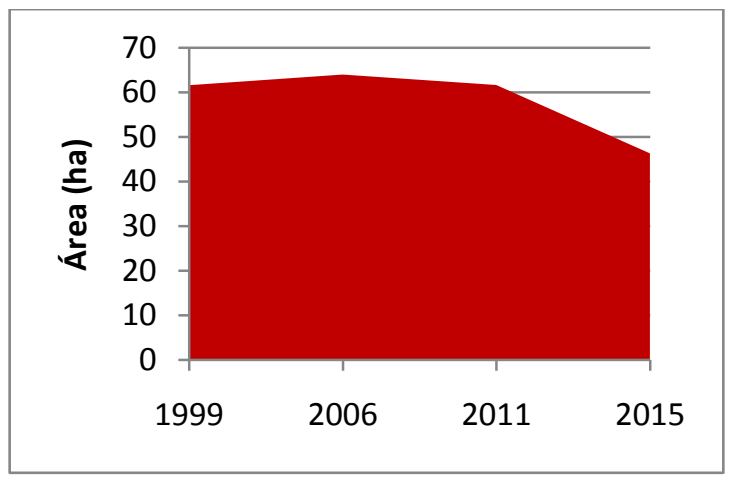

Figura 102 - Clareira 1ITP0001

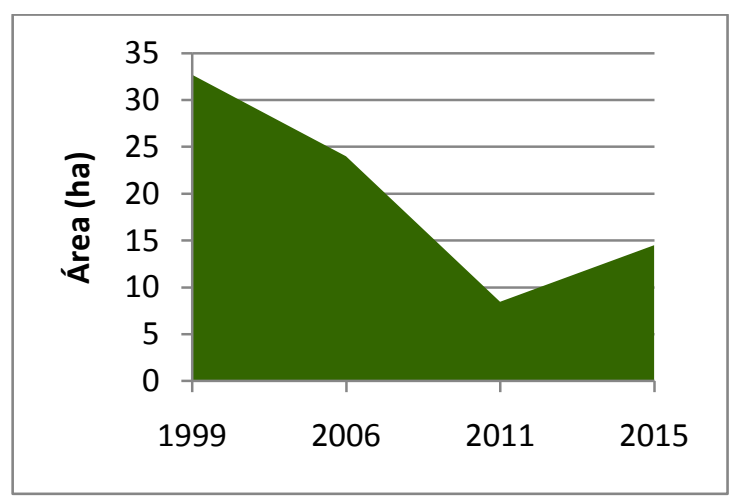

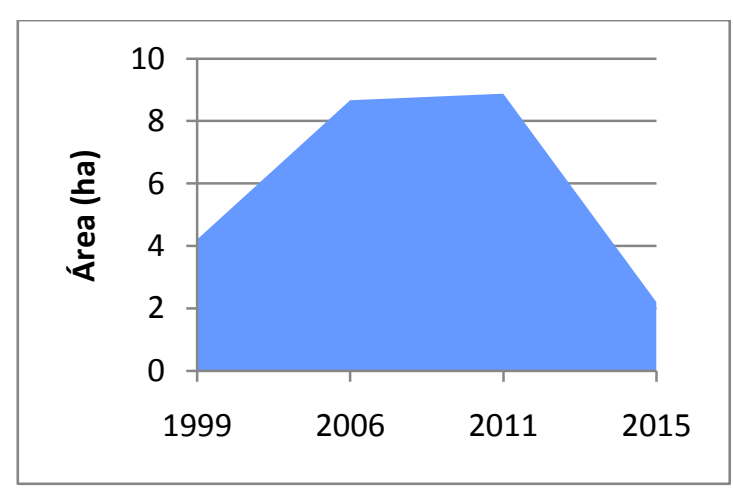

Figura 103 - Clareira 1RUT0001

\section{Figura 104 - Clareira 1UR0001}

As circunstâncias em que se encontram essas locações inserem alguns fatores subjetivos à análise, pois seria necessário saber se após a execução do PRAD a clareira foi integralmente devolvida ao ambiente e está isenta de atividades antrópicas, ou, se está havendo um uso passivo por terceiros, como alguma atividade de transbordo ou o transporte fluvial de pessoas.

Por outro lado na Bacia do Amazonas encontramos dois casos de regeneração completa de clareiras: 1LSA e 1TR. Trata-se de áreas antigas, mas que a partir do ano de 2011deixaram completamente de ser identificadas com o classificador SAM. Vale observar que a área 1LSA localiza-se em região inundável e a clareira 1TR possui acesso viário, situações que poderiam ter contribuído para sua regeneração. 
O resultado do processamento digital das imagens dos dois Blocos de Concessão (Solimões e Amazonas) encontrou um total de 88 clareiras na área da pesquisa, até o ano de 2015, que representam uma área degradada de 224,55 ha. Desse total 161,52 ha correspondem ao desmatamento realizado na Bacia do Solimões, onde as análises realizadas entre 2001 e 2015, mostraram que apenas 39,7\% dessa área foi revegetada.

A área degradada, gerada pelo extrativismo da Petrobras na Amazônia, demonstrou um percentual de recuperação muito baixo, mesmo após a execução dos PRADs. Esse é um fator importante de ser analisado antes da autorização de desmatamento, pois demonstra que as condicionantes de remediação ambiental não estão conseguindo reduzir o impacto ocasionado e um passivo ambiental muito sério está sendo deixado pra trás.

Considerando as áreas degradadas e a ineficácia dos PRADs, vale observar que, os impactos ambientais passam a ter uma tendência de aumento, com caráter contínuo e prolongado. Portanto, sobram passivos ambientais aos rios, por meio do assoreamento provocado pelo carreamento de sedimentos das clareiras; aos solos, por meio da erosão progressiva e perda potencial de nutrientes, além da perda da biodiversidade.

Nascimento (2009) fez uma estimativa que mais de 170.000 toneladas de terra foram transportadas para os canais fluviais e para a floresta, ao redor das 39 áreas degradadas de sua pesquisa. A radiação solar atinge diretamente a superfície que absorve a energia luminosa e a transforma em energia térmica. Limitando, assim, a redução da temperatura e o aumento da umidade relativa do ar, característicos das áreas internas da floresta. Menezes (2012) complementa que essas alterações causam a redução da retenção de água pelo solo, alterando a capacidade de sustentar a vida vegetal e animal no ambiente, acompanhado pela erosão.

Grime (1977) relatou que a erosão provoca o rebaixamento da superfície do terreno, deixando as raízes das plantas expostas e comprometendo sua estabilidade. Com isso, o escoamento difuso carreia os escassos nutrientes da superfície causando assoreamentos de cursos fluviais, soterrando plantas em áreas de deposição e gerando alagamentos. Arruda (2005) e Teixeira et al. (2006) demonstraram que as áreas submetidas a exploração petrolífera tem uma alta redução da circulação vertical da água no perfil do solo, potencializando a erodibilidade e o carreamento de sedimentos.

Nascimento (2009) aponta a perda da biodiversidade devido ao alastramento de espécies invasoras, muitas vezes exóticas, que foram introduzidas por hidrossemeadura para conter taludes e processos erosivos, relatando a ocorrência dessa invasão até 
mesmo em áreas isoladas. Menezes (2011) encontrou vários espécimes vegetais ameaçados, inclusive espécies protegidas por lei, como a castanheira, a sucupira e o pau rosa, devido os efeitos da compactação do solo. E a biodiversidade faunística sofreu alterações em seu número, pois existem espécies mais sensíveis a presença do homem, que sofrem maior diminuição, enquanto os animais mais tolerantes se sobressaem.

\subsubsection{Qualidade de Dados}

Os resultados das classificações realizadas com o algoritmo SAM passaram por uma avaliação da precisão temática por meio da aplicação da matriz de erros, com a qual foram geradas as medidas descritivas da Exatidão Global, Exatidão do Produtor, Exatidão do Usuário e o Índice Kappa. Dessa forma, foram geradas oito matrizes e suas medidas descritivas, uma para cada ano e para cada área. $\mathrm{O}$ resultado geral mostrou valores mais altos para as classificações realizadas na Bacia Sedimentar do Amazonas, enquanto a área do Solimões teve casos menos exatos. A tabela 09 apresenta a matriz de erros do ano de 2015 da classificação SAM aplicada nos blocos do Solimões.

Tabela 9 - Matriz de Confusão - Bloco do Solimões 2015

\begin{tabular}{l|rrrrr}
\hline \multirow{2}{*}{ Classificação } & \multicolumn{5}{|c}{ Verdade Terrestre (pixel) } \\
\cline { 2 - 7 } & Asfalto & $\begin{array}{c}\text { Solo } \\
\text { Exposto }\end{array}$ & $\begin{array}{c}\text { Corpo } \\
\text { d'água }\end{array}$ & Vegetação & Total \\
\hline Não-classificados & 0 & 16 & 109 & 0 & $\mathbf{1 2 5}$ \\
Asfalto & $\mathbf{5 4 3}$ & 299 & 32 & 0 & $\mathbf{8 7 4}$ \\
Solo Exposto & 18 & $\mathbf{2 2 7}$ & 0 & 0 & $\mathbf{2 4 5}$ \\
Corpo d'água & 0 & 0 & $\mathbf{2 6 9}$ & 0 & $\mathbf{2 6 9}$ \\
Vegetação & 73 & 95 & 350 & $\mathbf{6 7 0 7}$ & $\mathbf{7 2 2 5}$ \\
Total & $\mathbf{6 3 4}$ & $\mathbf{6 3 7}$ & $\mathbf{7 6 0}$ & $\mathbf{6 7 0 7}$ & $\mathbf{8 7 3 8}$ \\
\hline
\end{tabular}

Na tabela 09 a exatidão global foi $88,6 \%$ e seu índice Kappa teve $0,67 \%$, o que demonstra uma concordância muito boa (Landis \& Koch, 1977). O índice Kappa teve um resultado um pouco inferior à exatidão global devido à retirada de alguma casualidade da classificação. O resultado da exatidão do produtor mostrou uma qualidade de classificação mais baixa, devido ao pequeno valor percentual na classe de solo exposto. Isso denota a confusão resultante da mistura espectral com a classe asfalto, na qual se pode notar um elevado erro de omissão (299). A tabela 10, abaixo, demonstra os resultados da exatidão do produtor e do usuário para este caso. 
Tabela 10 - Exatidão do Produtor/ Exatidão do Usuário - Solimões 2015

\begin{tabular}{l|rr|rr}
\hline \multirow{2}{*}{ Classes } & \multicolumn{2}{|c|}{ Exatidão Produtor } & \multicolumn{2}{c}{ Exatidão Usuário } \\
\cline { 2 - 5 } & Pixels & $(\boldsymbol{\%})$ & Pixels & $(\boldsymbol{\%})$ \\
\hline Asfalto & $543 / 634$ & $\mathbf{8 5 , 6}$ & $543 / 874$ & $\mathbf{6 2 , 1}$ \\
Solo Exposto & $227 / 637$ & $\mathbf{3 5 , 6}$ & $227 / 245$ & $\mathbf{9 2 , 6}$ \\
Corpo d'água & $269 / 760$ & $\mathbf{3 5 , 4}$ & $269 / 269$ & $\mathbf{1 0 0 , 0}$ \\
Vegetação & $6707 / 6707$ & $\mathbf{1 0 0 , 0}$ & $6707 / 7225$ & $\mathbf{9 2 , 8}$ \\
\hline
\end{tabular}

Embora os valores encontrados com o índice Kappa, nos blocos do Solimões, tenham todos se enquadrado na categoria "muito bom", segundo o desempenho proposto por Landis \& Koch (1977), as classificações feitas com as imagens da Bacia Sedimentar do Amazonas alcançaram uma média da exatidão global, do produtor, do usuário e do índice Kappa normalmente mais altas do que os resultados advindos da Bacia Sedimentar Solimões. A tabela 11 apresenta a matriz de erros do ano de 2015 da classificação SAM aplicada na Bacia Sedimentar do Amazonas.

Tabela 11 - Matriz de Confusão - Bloco do Amazonas 2015

\begin{tabular}{l|rrrrrr}
\hline \multirow{2}{*}{ Classificação } & \multicolumn{5}{c}{ Verdade Terrestre (pixel) } \\
\cline { 2 - 6 } & Vegetação & $\begin{array}{c}\text { Solo } \\
\text { Exposto }\end{array}$ & $\begin{array}{c}\text { Massas } \\
\text { d'água1 }\end{array}$ & $\begin{array}{c}\text { Massas } \\
\text { d'água2 }\end{array}$ & Total \\
\hline Não-classificados & 0 & 0 & 0 & 0 & $\mathbf{0}$ \\
Vegetação & 10042 & 39 & 0 & 0 & $\mathbf{1 0 0 8 1}$ \\
Solo Exposto & 0 & 978 & 0 & 0 & $\mathbf{9 7 8}$ \\
Corpo d'água1 & 0 & 0 & $\mathbf{2 5 5 1}$ & 0 & $\mathbf{2 5 5 1}$ \\
Corpo d'água2 & 0 & 0 & 0 & $\mathbf{2 0 6 0}$ & $\mathbf{2 0 6 0}$ \\
Total & $\mathbf{1 0 0 4 2}$ & $\mathbf{1 0 1 7}$ & $\mathbf{2 5 5 1}$ & $\mathbf{2 0 6 0}$ & $\mathbf{1 5 6 7 0}$ \\
\hline
\end{tabular}

Nesse exemplo a exatidão global foi de $99,7 \%$ e seu índice Kappa teve 0,99, portanto, segundo a classificação de desempenho proposta por Landis \& Koch (1977) a qualidade do mapa temático foi "excelente". Consequentemente, as medidas de Exatidão do Produtor e do Usuário, também, apresentaram valores bastante elevados, denotando uma alta qualidade da classificação e grande probabilidade dos pixels representarem fidedignamente suas respectivas classes. Como apresentado na tabela 12. 
Tabela 12 - Exatidão do Produtor/ Exatidão do Usuário - Amazonas 2015

\begin{tabular}{l|rr|rr}
\hline \multirow{2}{*}{ Classes } & \multicolumn{2}{|c|}{ Exatidão Produtor } & \multicolumn{2}{c}{ Exatidão Usuário } \\
\cline { 2 - 5 } & \multicolumn{1}{|c|}{ Pixels } & $(\boldsymbol{\%})$ & \multicolumn{1}{c}{ Pixels } & \multicolumn{1}{c}{$(\boldsymbol{\%})$} \\
\hline Vegetação & $10042 / 10042$ & $\mathbf{1 0 0 , 0}$ & $10042 / 10081$ & $\mathbf{9 9 , 6}$ \\
Solo Exposto & $978 / 1017$ & $\mathbf{9 6 , 2}$ & $978 / 978$ & $\mathbf{1 0 0 , 0}$ \\
Corpo d'água1 & $2551 / 2551$ & $\mathbf{1 0 0 , 0}$ & $2551 / 2551$ & $\mathbf{1 0 0 , 0}$ \\
Corpo d'água2 & $2060 / 2060$ & $\mathbf{1 0 0 , 0}$ & $2060 / 2060$ & $\mathbf{1 0 0 , 0}$ \\
\hline
\end{tabular}

A metodologia aplicada possui um embasamento teórico reconhecido e os resultados da classificação SAM, single angle, foram analisados para a determinação da acurácia, com a aplicação de matrizes de confusão, exatidão global, exatidão do produtor e índice Kappa, para validação da precisão. Outros autores já vêm utilizando esses métodos estatísticos, obtendo resultados significativos na avaliação da classificação de imagens orbitais, como GONG \& HOWARTH (1989), que descreveram um método para avaliação da efetividade em diferentes combinações de feições e estratégias de treinamento. Neste estudo a qualidade dos dados classificados obteve resultados que variaram de muito bons a excelentes, segundo a categorização proposta por LANDIS \& KOCH (1977). Situação que reforça a importância de sua aplicação em estudos multitemporais de vegetação, com imagens de média resolução (Landsat). 


\section{CONCLUSÃO}

Os testes realizados com o classificador SFF demonstraram bom delineamento das áreas de 'corte raso' presentes nas clareiras de exploração, denotando um nível inicial de revegetação. Entretanto as áreas de solo exposto não foram classificadas. Enquanto as classificações realizadas com o SAM apresentaram limitações no delineamento da feição de 'corte raso', decorrentes da semelhança entre as assinaturas espectrais, que reduziram a precisão do classificador. Contudo obtiveram boa discretização das áreas de solo exposto, viabilizando a quantificação da área degradada.

$\mathrm{O}$ aumento do número de novas clareiras demonstra a importância do acompanhamento das intervenções geradas ao meio ambiente, para garantir o controle da recuperação das áreas degradadas. Haja vista a ineficácia demonstrada pelos PRADs é preciso se restringir a concessão de novas autorizações de desmatamento, de modo a se reverter este cenário ou cessar as atividades de exploração.

O desmatamento para abertura de clareiras, na maioria dos casos, possui um isolamento limitante na manutenção dos PRADs. O encerramento da atividade local imputa a desmobilização da infra-estrutura e a execução de ações de recuperação. Entretanto, quando se tratam de áreas remotas, com acesso exclusivo via fluvial ou aérea, o retorno para as atividades de manutenção do PRAD (aceiro, replantio de mudas, remoção de pragas, entre outros) fica seriamente comprometido, além de muito dispendioso e moroso, ainda se torna inacessível. Visto que com a retirada das infraestruturas, ocorre a remoção dos heliportos e dos portos.

A aplicação do modelo linear de mistura espectral e a classificação de imagens orbitais se mostraram ferramentas extremamente importantes para auxiliar no monitoramento das alterações impostas à floresta amazônica. O sensoriamento remoto permite a análise de áreas extensas, muitas vezes isoladas e de difícil acesso, promovendo as informações necessárias sobre o desenvolvimento da recuperação das clareiras e alertando sobre a necessidade de ações de apoio ao manejo para a manutenção dos resultados.

Outrossim, os resultados multitemporais foram capazes de demonstrar o desenvolvimento dos PRADs, apontando uma revegetação diminuta, com áreas de solo exposto atingindo um total de 224,55ha, evidenciando a ineficácia dos programas de recuperação e a necessidade de reavaliação da conduta para a exploração mineral e desmatamento na Amazônia. 
A realização da metodologia definida neste estudo e a análise dos resultados alcançados sugeriram algumas recomendações para trabalhos futuros:

A) O tempo de resposta do monitoramento ambiental do desmatamento na Amazônia requer um sensor com melhor resolução temporal, com um período menor de revisita, permitindo um acompanhamento mais próximo das intervenções geradas na floresta. E a avaliação dos estágios de sucessão vegetal precisa de um sensor com melhor resolução espacial e espectral, para aprimorar os resultados das análises e embasar a tomada de ações mais adequada.

B) O monitoramento do crescimento do número de clareiras perante o desenvolvimento dos PRADs deve constituir os parâmetros para fins de licenciamento ambiental, de modo a nortear a concessão de novas autorizações de desmatamento mediante a comprovação dos resultados de revegetação.

C) O desmatamento provocado pela exploração de petróleo e gás natural na Amazônia não acontece nas bordas da floresta ou nas margens dos municípios, pelo contrário, tem caráter interno e em regiões de difícil acesso, isso aumenta a fragmentação da floresta, que somando ao desmatamento marginal, amplia os impactos ambientais à fauna e a flora, além de criar diversas áreas inertes no interior do bioma. 


\section{REFERÊNCIAS BIBLIOGRÁFICAS}

ALMEIDA, W. S.; SOUZA, N. M. Coari: Petróleo e Sustentabilidade - um exemplo amazônico. Desenvolvimento e Meio Ambiente. n. 17, p. 69-92. Editora UFPR. 2008.

ALVARENGA, B. S. et al. Avaliação de técnicas de processamento digital de imagens para a estimativa de áreas de arroz irrigado: um estudo de caso no município de Santa Vitória do Palmar/RS. In: Anais XII Simpósio Brasileiro de Sensoriamento Remoto, Goiânia, Brasil. 2005. INPE, p. 3961-3966.

ALVES, D. S. Space-time dynamics of deforestation in Brazilian Amazônia. International Journal of Remote Sensing. 2001.

ANP. Brasil Rounds: Licitações de Petróleo e Gás Natural. Superintendência de Promoção de Licitações - SPL. Mapas de Concessões: Blocos Atualmente sob Concessão. Disponível em: <http://www.brasilrounds.gov.br/portugues/mapas_de_concessoes.asp>. Acesso em: 06/11/2014.

ARRUDA, W. C. Estimativa dos processos erosivos na base de operações geólogo Pedro de Moura Urucu - Coari - AM. Dissertação de Mestrado. Universidade Federal do Amazonas/Faculdade de Ciências Agrárias Manaus AM. 2005. 80pp.

ASNER, G.P. Cloud cover in Landsat observations of Brasilian Amazon. International Journal Remote Sensing 22. 2001. p.3855 - 3862.

BAKER, H.G. Some aspects of the natural history of seed Banks. Ecology of soil seed banks. In Ecology of soil seed banks. Leck. New York: Academic Press. 1989. p. 9-21

BARATA, C.F.; CAPUTO, M.V. 2007. Geologia do petróleo da bacia do Solimões. O "estado da arte". $4^{\circ}$. PDPETRO, Campinas, SP. Disponível em: <http://www.portalabpg.org.br/PDPetro/4/resumos/4PDPETRO110147-1.pdf.>.

Acesso em: 25/11/2014.

BAPTISTA, G. M. de M. Identificação de áreas degradadas e seus impactos ambientais, por meio do sensoriamento remoto. 1 ed. Brasília: Editora Universa. 2003. v. 1. 42p.

BAPTISTA, G. M. de M. Processamento de Dados Hiperespectrais. In: MENESES, P. R. \& ALMEIDA T. (Org.) Introdução ao processamento de imagens de sensoriamento remoto. Universidade de Brasília - UnB. Brasília: CNPq, 2012. cap. 13. pp. 221 a 238.

BARBOSA, C. C. F. Sensoriamento remoto da dinâmica de circulação da água do sistema planície de Curai/Rio Amazonas. Tese (Doutorado em Sensoriamento Remoto), INPE - Instituto Nacional de Pesquisas Espaciais, São José dos Campos, 2005. 
BIAS, E. S.; RAMOS, L. F.; RIBEIRO, C. J. R. Desenvolvimento de uma metodologia para mapeamento das matas de galeria no estado de Goiás - Brasil, com o uso de ferramentas de processamento digital de imagens - PDI. In: VI Seminário Latino Americano de Geografia Física e II Seminário Ibero Americano de Geografia Física. Universidade de Coimbra. Portugal. 2010.

BIAS, E. S.; BARBOSA, F. L. R. Aplicação do Modelo Linear de Mistura Espectral para Análise dos tipos de Água no Lago Paranoá, Brasília - DF. Anais XV Simpósio Brasileiro de Sensoriamento Remoto - SBSR, Curitiba-PR. INPE. 2011. p.760.

BISHOP, Y., S. Fienberg, and P. Holland. Discrete Multivariate Analysis: Theory and Practice. MIT Press, Cambridge, MA. 1975. 575 p.

BOARDMAN, J. W. \& KRUSE, F. A. Automated spectral analysis: A geologic example using AVIRIS data, north Grapevine Mountains, Nevada: In, ERIM Tenth Thematic Conference on Geologic Remote Sensing, 10, Environmental Research Institute of Michigan, Ann Arbor, MI. Proceedings. v. 1. (1994). p. 407-418.

BOARDMAN, J. W.; KRUSE, F. A.; GREEN, R. O. Mapping targets signatures via partial unmixing of AVIRIS data. In: JPL Airbone Geoscience Workshop 5, Pasadena, 1995.

BRITES, R.S.; SOARES, P.S.; RIBEIRO, C. A. A. S. Comparação de desempenho entre três índices de exatidão aplicados a classificação de imagens orbitais. In: Anais Simpósio Brasileiro de Sensoriamento Remoto, 8, Salvador: INPE, 1996.

CAMPBELL, J. B.; Introduction to remote sensing. New York, The Guilford Press, 1987. 551p.

CARVAlHO, A. P. F. et al. Metodologia para Análise de Mistura Espectral em Imagens TM-Landsat. In: Anais do X Simpósio Brasileiro de Sensoriamento Remoto - SBSR, Foz do Iguaçu/PR. 2001. INPE. p. 1531-1538.

CARVALHO JR., O. A.; MENEZES, P. R. Spectral Correlation Mapper (SCM): an improving Spectral Angle Mapper (SAM,). In: Nineth JPL Airborne Earth Science Workshop. 2000.

CARVALHO JUNIOR, O. A. C. Processamento digital de imagens hiperespectrais pelo método Multiple Endmember Spectral Mixture Models (MESMA) para análise da vegetação. In: Anais XI do Simpósio Brasileiro de Sensoriamento Remoto - SBSR. Belo Horizonte, 2003a. p. 1053-1060.

CARVALHO JUNIOR, O. A. et al. Mistura Espectral (I): Detecção dos membros finais utilizando a geometria do Simplex.Instituto Nacional de Pesquisas Espaciais INPE. In: Espaço \& Geografia, volume 06. 2003b. p. 147-173. ISSN: 1516-9375. 
CARVALHO JUNIOR, O. A. et al. Mistura Espectral (II): Classificadores espectrais para identificação. Espaço Geografia, volume 6. 2003c. p. 175-197. ISSN: 1516-9375.

CARVALHO JUNIOR, O. A. et al. Classificação de padrões de vegetação na região de transição entre o cerrado e a floresta amazônica. Instituto Nacional de Pesquisas Espaciais, INPE. Anais XI SBSR. Belo Horizonte, 2003.

CATTANI, C. E. V. et al. Desempenho de algoritmos de classificação supervisionada para imagens dos satélites RapidEye. Anais XVI Simpósio Brasileiro de Sensoriamento Remoto - SBSR, Foz do Iguaçu-PR. INPE. 2013.

COHEN, J. A coefficient of agreement for nominal scales. Educational and Psychological Measurement. Vol. 20, No. 1. 1960. p. 37-40.

CONGALTON, R.G. A comparison of five sampling schemes used in assessing the accuracy of land cover/land use maps derived from remotely sensed data. Blacksburg, Virginia Politechnic Institute and State University. 1984. 146 p.

CONGALTON, R. A Review of Assessing the Accuracy of Classification Remotely Sensed Data. Remote Sensing of Environment, USA, No 37. 1991. p. 35-36.

CONGALTON, R. G.; GREEN, K. Assessing the Accuracy of Remotely Sensed Data: principles and practices. CRC Press, $2^{\text {nd }}$ edition. Florida. 2009. ISBN 978-1-4200-55122. p.105-127

CORRÊA, R. S. Recuperação de áreas degradadas pela mineração no cerrado: manual de revegetação. Universidade Católica de Brasília. Ecoa ambiental consultoria. Brasília. 2006.

COUTINHO, C. I. JABLONSK,I S. Diretrizes para Exploração, Produção e Transporte de Petróleo e Gás Natural na Amazônia. Especialistas em Regulação. Agência Nacional do Petróleo, Gás Natural e Biocombustíveis - ANP. 2009.

DEFRIES, R; et al. Earth observations for estimating greenhouse gas emissions from deforestation in developing countries. Environmental Science Policy. 2007. p.385- 394 .

DUDLEY, K. L. et al. A multitemporal spectral library approah for mapping vegetation species across spatial and temporal phenological gradients. Remote Sensing of Environment. Elsevier. US. 2015.

ENVI. Tutorial Institucional. Disponível em: <C:IProgram FilesไExelis\ENVI51 \classic help\ENVI3WHelp.htm>. Acesso em: 27/08/2015.

EPE. Zoneamento Nacional de Recursos de Petróleo e Gás Natural: Atualização 2011. Ministério de Minas e Energia. Empresa de Pesquisa Energética. Documento Digital. Disponível em: <http://www.epe.gov.br>. Acesso em: 06/11/2014. 
EPIPHÂNiO, J. C. N.; FORMAGGIO, A. R. Sensoriamento Remoto de três parâmetros agronômicos de trigo e de feijão. Pesquisa Agropecuária Brasileira, v. 26. 1991. p. 1615-1624.

EZAWA, H. K. H; LEAL FILHO, N.; SENA, J. S. Avaliação do processo sucessional nas áreas sob recuperação em Urucu - AM. II Workshop técnico científico da Rede CT Petro Amazônia. Manaus, 2006.

FINER, M. et al. Oil and gas projects in the western Amazon: threats to wilderners, biodiversity, and indigenous people. PlosOne. 3(8):e2932 1-9. Disponível em: $<$ http://www.plosone.org/article/info:doi\%2F10.1371\%2Fjournal.pone.0002932?fb_pag e_id=6425923706e $>$. Acessado em: 06/11/2014.

GARWOOD, N.C. Tropical soil seed bank: a review. In Leck, M.A.; Parker, T.V.; Simpson, R.L.; (Eds). Ecology of soil seed banks. Nova York: Academic Press. 1989. p. 149-209.

GATES, D. M. et al. Spectral properties of plants. Apllied Optics, v.4, n.1, 1965. p.11-20.

GLENN-LEWIN, D.C.; PEET, R.K.; VESBLEN, T.T. (eds.). Plant Succession: Theory and prediction. Chapman e Hall. London. 1993. p. 368.

GOCH, Y. G. F. Efeitos do assoreamento sobre a comunidade de peixes do rio Urucu. Tese de doutorado em Ecologia. Instituto Nacional de Pesquisas da Amazônia. Manaus, 2007.

GONG, P., HOWART, P.J. An assessment of some factors influencing multispectral land-cover classification. Photogrammetric Engineering and Remote Sensing. Bethesda, 1990. p.597-603.

GRIME, J. P. Evidence for the existence of three primary strategies in plants and its relevance to ecological and evolutionary theory. The American Naturalist. 1977.

HANSEN, M. C. et al. Humid tropical forest claring from 2000 to 2005 quantified by using multitemporal and multiresolution remotely sensed data. Proceedings of the National Academy of Science of the United States of America 15(27):94399444.2008.

IBGE. Site Institucional. Manual Técnico da Vegetação Brasileira. Instituto Brasileiro de Geografia e Estatística. Diretoria de Geociências. Coordenação de Recursos Naturais e Estudos Ambientais. 2a edição. ISBN 978-85-240-4272-2. Rio de Janeiro, RJ. 2012. pp.

IBGE. Mapas Temáticos. Gerência de Recursos Naturais da Unidade Estadual do IBGE em Goiás, Pará e Bahia. Instituto Brasileiro de Geografia e Estatística - IBGE. 2014. Site institucional. Disponível em: 〈http://mapas.ibge.gov.br/tematicos〉. Acesso em: 06/11/2014. 
IBGE. Sistema Geodésico Brasileiro. Site Institucional. Disponível em: <http://www.ibge.gov.br/home/geociencias/geodesia/pmrg/faq.shtm\#2>. Acesso em: 06/11/2014a.

INPE. Site Institucional. Disponível em:<www.inpe.br>. Acesso em: 06/11/2014.

IRONS, J. R.; Weismiller, R. A.; Petersen, G. W. Soil reflectance. In: Asrar, G. Theory and applications of optical remote sensing. New York: J. Wiley, 1989. cap. 3, p. 66106.

JENTSCH, A. The challenge to restore processes in face of nonlinear dynamics: on the crucial role of disturbance regime. Restoration Ecology 15(2):334 - 339. 2007.

KLECKA, W. R. Discriminant Analysis. SAGE Publications, Inc., BH, California, 1980. 71p.

KOPACKOVA, V. Using multiple spectral feature analysis for quantitative pH mapping in a mining environment. International Journal of Applied Earth Observation and Geoinformation 28. 2014. p. 28-42.

KRUSE, F. A. et al. The spectral image processing system (SIPS) - interactive visualization and analysis of imaging spectrometer data. Remote Sensing of Environment, v. 44, n. 2-3. 1993. p.145-163.

LANDIS, J. R.; KOCH, G. G. The measurement of observer agreement for categorical data. International Biometric Society. Disponível em: <www.jstor.org/stable2529310>. Acesso em: 29/06/2016.

LATORRE, M. et al. Correção Atmosférica: conceitos e fundamentos. Instituto de Estudos Avançados - CTA - Centro Técnico Aeroespacial. São José dos Campos, SP. In: Espaço \& Geografia, volume 5, 2002. p. 153-178. ISSN:1516-9375.

LAURENCE, W. F; ALBERNAZ, A. K. M; Da Costa, C. O desmatamento está se acelerando na Amazônia brasileira? Biotaneotropica. 2002. Disponível em: <http://www.biotaneotropica.org.br/v2n1>. Acesso em: 06/11/2014.

LEAL FILHO, N. Dinâmica inicial da regeneração de florestas exploradas na amazônia brasileira. Tese de doutorado. Curso de Pós-Graduação em Ecologia. IB/USP. São Paulo, SP. 2000.

LELMGRUBER, P; et al. Forest cover change patterns in Myanmar (Burma) 1990 - 2000. Environmental Conservation 32: 356 - 364.

LEVADA, A. L. M. Combinação de modelos de campos aleatórios markovianos para classificação contextual de imagens multiespectrais. Tese (Doutorado) Instituto de Física de São Carlos, Universidade de São Paulo, São Carlos, 2010. 146p 
LILLESAND, T. M.; KIEFER, R. W.; CHIPMAN. J. W. Remote sensing and image interpretation. 6. ed. New York: J. Wiley \& Sons, Inc. 2008. 772 p. ISBN 978-0-47005245-7.

LOEBMANN, D. G. et al. Mistura espectral de imagens LANDSAT para análise multitemporal de uso da terra nas diferentes unidades pedológicas da bacia do rio Jardim, DF. In: XII Simpósio Brasileiro de Sensoriamento Remoto - SBSR, Goiânia/GO. 2005. INPE. p. 557-564.

MA, Z.; REDMOND, R.L.. Tau coefficients for accuracy assessment of classification of remote sensing data. Photogrammetric Engineering and Remote Sensing, 61(4). 1995. p.453-439.

MAIA, M. A. M.; MARMOS, J. L.. Geodiversidade do Estado do Amazonas: Programa geologia do Brasil levantamento da geodiversidade. Ministério de Minas e Energia - Serviço Geológico do Brasil (CPRM). Manaus/AM. 2010.

MDB. Mapas de Brasil. Mapa Geológico do Brasil. Site institucional. Disponível em: <http://www.mapasdebrasil.com/205/mapas-de-brasil-2>. Acesso em: 06/11/2014.

MENESES, P. R. \& ALMEIDA T. Introdução ao processamento de imagens de sensoriamento remoto. Universidade de Brasília - UnB. Brasília: CNPq, 2012.

MENEZES, A. L. Gasoduto Urucu-Coari-Manaus: impacto ambiental e socioeconômico no município de Manacapuru/AM. Dissertação de Mestrado apresentada ao Departamento de Geografia da Universidade de São Paulo - USP. São Paulo, 2011. pp. 16-35.

MERONI, M. et al. Performance of Spectral Fitting Methods for vegetation fluorescence quantification. Remote Sensing of Environment 114. Amsterdã. 2010. p. 363-374.

MMA. Mapas de Cobertura Vegetal. Ministério do Meio Ambiente. Site Institucional disponível em: <www.mma.gov.br/estruturas/arquivos/mapas_cobertura_vegetal.pdf>. Acesso em: 06/11/2014.

MOLINARO, L. C. Função ecológica de espécies arbóreas (Vismia guianensis, Inga edulis e Inga sp.) na sucessão vegetal em áreas degradadas pela exploração petrolífera na região de Urucu (AM). Dissertação de mestrado. Instituto Nacional de Pesquisa da Amazônia - INPA/ Fundação Universidade do Estado do Amazonas. Manaus, AM. 2005.

MOREIRA, E. C. G. Análise multitemporal dos impactos do desmatamento na floresta amazônica decorrentes da exploração e produção de petróleo e gás natural. Dissertação $\mathrm{N}^{\circ} \mathrm{xx}$. Mestrado em Geociências Aplicadas - Instituto de Geociências, Universidade de Brasília, UnB, Brasília, 2016. 
MOREIRA, R. C. Influência do posicionamento e da largura de bandas de sensores remotos e dos efeitos atmosféricos na determinação de índices de vegetação. Ministério da Ciência e Tecnologia. Instituto Nacional de Pesquisas Espaciais - INPE. São José dos Campos, 2000. INPE-7528-TDI/735. 161p.

NASCIMENTO, J. G. C. A influência da erosão na regeneração de clareiras. Tese de doutorado apresentada ao Instituto Nacional de Pesquisas da Amazônia- INPA. Programa de Pós-Graduação em Ciências de Florestas Tropicais - PPGCFT. Manaus, 2009.

PALACE, M. et al. Amazon forest structure from IKONOS satellite data and the automated characterization of forest canopy properties. Biotropica 40(2). 2008. p. $141-150$.

PERES, C. A; BARLOW, J; LAURANCE, W.F. Detecting anthropogenic disturbance in tropical forests. Trends in Ecology and Evolution. 2006. p.227 - 229.

PEREIRA, J. L. G. Batista, G. Roberts, D. A. Classificação da cobertura da terra na região amazônica através de classificação de regiões em imagens de proporção de componentes. Instituto Nacional de Pesquisas Espaciais, INPE. Anais IX SBSR. Santos, 1998.

PETROBRAS. Site institucional. Principais operações: bacias, refinarias, terminais, oleodutos e gasodutos. Disponível em: <http://www.petrobras.com.br/pt/nossasatividades/principais-operacoes/>. Acesso em: $\langle 06 / 11 / 2014\rangle$.

PESSOA, F. H. C. Análises dos solos de Urucu para fins de uso rodoviário. Departamento de Engenharia Civil e Ambiental, Universidade de Brasília, Brasília-DF. 2004. 151p.

PINAGÉ, E. R. Mapeamento e análise do corte seletivo em uma cena Landsat 5 TM no estado do Pará. Instituto Nacional de Pesquisas Espaciais, INPE. Anais XV Simpósio Brasileiro de Sensoriamento Remoto. Curitiba, 2011.

PHOENIX. Fundação Paleontológica Phoenix. Site Institucional. Disponível em: <http://www.phoenix.org.br/Phoenix50_Fev03.html>. Acesso em: 06/11/2014.

PONZONI, F. J.; REZENDE, A. C. P. Influência da resolução espacial de imagens orbitais na identificação de elementos da paisagem em Altamira-PA. Sociedade de Investigações Florestais. Viçosa-MG. V. 26. 2002. p. 403-410.

PRADO, B. R. et al. Identificação de áreas desmatadas através de segmentação e classificação de imagens do modelo linear de mistura espectral aplicado a dados do sensor landsat 5/TM no município de Sapezal-MT. IX Simpósio Nacional do Cerrado. Brasilia/DF. 2008. 
REIS, A.; TRÊS. D. R.; SIMINSKI, A. Restauração de áreas degradadas: imitando a natureza. Universidade Federal de Santa Catarina, Recursos Genéticos Vegetais - RGV. 90p. Florianópolis, 2006.

RENÓ, V. F. Avaliação do desflorestamento da várzea do baixo amazonas com imagens Landsat obtidas em 1975/1981 e 2008. Instituto Nacional de Pesquisas Espaciais, INPE. Dissertação de mestrado. São José dos Campos, 2010.

RESENDE, M. R. Investigação do uso de imagens de sensoriamento remoto hiperespectral e com alta resolução espacial no monitoramento da condição de uso de pavimentos rodoviários. Escola Politécnica da Universidade de São Paulo, dissertação de mestrado. São Paulo, 2010. p. 23-41

ROY et al. Tropical forest type mapping and monitoring using remote sensing. International Journal Remote Sensing 12. 1991. p. 2205 - 2225.

SANCHES, I. D.; EPIPHÂNIO, J. C. N.; FORMAGGIO, A. R. Culturas agrícolas em imagens multitemporais do satélite Landsat. In: Revista Agrícola São Paulo, São Paulo, v. 52, n. 1, 2005. p. 83-96.

SANO, E. E. et al. Mapeamento da cobertura vegetal natural e antrópica do bioma cerrado por meio de imagens Landsat ETM+. Instituto Nacional de Pesquisas Espaciais, INPE. Anais XVI Simpósio Brasileiro de Sensoriamento Remoto, SBSR. Natal, 2009.

SANTOS JR., U. M. S.; GONÇALVES, J. F. C.; FELDPAUSCH, T. R. Growth, leaf nutrient concentration and photosynthetic nutrient use efficiency in tropical tree species planted in degraded areas in central Amazonia. Forest Ecology Management 226. Amsterdã, 2006. p. 299-309.

SCARANO, F. R. Marginal plants: functional ecology at the Atlantic Forest periphery. In: Congresso Nacional de Botânica, 51. Brasília. 2000. p. 176-182.

SHIMABUKURO, Y. E. et al. Índice de vegetação e modelo linear de mistura espectral no monitoramento da região do Pantanal. Pesquisa Agropecuária Brasileira. Brasília, volume 33. 1998. p. 1729-1739.

SMITH, M. O.; ADAMS, J. B. Interpretation of AIS images of Cuprite, Nevada, using constrains of spectral mixtures. In: Airbone Image Spectrometer Data Analysis Workshop. Pasadena,CA.1985. p.62-68.

STEININGER, M.K. Tropical secondary forest regrowth in the Amazon: age, area and change estimation with thematic mapper data. International Journal of Remote Sensing. 1996. p. 9- 27.

USGS. Site Institucional. United States Geologic Service. Disponível em: <www.earthexplorer.usgs.gov>. Acesso em 07/03/2016. 
TARDIN, A.T. et al. Subprojeto desmatamento: convênio IBDF/CNPq - INPE. Relatório Técnico INPE-1649-RPE/103, Instituto de Pesquisas Espaciais, Brazil. 1980.

TEIXEIRA, W. G.; MARTING, G. C.; MACEDO, R. S. A qualidade física do solo como indicador da recuperação de áreas alteradas na Base Geólogo Pedro de Moura - BOGPM. Disponível em: <www.projetos.inpa.gov.br>. Acesso em: 07/03/2016.

TEIXEIRA, W. G. et al. Levantamento das bases pedológicas disponíveis para o município de Coari - AM. II Workshop de avaliação técnica e científica - Rede CTPETRO Amazônia. 2006.

VIÑA, A; ECHAVARRIA, R; RUNDQUIST, D.C. Satellite change detection analysis of deforestation rates and patterns along the Colombia-Ecuador Border. Ambio. 2004. pp. $118-125$.

YA'ALLAH, S.M.; SARADJIAN, M.R. Automatic normalization of satellite images using unchanged pixels within urban areas. Information Fusion, n.6, 2005. p.235-241.

YARRANTON, G. A. \& MORRISON R. G. Spatial dynamics of a primary succession: nucleation. Journal of Ecology 62(2). 1972. p.417-428. 
ANEXO 1 - MATRIZES DE ERROS

Tabela 13 - Matriz de Confusão - Bloco do Solimões 2001

\begin{tabular}{l|rrrrr}
\hline \multirow{2}{*}{ Classificação } & \multicolumn{5}{|c}{ Verdade Terrestre (pixel) } \\
\cline { 2 - 6 } & Vegetação & $\begin{array}{c}\text { Solo } \\
\text { Exposto }\end{array}$ & Asfalto & $\begin{array}{c}\text { Corpo } \\
\text { d'água }\end{array}$ & Total \\
\hline Não-classificados & 0 & 2 & 1 & 265 & $\mathbf{2 6 8}$ \\
Vegetação & 6138 & 66 & 37 & 126 & $\mathbf{6 3 6 7}$ \\
Solo Exposto & 0 & 111 & 33 & 8 & $\mathbf{1 5 2}$ \\
Asfalto & 0 & 62 & 116 & 13 & $\mathbf{1 9 1}$ \\
Corpo d'água & 0 & 0 & 0 & 143 & $\mathbf{1 4 3}$ \\
Total & $\mathbf{6 1 3 8}$ & $\mathbf{2 4 1}$ & $\mathbf{1 8 7}$ & $\mathbf{5 5 5}$ & $\mathbf{7 1 2 1}$ \\
\hline
\end{tabular}

Tabela 14 - Matriz de Confusão - Bloco do Solimões 2006

\begin{tabular}{l|rrrrrr}
\hline \multirow{2}{*}{ Classificação } & \multicolumn{7}{|c}{ Verdade Terrestre (pixel) } \\
\cline { 2 - 7 } & Vegetação & $\begin{array}{c}\text { Solo } \\
\text { Exposto }\end{array}$ & $\begin{array}{c}\text { Corpo } \\
\text { d'água }\end{array}$ & Asfalto & Nuvens & Total \\
\hline Não- & & & & & & \\
classificados & 0 & 1 & 113 & 0 & 0 & $\mathbf{1 1 4}$ \\
Vegetação & 3842 & 24 & 161 & 57 & 0 & $\mathbf{4 0 8 4}$ \\
Solo Exposto & 0 & 209 & 2 & 140 & 0 & $\mathbf{3 5 1}$ \\
Corpo d'água & 0 & 0 & 240 & 0 & 0 & $\mathbf{2 4 0}$ \\
Asfalto & 0 & 142 & 11 & 156 & 0 & $\mathbf{3 0 9}$ \\
Nuvens & 0 & 0 & 24 & 0 & 1018 & $\mathbf{1 0 4 2}$ \\
Total & $\mathbf{3 8 4 2}$ & $\mathbf{3 7 6}$ & $\mathbf{5 5 1}$ & $\mathbf{3 5 3}$ & $\mathbf{1 0 1 8}$ & $\mathbf{6 1 4 0}$ \\
\hline
\end{tabular}

Tabela 15 - Matriz de Confusão - Bloco do Solimões 2010

\begin{tabular}{l|rrrrr}
\hline \multirow{2}{*}{ Classificação } & \multicolumn{5}{|c}{ Verdade Terrestre (pixel) } \\
\cline { 2 - 6 } & Vegetação & $\begin{array}{c}\text { Solo } \\
\text { Exposto }\end{array}$ & Asfalto & $\begin{array}{c}\text { Corpo } \\
\text { d'água }\end{array}$ & Total \\
\hline Não-classificados & 0 & 0 & 0 & 0 & $\mathbf{0}$ \\
Vegetação & 1789 & 26 & 83 & 100 & $\mathbf{1 9 9 8}$ \\
Solo Exposto & 0 & 317 & 106 & 0 & $\mathbf{4 2 3}$ \\
Asfalto & 0 & 102 & 267 & 0 & $\mathbf{3 6 9}$ \\
Corpo d'água & 0 & 0 & 0 & 447 & $\mathbf{4 4 7}$ \\
Total & $\mathbf{1 7 8 9}$ & $\mathbf{4 4 5}$ & $\mathbf{4 5 6}$ & $\mathbf{5 4 7}$ & $\mathbf{3 2 3 7}$ \\
\hline
\end{tabular}


Tabela 16 - Matriz de Confusão - Bloco do Solimões 2015

\begin{tabular}{l|rrrrr}
\hline \multirow{2}{*}{ Classificação } & \multicolumn{5}{c}{ Verdade Terrestre (pixel) } \\
\cline { 2 - 6 } & Asfalto & $\begin{array}{c}\text { Solo } \\
\text { Exposto }\end{array}$ & $\begin{array}{c}\text { Corpo } \\
\text { d'água }\end{array}$ & Vegetação & Total \\
\hline Não-classificados & 0 & 16 & 109 & 0 & $\mathbf{1 2 5}$ \\
Asfalto & $\mathbf{5 4 3}$ & 299 & 32 & 0 & $\mathbf{8 7 4}$ \\
Solo Exposto & 18 & $\mathbf{2 2 7}$ & 0 & 0 & $\mathbf{2 4 5}$ \\
Corpo d'água & 0 & 0 & $\mathbf{2 6 9}$ & 0 & $\mathbf{2 6 9}$ \\
Vegetação & 73 & 95 & 350 & $\mathbf{6 7 0 7}$ & $\mathbf{7 2 2 5}$ \\
Total & $\mathbf{6 3 4}$ & $\mathbf{6 3 7}$ & $\mathbf{7 6 0}$ & $\mathbf{6 7 0 7}$ & $\mathbf{8 7 3 8}$ \\
\hline
\end{tabular}

Tabela 17 - Matriz de Confusão - Bloco do Amazonas 1999

\begin{tabular}{l|rrrrrr}
\hline \multirow{2}{*}{ Classificação } & \multicolumn{6}{|c}{ Verdade Terrestre (pixel) } \\
\cline { 2 - 7 } & Vegetação & $\begin{array}{c}\text { Corpo } \\
\text { d'água }\end{array}$ & Nuvem & $\begin{array}{c}\text { Solo } \\
\text { Exposto1 }\end{array}$ & $\begin{array}{c}\text { Solo } \\
\text { Exposto2 }\end{array}$ & Total \\
\hline Não- & & & & & & \\
classificados & 0 & 791 & 0 & 0 & 201 & $\mathbf{9 9 2}$ \\
Vegetação & 4743 & 0 & 0 & 1 & 0 & $\mathbf{4 7 4 4}$ \\
Corpo d'água & 0 & 9890 & 0 & 0 & 0 & $\mathbf{9 8 9 0}$ \\
Nuvem & 0 & 62 & 422 & 0 & 1 & $\mathbf{4 8 5}$ \\
Solo Exposto1 & 0 & 0 & 2 & 2118 & 132 & $\mathbf{2 2 5 2}$ \\
Solo Exposto2 & 0 & 0 & 0 & 0 & 1088 & $\mathbf{1 0 8 8}$ \\
Total & $\mathbf{4 7 4 3}$ & $\mathbf{1 0 7 4 3}$ & $\mathbf{4 2 4}$ & $\mathbf{2 1 1 9}$ & $\mathbf{1 4 2 2}$ & $\mathbf{1 9 4 5 1}$ \\
\hline
\end{tabular}

Tabela 18 - Matriz de Confusão - Bloco do Amazonas 2006

\begin{tabular}{l|rrrrrr}
\hline \multirow{2}{*}{ Classificação } & \multicolumn{6}{|c}{ Verdade Terrestre (pixel) } \\
\cline { 2 - 7 } & Vegetação & $\begin{array}{c}\text { Solo } \\
\text { Exposto1 }\end{array}$ & $\begin{array}{c}\text { Solo } \\
\text { Exposto2 }\end{array}$ & $\begin{array}{c}\text { Corpo } \\
\text { d'água1 }\end{array}$ & $\begin{array}{c}\text { Corpo } \\
\text { d'água2 }\end{array}$ & \multirow{2}{*}{ Total } \\
\hline Não- & & & & & & \\
classificados & 27 & 0 & 722 & 261 & 3 & $\mathbf{1 0 1 3}$ \\
Vegetação & 9196 & 0 & 0 & 0 & 0 & $\mathbf{9 1 9 6}$ \\
Solo Exposto1 & 16 & 2816 & 121 & 0 & 0 & $\mathbf{2 9 5 3}$ \\
Solo Exposto2 & 0 & 53 & 776 & 0 & 0 & $\mathbf{8 2 9}$ \\
Corpo d'água1 & 0 & 0 & 0 & 3472 & 443 & $\mathbf{3 9 1 5}$ \\
Corpo d'água2 & 0 & 0 & 0 & 0 & 2572 & $\mathbf{2 5 7 2}$ \\
Total & $\mathbf{9 2 3 9}$ & $\mathbf{2 8 6 9}$ & $\mathbf{1 6 1 9}$ & $\mathbf{3 7 3 3}$ & $\mathbf{3 0 1 8}$ & $\mathbf{2 0 4 7 8}$ \\
\hline
\end{tabular}


Tabela 19 - Matriz de Confusão - Bloco do Amazonas 2011

\begin{tabular}{l|rrrrrr}
\hline \multirow{2}{*}{ Classificação } & \multicolumn{6}{|c}{ Verdade Terrestre (pixel) } \\
\cline { 2 - 7 } & Vegetação & $\begin{array}{c}\text { Solo } \\
\text { Exposto }\end{array}$ & Nuvem & $\begin{array}{c}\text { Massas } \\
\text { d'água1 }\end{array}$ & $\begin{array}{c}\text { Massas } \\
\text { d'água2 }\end{array}$ & \multicolumn{1}{c}{ Total } \\
\hline Não- & & & & & & \\
classificados & 10 & 0 & 0 & 13 & 39 & $\mathbf{6 2}$ \\
Vegetação & 11590 & 0 & 0 & 0 & 1 & $\mathbf{1 1 5 9 1}$ \\
Solo Exposto & 22 & 1416 & 0 & 0 & 0 & $\mathbf{1 4 3 8}$ \\
Nuvem & 0 & 0 & 350 & 0 & 1 & $\mathbf{3 5 1}$ \\
Corpo d'água1 & 0 & 0 & 0 & 2067 & 5 & $\mathbf{2 0 7 2}$ \\
Corpo d'água2 & 1 & 0 & 0 & 1 & 2217 & $\mathbf{2 2 1 9}$ \\
Total & $\mathbf{1 1 6 2 3}$ & $\mathbf{1 4 1 6}$ & $\mathbf{3 5 0}$ & $\mathbf{2 0 8 1}$ & $\mathbf{2 2 6 3}$ & $\mathbf{1 7 7 3 3}$ \\
\hline
\end{tabular}

Tabela 20 - Matriz de Confusão - Bloco do Amazonas 2015

\begin{tabular}{l|rrrrrr}
\hline \multirow{2}{*}{ Classificação } & \multicolumn{5}{c}{ Verdade Terrestre (pixel) } \\
\cline { 2 - 6 } & Vegetação & $\begin{array}{c}\text { Solo } \\
\text { Exposto }\end{array}$ & $\begin{array}{c}\text { Massas } \\
\text { d'água1 }\end{array}$ & $\begin{array}{c}\text { Massas } \\
\text { d'água2 }\end{array}$ & Total \\
\hline Não-classificados & 0 & 0 & 0 & 0 & $\mathbf{0}$ \\
Vegetação & 10042 & 39 & 0 & 0 & $\mathbf{1 0 0 8 1}$ \\
Solo Exposto & 0 & 978 & 0 & 0 & $\mathbf{9 7 8}$ \\
Corpo d'água1 & 0 & 0 & 2551 & 0 & $\mathbf{2 5 5 1}$ \\
Corpo d'água2 & 0 & 0 & 0 & 2060 & $\mathbf{2 0 6 0}$ \\
Total & $\mathbf{1 0 0 4 2}$ & $\mathbf{1 0 1 7}$ & $\mathbf{2 5 5 1}$ & $\mathbf{2 0 6 0}$ & $\mathbf{1 5 6 7 0}$ \\
\hline
\end{tabular}




\section{ANEXO 2 - EXATIDÃO DO PRODUTOR E EXATIDÃO DO USUÁRIO}

Tabela 21 - Exatidão do Produtor/ Exatidão do Usuário - Solimões 2001

\begin{tabular}{l|rr|rr}
\hline \multirow{2}{*}{ Classes } & \multicolumn{2}{|c|}{ Exatidão Produtor } & \multicolumn{2}{c}{ Exatidão Usuário } \\
\cline { 2 - 5 } & \multicolumn{1}{|c|}{ Pixels } & $\mathbf{( \% )}$ & \multicolumn{1}{c}{ Pixels } & $\mathbf{( \% )}$ \\
\hline Vegetação & $6138 / 6138$ & $\mathbf{1 0 0 , 0}$ & $6138 / 6367$ & $\mathbf{9 6 , 4 0}$ \\
Solo Exposto & $111 / 241$ & $\mathbf{4 6 , 1}$ & $111 / 152$ & $\mathbf{7 3 , 0 0}$ \\
Asfalto & $116 / 187$ & $\mathbf{6 2 , 0}$ & $116 / 191$ & $\mathbf{6 0 , 7 0}$ \\
Corpo d'água & $143 / 555$ & $\mathbf{2 5 , 8}$ & $143 / 143$ & $\mathbf{1 0 0 , 0 0}$ \\
\hline
\end{tabular}

Tabela 22 - Exatidão do Produtor/ Exatidão do Usuário - Solimões 2006

\begin{tabular}{l|rr|rr}
\hline \multirow{2}{*}{ Classes } & \multicolumn{2}{|c|}{ Exatidão Produtor } & \multicolumn{2}{c}{ Exatidão Usuário } \\
\cline { 2 - 5 } & \multicolumn{1}{|c}{ Pixels } & $\mathbf{( \% )}$ & \multicolumn{1}{c}{ Pixels } & $\mathbf{( \% )}$ \\
\hline Vegetação & $3842 / 3842$ & $\mathbf{1 0 0 , 0}$ & $3842 / 4084$ & $\mathbf{9 4 , 1}$ \\
Solo Exposto & $209 / 376$ & $\mathbf{5 5 , 6}$ & $209 / 351$ & $\mathbf{5 9 , 5}$ \\
Corpo d'água & $240 / 551$ & $\mathbf{4 3 , 5}$ & $240 / 240$ & $\mathbf{1 0 0 , 0}$ \\
Asfalto & $156 / 353$ & $\mathbf{4 4 , 2}$ & $156 / 309$ & $\mathbf{5 0 , 5}$ \\
Nuvens & $1018 / 1018$ & $\mathbf{1 0 0 , 0}$ & $1018 / 1042$ & $\mathbf{9 7 , 7}$ \\
\hline
\end{tabular}

Tabela 23 - Exatidão do Produtor/ Exatidão do Usuário - Solimões 2010

\begin{tabular}{l|rr|rr}
\hline \multirow{2}{*}{ Classes } & \multicolumn{2}{|c|}{ Exatidão Produtor } & \multicolumn{2}{|c}{ Exatidão Usuário } \\
\cline { 2 - 5 } & \multicolumn{1}{c}{ Pixels } & $\mathbf{( \% )}$ & \multicolumn{1}{c}{ Pixels } & $\mathbf{( \% )}$ \\
\hline Vegetação & $1789 / 1789$ & $\mathbf{1 0 0 , 0}$ & $1789 / 1998$ & $\mathbf{8 9 , 5 0}$ \\
Solo Exposto & $317 / 445$ & $\mathbf{7 1 , 0}$ & $317 / 423$ & $\mathbf{7 4 , 9 0}$ \\
Asfalto & $267 / 456$ & $\mathbf{5 8 , 5}$ & $267 / 369$ & $\mathbf{7 2 , 4 0}$ \\
Corpo d'água & $447 / 547$ & $\mathbf{8 1 , 7}$ & $447 / 447$ & $\mathbf{1 0 0 , 0 0}$ \\
\hline
\end{tabular}

Tabela 24 - Exatidão do Produtor/ Exatidão do Usuário - Solimões 2015

\begin{tabular}{l|rr|rr}
\hline \multirow{2}{*}{\multicolumn{1}{c|}{ Classes }} & \multicolumn{2}{|c|}{ Exatidão Produtor } & \multicolumn{2}{|c}{ Exatidão Usuário } \\
\cline { 2 - 5 } & \multicolumn{1}{c}{ Pixels } & $\mathbf{( \% )}$ & \multicolumn{1}{c}{ Pixels } & \multicolumn{1}{c}{$\boldsymbol{( \% )}$} \\
\hline Asfalto & $543 / 634$ & $\mathbf{8 5 , 6}$ & $543 / 874$ & $\mathbf{6 2 , 1}$ \\
Solo Exposto & $227 / 637$ & $\mathbf{3 5 , 6}$ & $227 / 245$ & $\mathbf{9 2 , 6}$ \\
Corpo d'água & $269 / 760$ & $\mathbf{3 5 , 4}$ & $269 / 269$ & $\mathbf{1 0 0 , 0}$ \\
Vegetação & $6707 / 6707$ & $\mathbf{1 0 0 , 0}$ & $6707 / 7225$ & $\mathbf{9 2 , 8}$ \\
\hline
\end{tabular}


Tabela 25 - Exatidão do Produtor/ Exatidão do Usuário - Amazonas 1999

\begin{tabular}{l|r|r|r|r}
\hline \multirow{2}{*}{ Classes } & \multicolumn{2}{|c|}{ Exatidão Produtor } & \multicolumn{2}{c}{ Exatidão Usuário } \\
\cline { 2 - 5 } & \multicolumn{1}{c|}{ Pixel } & \multicolumn{1}{c}{$(\boldsymbol{\%})$} & \multicolumn{1}{c}{ Pixel } & \multicolumn{1}{c}{$\mathbf{( \% )}$} \\
\hline Vegetação & $4743 / 4743$ & $\mathbf{1 0 0 , 0}$ & $4743 / 4744$ & $\mathbf{9 9 , 9}$ \\
Corpo d'água & $9890 / 10743$ & $\mathbf{9 2 , 1}$ & $9890 / 9890$ & $\mathbf{1 0 0 , 0}$ \\
Nuvem & $422 / 424$ & $\mathbf{9 9 , 5}$ & $422 / 485$ & $\mathbf{8 7 , 0}$ \\
Solo Exposto1 & $2118 / 2119$ & $\mathbf{9 9 , 9}$ & $2118 / 2252$ & $\mathbf{9 4 , 0}$ \\
Solo Exposto2 & $1088 / 1422$ & $\mathbf{7 6 , 5}$ & $1088 / 1088$ & $\mathbf{1 0 0 , 0}$ \\
\hline
\end{tabular}

Tabela 26 - Exatidão do Produtor/ Exatidão do Usuário - Amazonas 2006

\begin{tabular}{l|r|r|r|r}
\hline \multirow{2}{*}{ Classes } & \multicolumn{2}{|c|}{ Exatidão Produtor } & \multicolumn{2}{c}{ Exatidão Usuário } \\
\cline { 2 - 5 } & \multicolumn{1}{c|}{ Pixel } & $\mathbf{( \% )}$ & \multicolumn{1}{c}{ Pixel } & \multicolumn{1}{c}{$(\boldsymbol{\%})$} \\
\hline Vegetação & $9196 / 9239$ & $\mathbf{9 9 , 5}$ & $9196 / 9196$ & $\mathbf{1 0 0 , 0}$ \\
Solo Exposto1 & $2816 / 2869$ & $\mathbf{9 8 , 1}$ & $2816 / 2953$ & $\mathbf{9 5 , 3}$ \\
Solo Exposto2 & $776 / 1619$ & $\mathbf{4 7 , 9}$ & $776 / 829$ & $\mathbf{9 3 , 6}$ \\
Corpo d'água1 & $3472 / 3733$ & $\mathbf{9 3 , 0}$ & $3472 / 3915$ & $\mathbf{8 8 , 6}$ \\
Corpo d'água2 & $2572 / 3018$ & $\mathbf{8 5 , 2}$ & $2572 / 2572$ & $\mathbf{1 0 0 , 0}$ \\
\hline
\end{tabular}

Tabela 27 - Exatidão do Produtor/ Exatidão do Usuário - Amazonas 2011

\begin{tabular}{l|r|r|r|r}
\hline \multirow{2}{*}{ Classes } & \multicolumn{2}{|c|}{ Exatidão Produtor } & \multicolumn{2}{c}{ Exatidão Usuário } \\
\cline { 2 - 5 } & \multicolumn{1}{|c|}{ Pixel } & \multicolumn{1}{c}{$\boldsymbol{( \% )}$} & \multicolumn{1}{c}{ Pixel } & $\mathbf{( \% )}$ \\
\hline Vegetação & $11590 / 11623$ & $\mathbf{9 9 , 7}$ & $11590 / 11591$ & $\mathbf{9 9 , 9}$ \\
Solo Exposto & $1416 / 1416$ & $\mathbf{1 0 0 , 0}$ & $1416 / 1438$ & $\mathbf{9 8 , 5}$ \\
Nuvem & $350 / 350$ & $\mathbf{1 0 0 , 0}$ & $350 / 351$ & $\mathbf{9 9 , 7}$ \\
Corpo d'água1 & $2067 / 2081$ & $\mathbf{9 9 , 3}$ & $2067 / 2072$ & $\mathbf{9 9 , 7}$ \\
Corpo d'água2 & $2217 / 2263$ & $\mathbf{9 7 , 9}$ & $2217 / 2219$ & $\mathbf{9 9 , 9}$ \\
\hline
\end{tabular}

Tabela 28 - Exatidão do Produtor/ Exatidão do Usuário - Amazonas 2015

\begin{tabular}{l|rr|rr}
\hline \multirow{2}{*}{\multicolumn{1}{c|}{ Classes }} & \multicolumn{2}{|c|}{ Exatidão Produtor } & \multicolumn{2}{c}{ Exatidão Usuário } \\
\cline { 2 - 5 } & \multicolumn{1}{|c|}{ Pixel } & $\mathbf{( \% )}$ & \multicolumn{1}{c}{ Pixel } & $\mathbf{( \% )}$ \\
\hline Vegetação & $10042 / 10042$ & $\mathbf{1 0 0 , 0}$ & $10042 / 10081$ & $\mathbf{9 9 , 6}$ \\
Solo Exposto & $978 / 1017$ & $\mathbf{9 6 , 2}$ & $978 / 978$ & $\mathbf{1 0 0 , 0}$ \\
Corpo d'água1 & $2551 / 2551$ & $\mathbf{1 0 0 , 0}$ & $2551 / 2551$ & $\mathbf{1 0 0 , 0}$ \\
Corpo d'água2 & $2060 / 2060$ & $\mathbf{1 0 0 , 0}$ & $2060 / 2060$ & $\mathbf{1 0 0 , 0}$ \\
\hline
\end{tabular}

